$\rightarrow$ Schriften zum Kultur- und Museumsmanagement Stromverbrauch ind

BERnd GÜNTER/ HaRTMut JoHn (Hg.)

\title{
Besucher zu Stammgästen machen!
}

Neue und kreative Wege zur Besucherbindung 
Besucher zu Stammgästen machen! 

Bernd Günter / HaRtMut John (HG.)

\section{Besucher zu Stammgästen machen!}

Neue und kreative Wege zur Besucherbindung 
Tagungsband zur gleichnamigen Veranstaltung

des Fortbildungszentrums Abtei Brauweiler/

Rheinisches Archiv- und Museumsamt

am 12./13. November 1998

Herausgegeben von Bernd Günter und Hartmut John

im Auftrag des LANDSCHAFTSVERBANDES RHEINLAND

- Amt für Öffentlichkeitsarbeit -

- Rheinisches Archiv- und Museumsamt -

Publikation der Abteilung Museumsberatung Nr. 9

LANDSCHAFTSVERBAND RHEINLAND

Rheinisches Archiv- und Museumsamt

\section{(C) $\$\left(\begin{array}{l}\text { This work is licensed under a Creative Commons } \\ \text { Attribution-NonCommercial-NoDerivatives } 3.0 \text { Lic }\end{array}\right.$}

Die Deutsche Bibliothek -

CIP-Einheitsaufnahme

Besucher zu Stammgästen machen! :

neue und kreative Wege zur Besucherbindung ;

[Tagungsband zur gleichnamigen Veranstaltung des Fortbildungszentrums Abtei Brauweiler/Rheinisches Archiv- und Museumsamt

am 12./13. November 1998] / Bernd Günter/Hartmut John (Hg.). [Im

Auftr. des Landschaftsverbandes Rheinland, Amt für Öffentlichkeitsarbeit ;

Rheinisches Archiv- und Museumsamt]. -

Bielefeld : transcript Verl., 2000

(Publikationen der Abteilung Museumsberatung ; Nr. 9)

(Schriften zum Kultur- und Museumsmanagement)

ISBN 3-933127-57-2

(C) 2000 transcript Verlag, Bielefeld

Landschaftsverband Rheinland und Autoren

Konzeption: Hartmut John

Umschlagfoto: Andreas Schiblon/Rheinisches

Industriemuseum Engelskirchen

Gestaltung: transcript Verlag, Bielefeld

Satz: digitron $\mathrm{GmbH}$, Bielefeld

Druck: Interpress, Budapest

Printed in Hungary

ISBN 3-933127-57-2 


\section{Inhalt}

Bernd GÜNTER/ HARTMUt JohN

Einführung

Dieter Pesch

Event-Marketing im Rheinischen Freilichtmuseum

und Landesmuseum für Volkskunde Kommern

Eine Marketingstudie zur Besucherbindung

Maja Majer-Wallat

Das Programm der Kunst- und Ausstellungshalle zwischen Bildungsauftrag und Besucherquote

JOHANNES WERNER

Kundenbindungsprogramme am Beispiel der

Galeria Kaufhof Warenhaus AG

JAN SAS

Der Besucher als Berater

BERND GÜNTER

Was behindert und was eröffnet Wege zu

Besucherbindung und Besucherintegration? 67 
PATRICIA MunRo

Brückenschlag zwischen Museen und ihren

Besuchern mittels Vorab-Evaluation

Rick VERCAUTEREN

Sorry is not enough

Besucherbindung durch Beschwerde-Management

Beate Hobein

Partnerschaft mit dem Besucher als

strukturelles Element der Museumsarbeit 107

Autoren

129 
BERND GÜNTER/ HARTMUT JoHN

\section{Einführung}

Wer die Programmangebote des Fortbildungszentrums Abtei Brauweiler in den letzten Jahren etwas genauer verfolgt hat, wird wissen, daß wir einen Schwerpunkt unserer Arbeit darin sehen, das Personal der Museen dabei zu unterstützen, modernes Kulturmanagement und insbesondere Museumsmarketing zu einer Kernkompetenz innerhalb ihres Tätigkeitsprofils zu entwickeln.

Als das Fortbildungszentrum Museumsfachleute Anfang der 9oer Jahre erstmals mit dem Thema Marketing konfrontierte, stießen wir nicht nur auf fest verwurzelte Vorurteile, sondern auch auf massive Ablehnung und unüberbrückbar erscheinende Aversionen. Im Museumskontext war der Begriff "Marketing" noch weithin tabuisiert, sein "Werkzeugkasten« nicht selten als »Teufelszeug « verschrieen. Ein offener, rationaler Diskurs über ein modernes, auch auf den Nonprofit-Sektor übertragbares Marketing-Verständnis kam nur schleppend in Gang. Nur zögerlich setzte sich die Einsicht durch, daß die öffentliche Wahrnehmung und Akzeptanz eines Museums ganz wesentlich davon bestimmt wird, inwieweit es ihm gelingt, seine Angebote und Leistungen so attraktiv und unverwechselbar zu gestalten, daß das Publikum sie anderen Offerten vorzieht. Inzwischen haben viele Museumsexperten verstanden und - vor dem Hintergrund der unaufhaltsamen Erosion staatlicher Subventionsleistungen für Kultur - auch begreifen müssen, daß ihre Häuser sich nur als profilierte Anbieter auf dem hart umkämpften Freizeit- und Unterhaltungsmarkt be- 
haupten können. Denn hier stehen sie im scharfen Wettbewerb um die immer knapperen Zeit- und Finanzbudgets des Publikums, aber auch um dessen kulturelles und intellektuelles Engagement für die Sache der Museen.

Zwar mag der Begriff »Besucherorientierung« als zentrales Vehikel zur Erzielung notwendiger Wettbewerbsvorteile mittlerweile in die Köpfe mancher Museumsmitarbeiter eingedrungen sein; zwar ist "Kundenorientierung « und »Kundenfreundlichkeit« heute in vielen Museen, Kulturverwaltungen und in der Politik eine gern benutzte und nicht selten wie eine Monstranz weihevoll hochgehaltene Vokabel, unter der jeder allerdings etwas anderes versteht. Aber die wohlfeilen Lippenbekenntnisse und frommen Wunschvorstellungen kontrastieren häufig scharf mit den großen Wissensdefiziten und -lücken in modernem Marketing. Eine entsprechende Bewußtseinsbildung ist die notwendige Voraussetzung für Verhaltensänderungen und eine neue Praxis der Museumsarbeit. Welches Museum vermittelt dem Besucher heute schon das Gefühl: »Hier bin ich erwünscht und willkommen, hier werde ich persönlich angesprochen und man bemüht sich, mir den Aufenthalt so angenehm, anregend und interessant wie möglich zu machen, kurz: mir eine Gegenleistung für meine Zeit- und Geldinvestition zu bieten!« Dazu gehören z. B. Hinweise, Erschließungshilfen und Parkplätze, die den Weg ins Museum erleichtern, dazu gehört eine einladende Eingangs- und Kassenzone, die nicht den abweisenden Charme eines Behördenschalters hat, dazu gehört beispielsweise ein Wickelraum für Kleinstkinder, ein attraktiver Museumsshop, ausreichende Sitzgelegenheiten und zuvorkommende, informierte und jederzeit verfügbare Ansprechpartner für Auskünfte und zur Beantwortung von Sachfragen.

Wie schlecht es hierzulande insgesamt noch um die Besucherorientierung bestellt ist, erhellt nicht nur ein Gang durch Museen in England, den USA, Kanada, den Niederlanden oder in Schweden; auch die jüngst von der Bertelsmann Stiftung im Rahmen des Modellprojekts »Wirkungsvolle Strukturen im Museumsbereich" in Auftrag gegebene Untersuchung zum »Besucherservice in deutschen Museen« kommt zu sehr ernüchternden Ergebnissen: Viele der überwiegend namhaften großstädtischen Museumseinrichtungen - insgesamt beteiligten sich 21 Museen an der Untersuchung wiesen deutliche, zum Teil gravierende Defizite und Mängel in puncto Service und Besucherfreundlichkeit auf.

Daß sich die Museen dabei in schlechter Gesellschaft mit der 
Wirtschaft befinden und das inzwischen geflügelte Wort von der "Service-Wüste Deutschland« nicht nur etwas mit den Museen und dem Kultursektor zu tun hat, ist sicher kein Trost. Im Gegenteil: Die verbreitete Grundauffassung - für die Deutschland offenbar weithin bekannt ist -, daß der Kunde in erster Linie lästig ist, hemmt die Durchsetzung einer besucherfreundlichen Museumspraxis zusätzlich. Aufmerksame ausländische Beobachter haben denn auch - von vergleichenden empirischen Untersuchungen unterfüttert - eine besondere Spielart der Kundenfeindlichkeit in Deutschland ausgemacht. Der japanische Volkswirtschaftler und Unternehmensberater Minoru Tominaga beispielsweise diagnostiziert in Deutschland nicht einfach »Gedankenlosigkeit, Lustlosigkeit, Ignoranz und Bequemlichkeit einzelner Personen«, sondern Kundenfeindlichkeit als »Teil der deutschen Kultur und der Umgangsformen« (Die kundenfreundliche Gesellschaft, Düsseldorf/ München 1998: 8) - eine Einschätzung, mit der Tominaga nicht alleine steht. Es paßt daher vielleicht auch ins Bild, wenn eine nordamerikanische Airline vor kurzem Merkblätter an ihre Deutschland-Passagiere verteilen ließ mit dem aufklärenden Hinweis, abweisende Mienen des Personals in deutschen Geschäften entsprächen der Landessitte und seien keineswegs böse gemeint.

Doch selbst wenn »Kundenmißhandlung - um einen von Prof. Bernd Günter gern benutzten Begriff aufzugreifen - bei uns eher Regel denn Ausnahme wäre, muß man differenzieren. Auch hierzulande gibt es »Champions« der Kundenorientierung, Unternehmen, die sich kompromißlos dem Konzept des »Total Customer Care« (TCC) verschrieben haben und von denen Museen eine Menge lernen können. Und natürlich gibt es signifikante branchenspezifische Unterschiede in der Fremdeinschätzung und Bewertung der Servicequalität, von den Apotheken bis zu den Telekommunikations-Dienstleistern. Nicht nur in den Ranking-Listen für Servicequalität, wie sie z.B. vom deutschen »Kundenbarometer « zusammengestellt werden, rangieren die Stadt- und Kommunalverwaltungen - und damit auch fast zwei Drittel unserer Museen - knapp vor den Service-Schlusslichtern »Duales System Deutschland « und den Fernsehsendern. Gute Gründe mithin, den Blick über den Museums-Tellerrand zu richten, um zu sehen - und möglichst auch zu lernen -, welcher Marketinginstrumente sich ein großer deutscher Kaufhauskonzern bedient, um eine anonyme Kundschaft zu binden.

»Wege zur Kunden- oder Besucherbindung im Museum« war 
deshalb auch das Thema einer Tagung, die das Fortbildungszentrum in Zusammenarbeit mit Herrn Prof. Dr. Bernd Günter, Inhaber des Lehrstuhls für Betriebswirtschaft, insbesondere Marketing an der Wirtschaftswissenschaftlichen Fakultät der HeinrichHeine-Universität Düsseldorf, Ende 1998 durchgeführt hat.

Daß das Museumspublikum überwiegend noch weit entfernt von habituellen Ausstellungsgängern und Museumsstammgästen ist, ist bekannt; daß Bürgerinnen und Bürger viel zu selten von den Angeboten und Leistungen der Museen überzeugt und begeistert sind und sich noch viel zu wenig für Museumskultur engagieren und in das "Unternehmen Museum « involvieren und integrieren lassen, ist offenkundig. Daher kann man mit Recht die Frage stellen, weshalb hier schon über Besucherbindung, über das ultimative Ziel im Umgang des Museums mit dem Besucher diskutiert wird, obgleich die große Mehrzahl der Museen noch erheblich von einer ausgeprägten Orientierung auf ihre primären Zielgruppen entfernt ist.

Unseres Erachtens können und dürfen Museen nicht ausschließlich als bedarfsdeckende Servicebetriebe definiert werden, die ihr Publikum als "Abnehmer« kultureller Leistungen oder als Objekte museumsbezogener Angebote und der sogenannten kulturellen »Daseinsvorsorge« verstehen. Wenn es richtig ist, daß Museumsangebote nicht nur für, sondern vor allem auch mit dem Publikum entwickelt werden müssen, wenn die sogenannte öffentlich-private "Verantwortungspartnerschaft für Kultur« nicht nur eine neue, wohlklingende Wortschöpfung im kulturpolitischen Diskurs sein soll und erkannt wird, daß der Museumskultur eine Marginalisierung in unserer Gesellschaft droht, wenn Besucher nicht zu aktiven Nutzern, Teilnehmern und letztlich zu Mitwirkenden bei der Aufgabenerfüllung unserer Museen werden, dann muß »Besucherbindung « in der Tat das zentrale Museumsziel und der entscheidende Baustein der Besucherorientierung sein.

Wie aber erreicht man es, daß sich Bürgerinnen und Bürger dauerhaft für diese Museumskultur interessieren, sich von Museen fesseln und an sie binden lassen? Der Tagungsband »Besucher zu Stammgästen machen!«, den wir hiermit einem breiteren Interessentenkreis vorstellen, kann hierauf zugegebenermaßen nur erste und keine erschöpfenden und in allen Details befriedigenden Antworten geben, und nicht nur, weil die hierfür notwendigen Grundlagen- und Forschungsarbeiten noch nicht geleistet sind und wir erst am Anfang eines Neuorientierungsprozesses stehen. 
Mit dem vorliegenden Band wollen die Herausgeber der in Deutschland nur zögerlich in Gang kommenden Diskussion um Methoden und Strategien der Besucherbindung im Museum Impulse und Schubkraft geben. Denn sicher ist, daß unsere Museen über ein großes, unausgeschöpftes Potential für Besucherintegration und Besucherbindung verfügen. Und wie die nun vorgelegte Publikation dokumentiert, gibt es auch bereits vielfältige, zum Teil langjährige Praxiserfahrung mit diesem Thema in den Museen und natürlich auch in der Wirtschaft. Schließlich verfügt die moderne Betriebswirtschaftslehre über einen gut gefüllten und überwiegend praktisch erprobten "Instrumentenkasten« für die Kundenbindung, den wir nun für Sie öffnen.

Die Herausgeber danken an dieser Stelle noch einmal allen Referentinnen und Referenten für ihre Beiträge. Dank gebührt auch dem transcript Verlag in Bielefeld für die verlegerische Arbeit und für die Aufnahme des Bandes in seine profilierte Schriftenreihe zum Kultur- und Museumsmanagement.

Bernd Günter

Hartmut John 



\section{Dieter Pesch}

\section{Event-Marketing im Rheinischen Freilichtmuseum und Landesmuseum für Volkskunde Kommern}

Eine Marketingstudie zur Besucherbindung

In den Jahren 1995 bis 1997 führte der Landschaftsverband Rheinland als Träger des Rheinischen Freilichtmuseums und Landesmuseums für Volkskunde Kommern eine Marketingstudie durch, die von zwei Halbtagskräften, einer Marketing- und einer Tourismusfachfrau, mit Hilfe des Lehrstuhls für Betriebswirtschaftslehre (insbesondere Marketing) der Heinrich-Heine-Universität in Düsseldorf getragen war. Gegenstand der Studie waren vier vom $\mathrm{Mu}$ seum gewünschte Untersuchungen:

- Analyse von Besucherstruktur und Besucherzufriedenheit

- Barrieren des Museumsbesuchs, eine Nichtbesucherbefragung

- Kaufverhalten von Besuchern, eine Befragung von Kunden des Museumsshops

- Events und Museumsbesuch, eine Befragung von Besuchern des Historischen Jahrmarkts

Anlaß der Befragung war die Erarbeitung einer Stärken-Schwächen-Analyse, auf deren Basis ein Marketing-Konzept für das Rheinische Freilichtmuseum erstellt werden sollte, mit dem Ziel, einerseits das Marketing-Denken aller Museumsmitarbeiter zu wecken oder zu verbessern, andererseits neue Besuchergruppen $\mathrm{zu}$ rekrutrieren, Wiederholungsbesucher $\mathrm{zu}$ binden und generell die Zufriedenheit der Besucher mit den Angeboten des Rheinischen Freilichtmuseums zu mehren. Ein Ziel das nicht nur in Zei- 
ten von Besucherstagnation oder Besucherrückgang verfolgt werden darf.

\section{Events und Museumsbesuch -} Eine Befragung von Besuchern des Historischen Jahrmarkts

Seit mehreren Jahren wird über Ostern, von Karsamstag bis zum Weißen Sonntag, gewissermaßen als Saisonauftakt, im Rheinischen Freilichtmuseum ein Historischer Jahrmarkt durchgeführt, der aufgrund der Besucherzahlen von den Museumsmitarbeitern stets als erfolgreich betrachtet wurde. Die Besucherzählungen fanden in der Vergangenheit allerdings lediglich über die Zahl der verkauften Eintrittskarten statt. Auf diese Weise ergaben sich selbstverständlich keine Argumente für eine Entscheidung nach Marketinggesichtspunkten und zur besucherorientierten Planung des Events.

Ziel der Befragung war daher, genauere Information über die Besucherstruktur und die Zufriedenheit oder Unzufriedenheit der Besucher mit den Angeboten des Historischen Jahrmarkts zu erhalten. Da dieser Jahrmarkt auch in Zukunft stattfinden soll, weil er von zahlreichen Besuchern aus dem unmittelbaren Umfeld des Museums schon seit Jahren gern angenommen wird, sollten die Untersuchungsergebnisse Hilfestellung geben bei der Aufdeckung von Schwachstellen und damit die Verbesserung des Gesamtangebots Historischer Jahrmarkt ermöglichen.

Die Befragung der Besucher geschah sowohl durch Fragebogen (s. Anhang) als auch durch Interview. Zeitraum der Befragung war der 6. bis 14. April 1996. Insgesamt gaben 466 Gäste des Museums Auskunft über ihre Eindrücke vom Historischen Jahrmarkt.

Der Historische Jahrmarkt 1996 war neben historischen Geschäften, die teils bis in die 2oer Jahre dieses Jahrhunderts zurüchdatierten, ebenso mit modernen Fahrgeschäften von den Marktbeschickern bedient worden. Als eine besondere Attraktion war mit einer hohen Gage der Zauberer Moretti mit dessen Sohn, der eigens aus Las Vegas eingeflogen war, verpflichtet worden. Außerdem war der bekannte Hypnotiseur Faro angereist, dem es sogar gelang, politische Vertreter der Landschaftsversammlung Rheinland gewissermaßen im Schnellverfahren in wenigen Sekunden in Tiefschlaf zu versetzen.

Insgesamt besuchten an den neun Jahrmarktstagen fast 43.000 Besucher das Rheinische Freilichtnusem. Trotz des guten Besu- 
chererfolges, in Zahlen gemessen, ergab die Befragung für die Folgejahre einen erheblichen Bedarf zur Verbesserung des Jahrmarktkonzepts. Besucherzahlen weisen eben nur zu einem Bruchteil auf Besucher- oder Kundenzufriedenheit hin.

Das Hauptziel hatte der Jahrmarkt 1996 sicherlich erreicht, die Kundenbindung. Denn auch wenn im Gegensatz zum Vorjahr 1995 rund 2.00o Besucher weniger den Weg in das Rheinische Freilichtmuseum gefunden hatten, war dies ein zahlenmäßig schmeichelndes Ergebnis. Der Versuch, über einen solchen Event neue Besuchergruppen anzuwerben, sie gewissermaßen zum Museumsbesuch zu verführen, schlug nicht gerade fehl, war aber von weitaus geringerem Erfolg.

Wie häufig bei Museumsevents kommen die Gäste einer solchen Veranstaltung aus dem näheren Umkreis des Anbieters. Das hängt einerseits mit der Art und Weise der Bewerbung und deren Positionierung (Anzeigen, Plakate, Handzettel) zusammen, andererseits mit dem Wissen um eine solche Veranstaltung, das in zahlreichen örtlichen und regionalen, meist kommunalen Druckwerken - eigentlich ohne direktes Zutun des Museums - generiert wird. So wie der Jahrmarkt konzipiert und beworben wurde, war er mehr ein Mittel der Besucherbindung und weniger der Besuchergewinnung.

Dennoch konnte erfreulicherweise festgestellt werden, daß nicht nur die Wiederholungsbesucher, sondern auch Erstbesucher einen weiteren, zukünftigen Besuch des Museums in Erwägung zogen. Denn immerhin 80,2 Prozent derjenigen, die das Rheinische Freilichtmuseum zum ersten Mal besucht hatten, wollten auf jeden Fall wiederkommen, 15,5 Prozent zeigten sich unschlüssig und nur 4,3 Prozent schlossen einen weiteren Besuch kategorisch aus. So schien das Ziel vordergründig erreicht zu sein. Neue Besuchergruppen waren dem Museum erschlossen und bestätigten darüberhinaus die Absicht eines zusätzlichen späteren Besuchs. Allerdings sollte in diesem Zusammenhang nicht unerwähnt beliben, daß Absicht und tatsächlicher Besuch divergieren. Die Ergebnisse der sogenannten Sonntagsfrage vor politischen Wahlen stimmten selten genug mit dem tatsächlichen Wahlergebnis überein.

Allerdings muß auch festgestellt werden, daß der Event selbst, der Historische Jahrmarkt, nur 64,6 Prozent der Befragten so begeistern konnte, daß sie die Absicht äußerten, noch einmal wiederkommen zu wollen, 13,1 Prozent schlossen diesen Wunsch gänzlich aus. 
Bei den Erstbesuchern fiel das Ergebnis noch etwas dürftiger aus. Lediglich 53,8 Prozent sagten $\mathrm{zu}$, in den nächsten Jahren nochmals den Historischen Jahrmarkt des Rheinischen Freilichtmuseums besuchen zu wollen. 17,1 Prozent der Befragten sprachen sich gegen einen weiteren Besuch aus. Jeder zehnte Erstbesucher wollte den Jahrmarkt nicht einmal Bekannten und Freunden weiterempfehlen.

Argumente gegen einen Wiederbesuch wurden vor allem mit dem mangelnden Interesse der Besucher am Jahrmarkt und der teilweise äußerst starken Besucherballung auf dem Jahrmarktgelände erklärt. Denn alleine an Ostersonntag und Ostermontag kamen rund 18.00o Besucher. Selbst bei einer Verteilung der Besucher auf die rund 8o Hektar des Museums entsteht natürlich bei diesen Zahlen ein gewaltiges Gedränge, das vor allem dann als störend empfunden wird, wenn Besucher nicht mit einer derartigen Veranstaltung gerechnet haben und das Museum mit dem Wunsch angefahren waren, in Ruhe die vier Baugruppen besichtigen zu können.

Dieses Beispiel erhellt, daß eine scheinbare Unvereinbarkeit zwischen dem Wunsch nach Besuchergewinnung und der Steigerung der Besucherzahlen erwächst. Die Aufnahmekapazität des Jahrmarktplatzes war vor allem an den Sonn- und Feiertagen völlig überschritten. Die Lehre für die Zukunft konnte nur in einer Vergrößerung der Marktfläche, einer besseren Koordinierung der Show-Angebote und einer intensiveren Besuchberatung durch Presseinformation von Fahrgeschäften und Besucherballung zu erreichen.

Außerdem mußte festgestellt werden, daß ein vermeindlicher Wettbewerbsvorteil des Historischen Jahrmarkts aus der Sicht zahlreicher Besucher nicht erreicht werden konnte, was sich darin äußerte, daß Erwartungen nicht entsprechend erfüllt wurden. Denn der Jahrmarkt wurde von vielen Gästen nicht - wie propagiert - als "historisch" empfunden. Die für eine hohe Gage eingekaufte Show des Entfesselungskünstlers Moretti, mit Hubschrauber an einem brennenden Seil in große Höhen gehoben, Pommes-Frites-Buden, Plastikspielzeug etc. vermittelten manchen Gästen nicht den Besuch eines historischen Jahrmarkts.

Nicht die große Show war erwartet worden sondern vielmehr für den Veranstalter recht preiswerte Angebote wie Gaukler, Feuerspucker und Jongleure. Deshalb führte 1998 die Gauklertruppe 
Saltimbanque aus Paris ihre Kunststücke nicht nur in einem $\mathrm{Mu}$ seumszelt, sondern bei guter Wetterlage auch im Freien auf und fand dabei eine stärkere Beachtung als die zuvor von relativ wenigen Besuchern (ca. 350 pro Vorstellung) wahrgenommenen Zauber- und Hypnose-Shows im Zelt.

Die im Jahr vor der Befragung mit einer international renommierten Hochseiltruppe erzielten Maßstäbe - immerhin jonglierte ein Mitglied der Truppe im einarmigen Handstand in 65 Metern Höhe auf einem schwingenden Mast - konnten nicht wieder erreicht werden. Dieses Spektakel sahen mehrmals 2 bis 3.000 Besucher, wobei gerade die Familienväter bei den schwindelerregenden Szenen lieber zu Boden schauten.

Es ist notwendig, Events wie den Historischen Jahrmarkt so zu bewerben, daß Unzufriedenheit aufgrund falscher Erwartungen ausgeschlossen wird. Erwähnt sei noch, daß die Ankündigung "nostalgischer Preise« von vielen Besuchern als unzutreffend empfunden wurde, obwohl die Preise tatsächlich stark reduziert waren. Es wäre besser gewesen, es bei üblichen, vielleicht leicht gesenkten Marktpreisen zu belassen, statt mit historischen Preisen zu werben. Auf diese Weise hätte Unzufriedenheit wegen falscher Erwartungen vermieden werden können.

Bemängelt wurde gelegentlich die Ausrichtung der Jahrmarktsattraktionen auf den Eingangsbereich. Manche Besucher wünschten die Fahrgeschäfte und Buden vor den historischen Kulissen in den Baugruppen, was absichtlich vermieden worden war, um eine noch stärkere Besucherballung zu vermeiden. Diesen Wünschen standen dann auch die Kommentare der Besucher entgegen, die nicht wegen des Historischen Jahrmarkts in das Rheinische Freilichtmuseum gekommen waren. Sie erfuhren erst bei der Anreise nach Kommern von dieser Veranstaltung und fühlten sich durch den Jahrmarktsrummel gestört.

Unter anderem wegen der geringen Zeltgröße (ca. 350 Sitzplätze) konnte ein Großteil der Gäste die Show von Zauberer und Hypnotiseur nicht besuchen. Dies korrelierte mit der Unzufriedenheit mancher Besucher im Hinblick auf die Eintrittspreise, da der freie Zutritt zu den Shows nicht bedacht werden konnte.

Bedenklich stimmt, daß die Erstbesucher meist schlechtere Bewertungen abgaben, als die Wiederholungsbesucher. Die kritischere Einstellung der Erstbesucher erfordert für die Zukunft bessere Information und ein Mehr an Besucherorientierung, eine 
noch stärkere Berücksichtigung der Besucherwünsche, um die Bindung nicht nur an diesem Event, sondern an das Museum als solches zu gewährleisten.

Es wird zukünftig Wert darauf gelegt, Events so zu planen und zu konzipieren, daß sie den Inhalten eines Freilichtmuseum gerechter werden. Die Events des Rheinischen Freilichtmuseums müssen einmaligen Charakter haben - schließlich wird der Raum Freizeitmarkt, in dem sich auch Museen befinden, immer enger. Events müssen außerdem auf spezielle Zielgruppen ausgerichtet sein, die bisher das Rheinische Freilichtmuseum noch nicht besuchen. Auf diese Weise wird das Museum sowohl dem Instrument der Besucherbindung als auch dem der Gewinnung von Erstbesuchern gerecht werden.

\section{Literatur}

Helm, Sabrina / Klar, Susanne (1996): Arbeitsberichte zum Projekt Museumsmarketing des Rheinischen Freilichtmuseums und Landesmuseums für Volkskunde Kommern, Nr. 4, Events und Museumsbesuch, Ergebnisse der Befragung von Besuchern des Historischen Jahrmarkts im Rheinischen Freilichtmuseum und Landesmuseum für Volkskunde Kommern, unveröffentliches Manuskript. 
Fragebogen für Besucher des Historischen

Jahrmarkts im Rheinischen Freilichtmuseum und

Landesmuseum für Volkskunde Kommern

\begin{tabular}{|c|c|c|c|}
\hline \multicolumn{2}{|c|}{ Bogennummer: } & Datum: & Uhrzeit: \\
\hline Wetter: & gut & mittel & schlecht \\
\hline
\end{tabular}

1. Sind Sie heute zum ersten Mal hier im Rheinischen Freilichtmuseum Kommern?

ja

nein $\rightarrow$ Waren Sie letztes Jahr beim Historischen Jahrmarkt? $\square$ nein $\square$ ja

$\longrightarrow$ Waren Sie vorher schon einmal in diesem

Museum (und wie oft)? $\square$ nein $\square$ ja, _ mal

2. Wie sind Sie auf den Historischen Jahrmarkt aufmerksam geworden? (Mehrfachnennungen möglich, bitte max. drei Nennungen)

durch frühere Besuche im Rheinischen Freilichtmuseum

Plakate

Empfehlung durch Freunde/Verwandte/Bekannte

Radio $\rightarrow$ Welcher Sender?

Zeitung $\longrightarrow$ Welche?

Stadtmagazin $\longrightarrow$ Welches?

Handzettel

Fernsehen

Hinweisschilder an der Straße

Touristinformation/Fremdenverkehrsamt

$\longrightarrow$ Wo?

Sonstiges, und zwar 


\section{Was haben Sie heute im Rheinischen Freilichtmuseum unternommen, und wie zufrieden waren Sie mit den folgenden Aspekten?}

\begin{tabular}{|c|c|c|c|c|c|c|}
\hline Aktivitäten & $\begin{array}{l}\text { sehr zu- } \\
\text { frieden }\end{array}$ & \begin{tabular}{|l} 
zufrie- \\
den
\end{tabular} & $\begin{array}{l}\text { weder } \\
\text { noch }\end{array}$ & $\begin{array}{l}\text { unzu- } \\
\text { frieden }\end{array}$ & $\begin{array}{l}\text { sehr un- } \\
\text { zufrie- } \\
\text { den }\end{array}$ & $\begin{array}{l}\text { nicht ge } \\
\text { nutzt/ } \\
\text { gekauft }\end{array}$ \\
\hline $\begin{array}{l}\text { Fahrgeschäfte } \\
\text { (Karussells u. ä.) }\end{array}$ & & & & & & \\
\hline Schaubuden (innen) & & & & & & \\
\hline \begin{tabular}{|l|} 
Mitbringsel/ \\
Souvenirs
\end{tabular} & & & & & & \\
\hline $\begin{array}{l}\text { Imbiß/gastrono- } \\
\text { misches Angebot }\end{array}$ & & & & & & \\
\hline Moretti-Show & & & & & & \\
\hline Phoro-Hypno-Show & & & & & & \\
\hline Circus Julius & & & & & & \\
\hline $\begin{array}{l}\text { Museumsgelände/ } \\
\text { Häuser }\end{array}$ & & & & & & \\
\hline \begin{tabular}{|l} 
Eintrittspreis der \\
Schaubuden
\end{tabular} & & & & & & \\
\hline Vielfalt des Angebots & & & & & & \\
\hline $\begin{array}{l}\text { Unterhaltungswert } \\
\text { des Jahrmarkts }\end{array}$ & & & & & & \\
\hline $\begin{array}{l}\text { Anfahrt/ } \\
\text { Beschilderung }\end{array}$ & & & & & & \\
\hline Parksituation & & & & & & \\
\hline Buspendeldienst & & & & & & \\
\hline $\begin{array}{l}\text { Information auf dem } \\
\text { Gelände }\end{array}$ & & & & & & \\
\hline $\begin{array}{l}\text { Wartezeit an der } \\
\text { Kasse }\end{array}$ & & & & & & \\
\hline
\end{tabular}

Sonstiges unternommen und zwar 
4. Heute ist hier so viel los, daß die historischen Häuser des Museums kaum zu sehen sind. Haben Sie Interesse, das Rheinische Freilichtmuseum auch außerhalb des Jahrmarkts einmal zu besuchen?

ja $\quad \square$ vielleicht $\square$ nein

5. Der Historische Jahrmarkt im Rheinischen Freilichtmuseum Kommern findet jedes Jahr zu Ostern statt. Werden Sie den Jahrmarkt voraussichtlich nochmals besuchen?

ja, diesen (diese Woche nochmal)

ja, in den nächsten Jahren

vielleicht

nein $\longrightarrow$

keine Zeit

kein Interesse

zu weit

schlechte Erfahrungen

sonstige Gründe:

6. Sind Thre Erwartungen von einem »historischen Jahrmarkt« erfüllt worden?

ja

ich hatte keine speziellen Erwartungen

nein $\longrightarrow$ warum nicht?

7. Würden Sie den Historischen Jahrmarkt weiterempfehlen?

$\square$ ja $\square$ vielleicht $\square$ nein 
8. Würden Sie auch das Rheinische Freilichtmuseum insgesamt weiterempfehlen?

ja

vielleicht

ich kann es nicht gut vom Jahrmarkt unterscheiden nein

9. Was ist Ihnen heute besonders negativ aufgefallen, und / oder was hat Ihnen besonders gut gefallen?

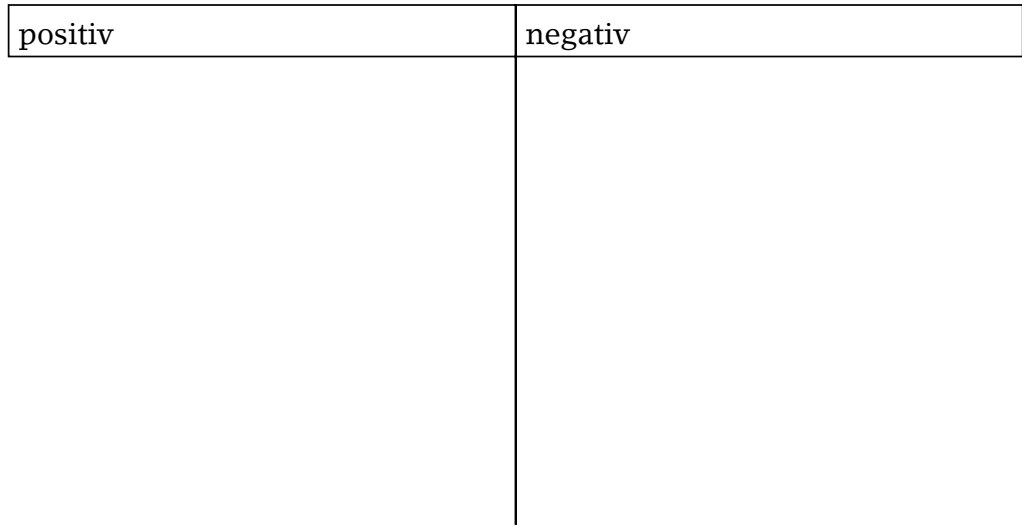

10. Wie weit entfernt vom Museum wohnen Sie?

bis $\mathrm{zu} 10 \mathrm{~km}$ entfernt über 10 bis $20 \mathrm{~km}$ entfernt über 20 bis $50 \mathrm{~km}$ entfernt über 50 bis $100 \mathrm{~km}$ entfernt $\longrightarrow$ welche Stadt/Region? über $100 \mathrm{~km}$ entfernt $\longrightarrow$ welche Stadt/Region? 
11. Wie alt sind sie?

bis 19 Jahre 20 bis 29 Jahre 30 bis 39 Jahre 40 bis 49 Jahre
50 bis 59 Jahre 60 bis 65 Jahre ber 65 Jahre

12. Mit welcher Begleitung sind Sie heute hier?

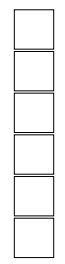

allein

mit Partner(in) und Kind(ern)

mit Partner(in)

mit Kind(ern)

mit Bekannten/Verwandten/Freunden

mit einer organisierten Gruppe

Sonstiges:

\section{Geschlecht}

weiblich

männlich

14. Werden Sie noch den Jahrmarkt in Zülpich besuchen bzw. haben Sie diesen bereits besucht?

ich/wir werden diesen noch besuchen

ich/wir haben diesen bereits besucht

vielleicht

nein

nichts davon gehört 



\section{Das Programm der Kunst- und Ausstellungshalle zwischen Bildungsauftrag und Besucherquote}

Das Programm der Kunst- und Ausstellungshalle der Bundesrepublik Deutschland (KAH) basiert auf einem breiten Kunst- und Kulturbegriff, der neben Kunst- und Kulturgeschichte auch die Bereiche Wissenschaft und Technik einschließt. Das Haus hat die Aufgabe, geistige und kulturelle Entwicklungen von nationaler und internationaler Bedeutung sichtbar zu machen und den Dialog mit Persönlichkeiten aus Kunst, Kultur und Geistesleben sowie aus dem Bereich der Politik zu fördern.

Es gilt, im Falle der hier betroffenen Institution, die wechselnden Inhalte im Programm als Chance für eine Ausweitung des Besucherspektrums und die unterschiedlichen Ausstellungsreihen als Grundlage für eine Bindung verschiedenster Gruppen an das Haus zu verstehen. Im Folgenden wird eine Übersicht zum Programm gegeben, anhand einiger Beispiele das Besucherverhalten dargestellt und ein Ausblick in die Zukunft gewagt.

Auf der Grundlage der genannten Zielsetzung wurden seit der Eröffnung des Hauses im Juni 1992, unterschiedliche Programmschienen entwickelt. Einige werden kurz erläutert, um darzustellen, inwieweit sie die inhaltliche Voraussetzung für einen Marketingansatz bilden oder ob das Programm bereits integraler Bestandteil des Marketing ist.

Monografische Ausstellungen beziehen sich auf das Gesamtwerk einzelner Künstler wie Niki de St. Phalle, Sam Francis, Claes Oldenburg, Gerhard Richter, und Siegmar Polke. 
Die Großen Sammlungen stellen die jeweilige Sammlungsgeschichte anhand bedeutender Werke dar: I. The Museum of Modern Art New York, von Cézanne bis Pollock, II. Unter dem Vulkan, Meisterwerke der Antike aus dem Archäologischen Nationalmuseum Neapel, VI. Zwei Gesichter der Eremitage, St.Petersburg.

Wissenschaftliche Ausstellungen: Sie befassen sich mit der Darstellung von komplexen Zusammenhängen unterschiedlicher Fachrichtungen und widmen sich vornehmlich Themen, aus den Naturwissenschaften. Z. B. "Erdsicht Global Change«, »Future Garden«, »Arktis - Antarktis« sowie »Gen-Welten, Prometheus im Labor? « sind hier als Beispiel zu nennen.

Kulturhistorische Ausstellungen: In dieser Reihe werden kulturelle Phänomene und spezielle Enwicklungen untersucht, deren Ursprung in ethnologischer, religiöser oder geografischer Besonderheit liegt und $\mathrm{zu}$ bemerkenswerten Ausdrucksformen geführt hat; z.B. »Tanzende Bilder - asafo-Fahnen der Fante in Ghana«, „Wunderkammer des Abendlandes - Museum und Sammlung im Spiegel der Zeit" oder "Weisheit und Liebe - Tausend Jahre Kunst des tibetischen Buddhismus«, um auch hier nur einen Einblick zu geben.

Weitere Schwerpunkte sind Architektur, Fotografie und Medienkunst. Diesen Medien werden Ausstellungen gewidmet, deren Inhalte sich herausragenden Gesamtwerken, z. B. von Luis Buñuel, Marlene Dietrich oder Renzo Piano, widmen. Darüber hinaus werden einzelne Installationen im Medienkunstraum gezeigt von Künstlern wie z.B. Ulrike Rosenbach, Nan Hoover, Agnes Hegedüs oder Marcel Odenbach.

Die aus den Ausstellungen abgeleiteten Begleitprogramme wie Filme, Konzerte und Lesungen, oder Kongresse, Festivals und die Internationale Filmmusikbiennale sind zusammen mit einem vielseitigen Openair-Konzertprogramm im Sommer Anlässe für zusätzliches Besucherinteresse.

In den ersten Jahren waren die Anstrengungen des Hauses im wesentlichen darauf ausgerichtet, Inhalte, Zweck und Ziele bekannt $\mathrm{zu}$ machen und ein möglichst positives Image $\mathrm{zu}$ installieren. Anhand von Besucherumfragen wurde ermittelt, wie sich Besucher im Hause fühlen, wie öffentlichkeitswirksame Medien beurteilt und wahrgenommen werden, wie Leistungen von Museumspädagokik und Öffentlichkeitsarbeit Wirkung zeigen und welche soziodemographischen Eigenschaften unsere Besucher ausma- 
chen. Die so gewonnenen Wertungen unserer Besucher fanden mitgestaltend Eingang in die Konzeption von Ausstellungen und deren Vermarktungsstrategien.

In diesem Kontext möchte ich auf eine vergleichende Untersuchung eingehen, die mittels einer Besucherumfrage zu "Arktis Antarktis« Vergleichsdaten zu den Ausstellungen "Eremitage« und »Sigmar Polke - Drei Lügen der Malerei« gegenüberstellt. Diese Untersuchung wurde vom Zentrum für Kulturforschung in $\mathrm{Zu}$ sammenarbeit mit unserem Hause durchgeführt.

In Abständen von zwei Monaten wurden, je eine Woche lang, jedem 15. Besucher Fragebögen überreicht. Die Rücklaufquote lag bei 85 Prozent, und es konnten 1.090 Auswertungen vorgenommen werden.

Aus der Fülle von Fragen, die gestellt und beantwortet werden mußten, um ein Meinungsbild zu erhalten, können hier nur einige Beispiele exemplarisch herausgestellt werden.

\section{Urteil zur Ausstellung »Arktis - Antarktis»}

Beeindruckend ist die einheitliche Bewertung des Besuchs in der kulturhistorischen Ausstellung »Eremitage«, der Präsentation zeitgenössischer Kunst in der monographischen Übersicht des Werkes von Sigmar Polke und der vor allem naturwissenschaftlichen Ausstellung »Arktis - Antarktis«:

- So ist die Resonanz auf die Ausstellung "Arktis - Antarktis«, wie bei den beiden vorangegangenen Ausstellungen, insgesamt sehr positiv! Nur 2 Prozent urteilten negativ, dagegen 24 Prozent mit der Note »sehr gut« und 58 Prozent mit der Note »gut«.

- Die Hälfte der ausländischen Besucher vergibt übrigens die Note »sehr gut« im Kontext der Ausstellung.

\section{Auswahl der gezeigten Werke}

- Besonders positiv wird auch die Auswahl der gezeigten Werke von den Befragten bewertet, vor allem von den über 50jährigen und älteren als auch den regelmäßigen Besuchern. 92 Prozent vergeben hier die Noten »sehr gut« bzw. »gut«. 
Abbildung 1: Durchschnittliche Beurteilung der Ausstellungen

"Eremitage«, "Sigmar Polke« und »Arktis - Antarktis« (Mittelwerte)

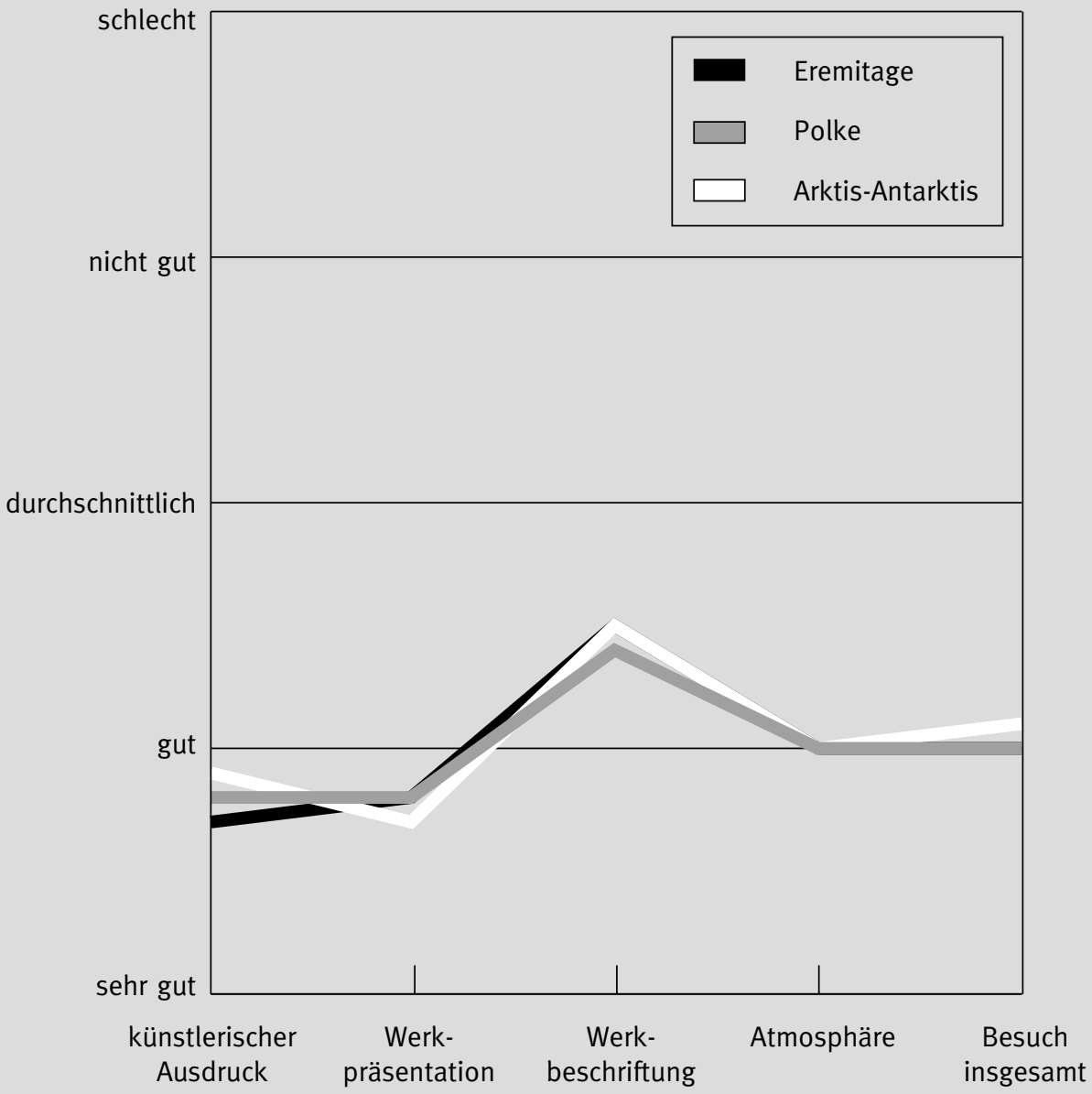

Quelle: ZfKf 1998 


\section{Präsentation der Werke}

- Die Präsentation der Werke erhält ebenfalls sehr positive Noten und ist vor allem von einem großen Anteil der ausländischen Besucher (54 Prozent) und den Befragten ab 50 Jahren (46 Prozent) »sehr gut« beurteilt worden.

\section{Beschriftung der Werke}

- Die Beschriftung wird, wie auch in den anderen Ausstellungen, nicht so positiv bewertet wie die anderen hier zur Disposition stehenden Kriterien. 14 Prozent vergeben hier die Noten »nicht gut« bzw. »schlecht«.

- Negativ wird die Beschriftung vor allem von den Besuchern beurteilt, die insgesamt mit ihrem Ausstellungsbesuch unzufrieden gewesen sind. Fast die Hälfte dieser Besuchergruppe (47 Prozent) vergeben im Kontext der Beschriftung die Noten »nicht gut« bzw. »schlecht«.

\section{Atmosphäre der Ausstellung}

- 82 Prozent der Befragten beurteilen die Atmosphäre der Ausstellung als »sehr gut« bzw. "gut«.

- Vor allem die regelmäßigen Besucher (88 Prozent) und die ausländischen Besucher (88 Prozent) geben auch hier der Ausstellungsatmosphäre besonders gute Noten.

- Trotz der hohen Besucherzahlen um die Ostertage wird die Atmosphäre von den Feiertags-Besuchern nicht auffallend schlechter beurteilt.

\section{Urteil zum Besuch insgesamt}

- Bei einer Korrelation des erfaßten Gesamturteils zu einzelnen Aspekten der Ausstellung zeigt sich, wie auch in den Ausstellungen »Eremitage u und "Sigmar Polke«, daß in der Ausstellung "Arktis - Antarktis« am ehesten die Einschätzung der Atmosphäre eine positive Beziehung zum Gesamturteil aufweist. Einen auffallenden Kontrast zwischen den Besuchern der Ausstellung "Sigmar Polke« und denen der »Arktis - Antarktis« findet man in der Urteilsbeeinflussung des Besuchs überraschenderweise durch das Speiseangebot im Museumsrestaurant. Besitzt 
Abbildung 2: Was beeinflußt positiv oder negativ das Gesamturteil zur Ausstellung »Arktis - Antarktis« am stärksten?

\begin{tabular}{|lll|}
\hline & $\begin{array}{l}\text { Beziehung zum } \\
\text { Gesamturteil }\end{array}$ & $\begin{array}{l}\text { Korrelations- } \\
\text { koeffizient } \\
\text { Signifikanzwert }\end{array}$ \\
\hline Atmosphäre der Ausstellung & ++ & $0,494^{* * *}$ \\
\hline Präsentation der Werke & ++ & $0,476^{* * *}$ \\
\hline künstlerischer Ausdruck & ++ & $0,467^{* * *}$ \\
\hline Speisen im Restaurant & ++ & $0,351^{* * *}$ \\
\hline Inhalt des Katalogs & ++ & $0,348^{* * *}$ \\
\hline Beschriftung der Werke & ++ & $0,337^{* * *}$ \\
\hline Informationen des Personals & ++ & $0,320 * * *$ \\
\hline Gestaltung des Katalogs & ++ & $0,313^{* * *}$ \\
\hline Service im Museumsshop & ++ & $0,301 * * *$ \\
\hline Angebot im Museumsshop & ++ & $0,270^{* * *}$ \\
\hline Inhalt der Informationsbro- & ++ & $0,251^{* * *}$ \\
\hline schüre & & $0,221^{* * *}$ \\
\hline Service an der Kasse & ++ & $0,177^{* * *}$ \\
\hline $\begin{array}{l}\text { Gestaltung der Informations- } \\
\text { broschüre }\end{array}$ & ++ & $0,164^{* *}$ \\
\hline Preis des Katalogs & ++137 \\
\hline Service im Restaurant & $+* *$ \\
\hline Plakat zur Ausstellung & + & $0,125^{* *}$ \\
\hline
\end{tabular}

$++=$ sehr stark; + = stark; $\left(p=0,001^{* * *}\right) ;\left(p=0,01^{* *}\right) ;\left(p=0,05^{*}\right)$

Quelle: ZfKf 1998

das Urteil zum Speiseangebot in "Sigmar Polke« keinen nachweisbaren Einfluß auf das zum Ausstellungsbesuch insgesamt, ist der Einfluß des Speiseangebots auf das Gesamtbefinden der Besucher in "Arktis - Antarktis « relativ groß. In diesem Zusammenhang wäre es interessant, Angaben zu der Verweildauer der Besucher zu analysieren. Man könnte vermuten, daß der sehr interessierte Besucher, der das breite Informationsspektrum der Ausstellung "Arktis - Antarktis « an einem Tag erfassen wollte (was an sich kaum möglich gewesen ist!) länger verweilte und 
zwischenzeitlich auf ein magenfüllendes oder appetitanregendes Angebot angewiesen war.

\section{Informationsmedien zur Bekanntheit der Ausstellung "Arktis - Antarktis«}

Ein erstaunlich hoher Anteil von Besuchern ist durch Verwandte, Freunde und Bekannte und durch das Plakat zur Ausstellung auf »Arktis - Antarktis" aufmerksam geworden«.

- Im Vergleich mit den anderen beiden Ausstellungen ist festzustellen, daß speziell die Mund-Propaganda für »Arktis - Antarktis « sehr gut aktiviert worden ist.

- Der hohe Stellenwert des Plakats ist, wie schon bei der Auswertung zur Besucherumfrage der Eremitage diskutiert, bei der Betrachtung einer bundesweiten Repräsentativbefragung (Kulturbarometer 1994/95), wie auch anderer Besucherumfragen, zum Thema Informationsmedien für kulturelle Veranstaltungen ungewöhnlich. In Bürgerbefragungen (Stadtkultur 1996/97) hat sich jedoch schon gezeigt, daß Befragte mit hohem Bildungsstand wesentlich stärker auf die Signalwirkung des Plakates reagieren als Befragte mit niedrigem Bildungsstand. Da das $\mathrm{Pu}-$ blikum in der Kunst- und Ausstellungshalle erwiesenermaßen einen hohen Bildungsstand besitzt, erklärt sich der hohe Stellenwert des Plakates vor allem zu den Ausstellungen "Arktis Antarktis« und »Eremitage«.

- Die Signalwirkung des Plakats verliert, leicht nachvollziehbar, für Befragte aus weiter entfernten Regionen an Bedeutung.

- Anzeigen in der Presse, vor allem in Fachzeitschriften, spielen im Kontext der Ausstellung »Arktis - Antarktis« für das Erreichen von Zielgruppen eine untergeordnete Rolle, im Gegensatz beispielsweise zu den Besuchern von "Sigmar Polke» (Liebhaber zeitgenössischer Kunst), die diese aufmerksamer verfolgten.

- Ältere Besucher (52 bis 79 Prozent) wie auch das Stammpublikum (53 bis 62 Prozent) haben sich in allen drei Ausstellungen vor allem mittels Berichten in Zeitungen und Zeitschriften informiert. Im Vergleich zu den anderen beiden Ausstellungen ist jedoch der Anteil der Stammbesucher und der älteren Besucher, die sich über Zeitungsberichte informieren, deutlich kleiner. 
Abbildung 3: Informationsquellen zur Ausstellung

"Arktis - Antarktis"

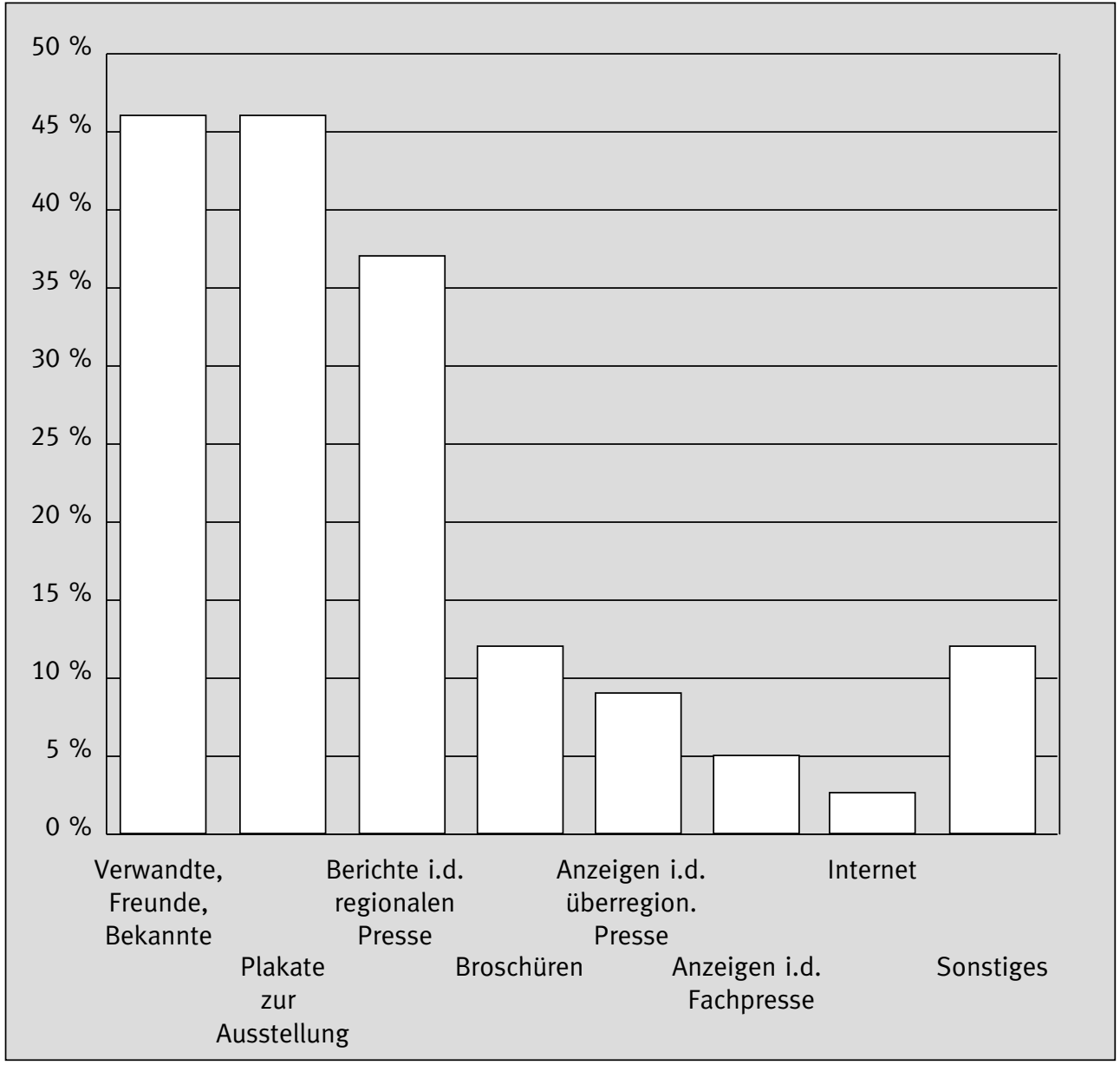

Quelle: ZfKf 1998

Jüngere Besucherschichten können über Zeitungsmedien kaum erreicht werden.

- Die persönliche Referenz durch den Bekanntenkreis spielt vor allem für die jüngeren Befragten (55 Prozent in »Arktis - Antarktis«) eine erhebliche Rolle (vgl. auch Abbildung 4). Auch die ausländischen Besucher (58 Prozent) haben sich im Kontext der »Arktis - Antarktis« weniger von der internationalen Berichterstattung als vielmehr durch entsprechende Berichte ihres Be- 
Abbildung 4: Vergleich der Informationsmedien zur Bekanntheit der Ausstellungen »Eremitage«, "Sigmar Polke« und »Arktis - Antarktis« (Mehrfachnennungen möglich)

\begin{tabular}{|l|l|l|l|l|l|l|l|l|l|}
\hline & \multicolumn{3}{|l}{ Eremitage } & \multicolumn{3}{l|}{ Polke } & \multicolumn{3}{l|}{ Arktis - Antarktis } \\
\cline { 2 - 10 } & abs. & $\%$ & Rang & abs. & $\%$ & Rang & abs. & $\%$ & Rang \\
\hline $\begin{array}{l}\text { Verwandte/ } \\
\text { Freunde/Bekannte }\end{array}$ & 324 & 33 & $\mathbf{3}$ & 197 & 34 & $\mathbf{2}$ & 500 & 46 & $\mathbf{1}$ \\
\hline $\begin{array}{l}\text { Plakat zur Ausstel- } \\
\text { lung }\end{array}$ & 414 & 43 & $\mathbf{1}$ & 163 & 28 & $\mathbf{3}$ & 498 & 46 & $\mathbf{2}$ \\
\hline $\begin{array}{l}\text { Berichte in der } \\
\text { Presse (Zeitun- } \\
\text { gen/Zeitschriften) }\end{array}$ & 398 & 41 & $\mathbf{2}$ & 264 & 46 & $\mathbf{1}$ & 394 & 36 & $\mathbf{3}$ \\
\hline $\begin{array}{l}\text { Anzeigen in der } \\
\text { Presse (überregio- } \\
\text { nale Zeitungen/ } \\
\text { Fachzeitschriften) }\end{array}$ & 152 & 16 & 5 & 147 & 26 & 4 & 154 & 14 & 4 \\
\hline $\begin{array}{l}\text { Unsere Broschüren } \\
\text { (»Ausstellungen« } \\
\text { etc.) }\end{array}$ & 213 & 22 & 4 & 103 & 18 & 5 & 132 & 12 & 5 \\
\hline Insgesamt & 974 & 100 & & 575 & 100 & & 1090 & 100 & \\
\hline
\end{tabular}

Quelle: ZfKf 1998

kanntenkreises zu einem Besuch animieren lassen. Ähnliches konnte auch für die Besucher in "Sigmar Polke« beobachtet werden.

- Aufgrund des eingeschränkten Verbreitungsraumes ist der Stellenwert der hausinternen Informations- und Programmhefte, wie zu erwarten, im Vergleich mit den anderen hier aufgeführten Informationsmedien vergleichsweise gering. Bei den regelmäßigen Besucher, die in der Regel eher eine Zugriffsmöglichkeit auf die hausinternen Informations- und Programmhefte besitzen, spielen diese jedoch eine wichtige Rolle im Kontext der Besuchsplanung künftiger Ausstellungen: 32 Prozent dieser Besucherklientel sind durch die hausinternen Broschüren auf die Ausstellung »Arktis - Antarktis « aufmerksam geworden.

- Das Internet nimmt, wie zu erwarten, eine untergeordnete Funktion im Kontext der Ausstellungsbekanntheit ein. Am ehesten informieren sich in »Arktis - Antarktis « Jüngere (5 Prozent) 
und Spontanbesucher (8 Prozent) im Internet über die Ausstellung.

\section{Bisherige und geplante Besuchsfrequenz in der Kunst- und Ausstellungshalle der BRD}

Betrachtet man nachfolgende Übersicht, wird deutlich, daß es sich bei den Ausstellungsbesuchern von »Arktis - Antarktis«, wie schon im vorangegangenen Kapitel vermutet, tatsächlich um viele Erstbesucher handelt. Der Anteil von Stammbesuchern in "Arktis Antarktis « ist mit 10 Prozent im Vergleich zu den anderen beiden Ausstellungen deutlich geringer.

\section{Bisherige Besuchsfrequenz}

- Es sind vor allem die unter 25jährigen, die erstmals durch die Ausstellung "Arktis - Antarktis« zu einem Besuch der Kunstund Ausstellungshalle motiviert wurden.

- Immerhin 18 Prozent der nicht im Bonner Raum ansässigen deutschen Besucher in "Arktis - Antarktis" geben an, mindestens viermal zu Besuch in der Kunst- und Ausstellungshalle gewesen zu sein.

- Fast die Hälfte (45 Prozent) der 50jährigen und älteren Besucher, die in der Polke-Ausstellung befragt wurden, können zu den regelmäßigen Besuchern gezählt werden.

- Unter den mit der Ausstellung unzufriedenen Besuchern befinden sich, wie schon in "Sigmar Polke", auch in "Arktis - Antarktis« regelmäßige Besucher. 40 Prozent der Besuchskritiker sind mindestens schon viermal in der Kunst- und Ausstellungshalle der BRD gewesen.

\section{Geplante Besuchsfrequenz}

- Wie schon bei der Ausstellung "Sigmar Polke« (8o Prozent), bejahen beachtliche 82 Prozent der befragten Besucher in "Arktis - Antarktis « die Frage, die Kunst- und Ausstellungshalle dieses Jahr wieder zu besuchen. 56 Prozent dieser Befragten machen einen Folgebesuch von dem angebotenem Programm und teilweise zusätzlich von den Eintrittspreisen abhängig, signalisieren jedoch generell ihre Bereitschaft. Nur 2 Prozent aller Befragten 
Abbildung 5: Bisheriges Besucherverhalten der Befragten in den Ausstellungen »Eremitage«, "Sigmar Polke« und "Arktis - Antarktis« in der Kunst- und Ausstellungshalle der BRD

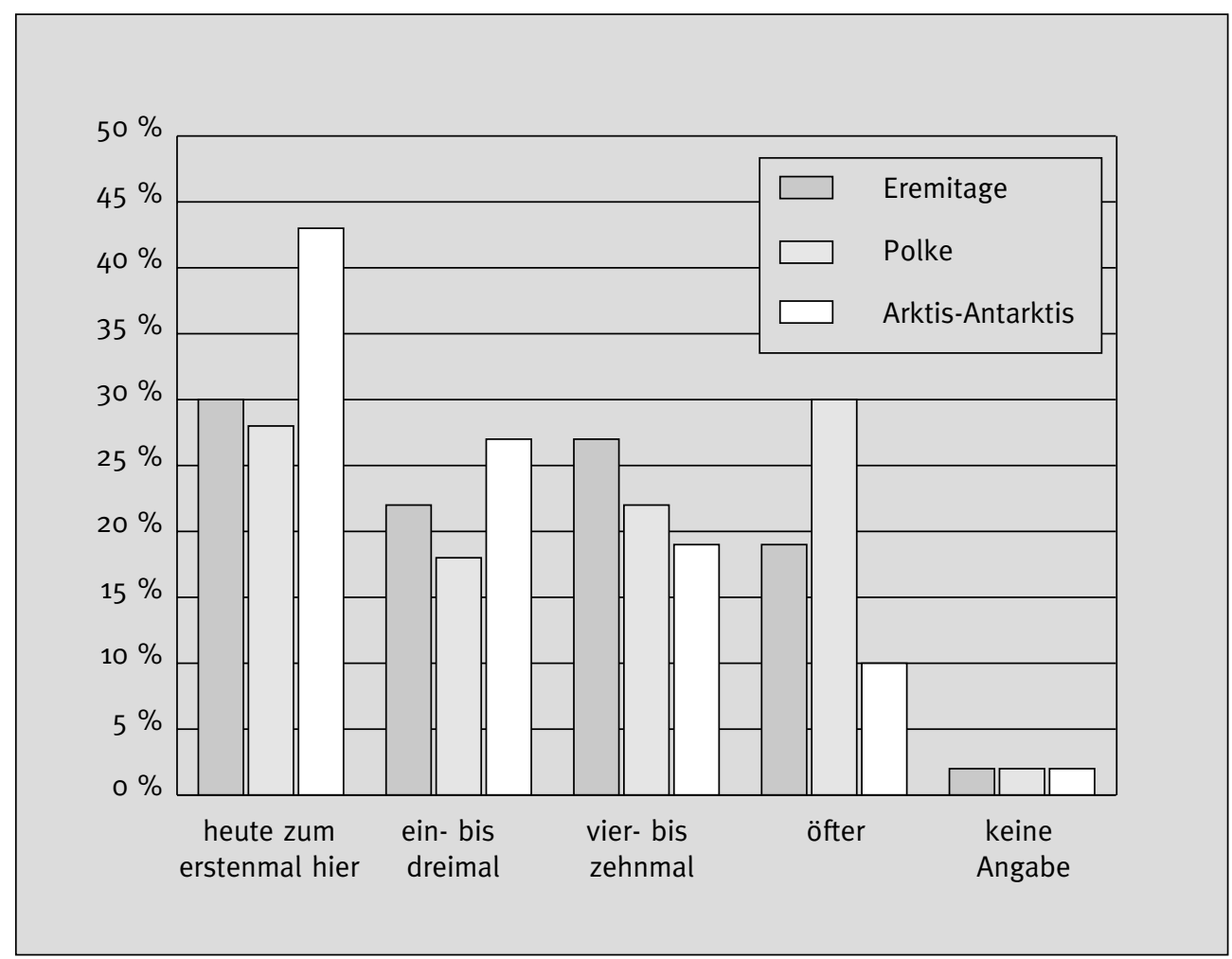

Quelle: ZfKf 1998

in "Arktis-Antarktis " geben definitiv an, die Einrichtung dieses Jahr auf keinen Fall mehr zu besuchen.

Im Hinblick auf die vielen Besucher (43 Prozent), die »ArktisAntarktis« erstmals besuchen, ist dies ein herausragendes Ergebnis.

- Die regelmäßigen Besucher beweisen, wie schon in den anderen Ausstellungen, besondere "Treue«. 96 Prozent bestätigen, daß sie 1998 auf jeden Fall die Kunst- und Ausstellungshalle der BRD wieder besuchen wollen. Nur 39 Prozent dieser Gruppe, die grundsätzlich noch dieses Jahr einen weiteren Besuch einplant, nennt als zusätzliches Entscheidungskriterium das Angebot des Hauses und teilweise die Höhe des Eintrittspreises. 
Abbildung 6: Geplantes Besucherverhalten der Befragten der Ausstellungen »Eremitage", "Sigmar Polke» und »Arktis - Antarktis"

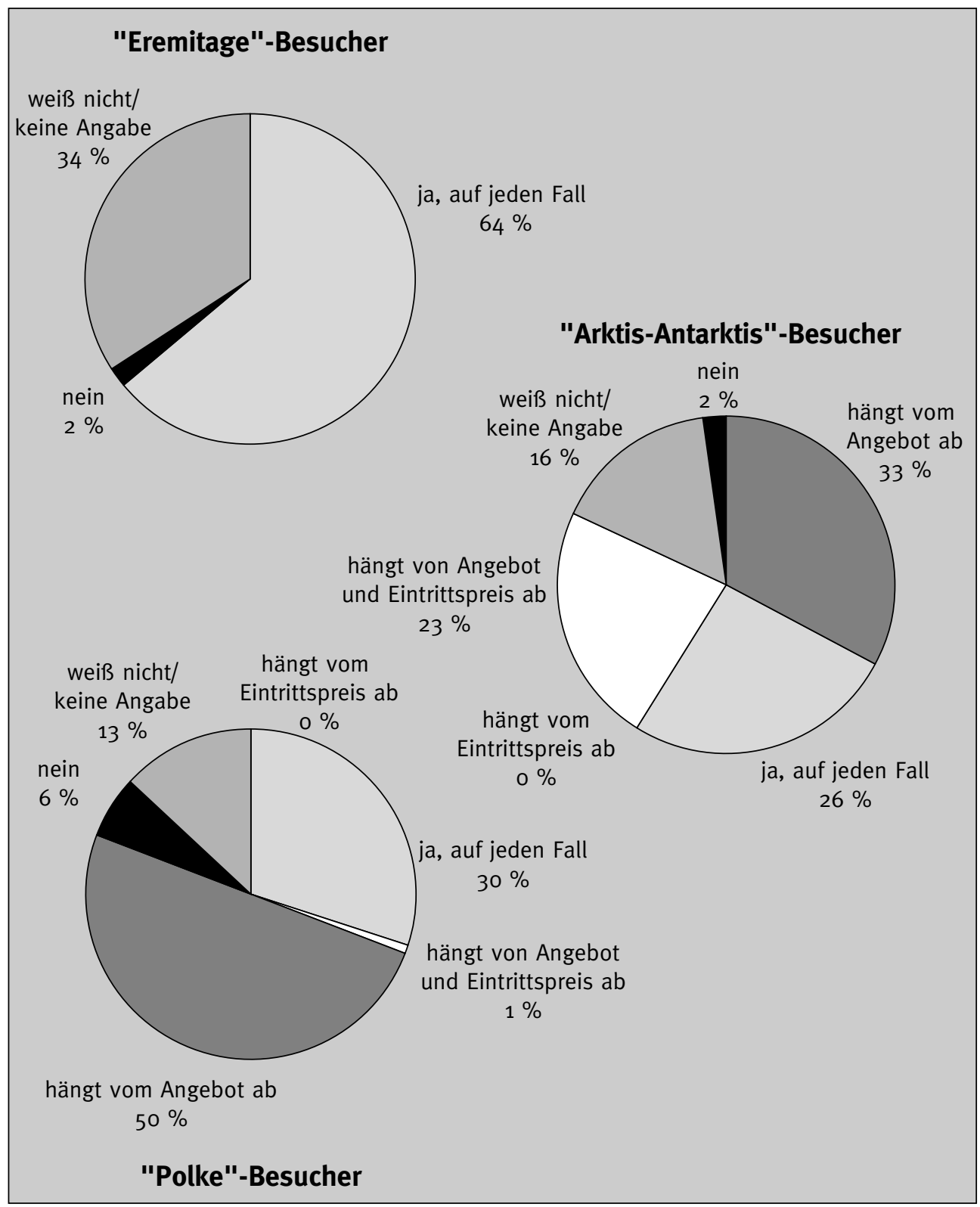

Quelle: ZfKf 1998 
- Selbst 83 Prozent der unzufriedenen Besucher wollen übrigens, bei akzeptablem Angebot und ebensolchen Eintrittspreisen, 1998 wieder die Kunst- und Ausstellungshalle der BRD aufsuchen. Weitere 6 Prozent dieser Besuchergruppe tut dies auf alle Fälle.

Abbildung 7: Geplantes Besucherverhalten der befragten Erstbesucher der Kunst- und Ausstellungshalle der BRD in "Arktis - Antarktis"

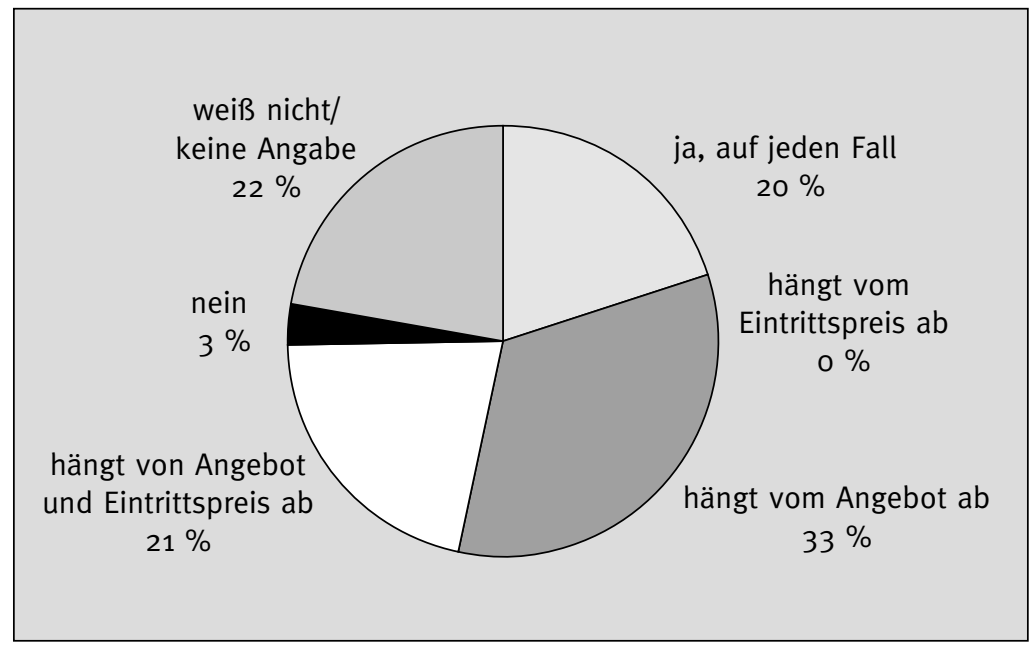

Quelle: ZfKf 1998

\section{Besucherinteresse an verschiedenen Ausstellungsarten}

- Beim Vergleich von Ausstellungsinteressen der Besucher in allen drei Ausstellungen wird deutlich, daß je nach thematischem Schwerpunkteiner Ausstellungin derKunst-und Ausstellungshalle auch das entsprechende »Liebhaber«-Publikum angesprochen wird. So steht selbstverständlich bei den Besuchern von "Sigmar Polke« auf Platz eins ihrer Präferenzliste »Zeitgenössische Kunst« (74 Prozent). Im Vergleich hierzu finden sich in »Eremitage« nur bzw. immerhin 33 Prozent und in »Arktis - Antarktis « 29 Prozent der Besucher, die sich für zeitgenössische Kunst interessieren. In »Arktis - Antarktis« hingegen interessiert sich die Mehrheit der 
Abbildung 8: Interesse der Besucher an Kunst- und Ausstellungsarten in den Ausstellungen »Eremitage", »Sigmar Polke« und »Arktis - Antarktis»

\begin{tabular}{|c|c|c|c|c|c|c|}
\hline & \multicolumn{2}{|c|}{ Eremitage } & \multicolumn{2}{|c|}{ Polke } & \multicolumn{2}{|c|}{$\begin{array}{l}\text { Arktis - } \\
\text { Antarktis }\end{array}$} \\
\hline & $\%$ & Rang & $\%$ & Rang & $\%$ & Rang \\
\hline Antike Kunst und Archäologie & 57 & 1 & 27 & 7 & 36 & 4 \\
\hline Impressionismus & 55 & 2 & 47 & 4 & 31 & 6 \\
\hline Expressionismus & 51 & 3 & 55 & 3 & 30 & 7 \\
\hline Kulturgesch. Ausstellungen & 43 & 4 & 25 & 11 & 38 & 3 \\
\hline Kunst der Renaissance & 42 & 5 & 26 & 9 & 15 & 15 \\
\hline Kunst des Mittelalters & 40 & 6 & 26 & 9 & 25 & 11 \\
\hline Klassische Moderne & 39 & 7 & 57 & 2 & 24 & 12 \\
\hline Völkerkunde & 34 & 8 & 19 & 15 & 45 & 2 \\
\hline Architektur & 33 & 9 & 43 & 5 & 33 & 5 \\
\hline Kunst des Barocks & 33 & 9 & 19 & 14 & 12 & 16 \\
\hline Zeitgenössische Kunst & 33 & 9 & 74 & 1 & 29 & 10 \\
\hline Romantik & 32 & 12 & 20 & 12 & 17 & 13 \\
\hline Design & 26 & 13 & 35 & 6 & 30 & 7 \\
\hline Techn.-naturw. Ausstellungen & 22 & 14 & 14 & 16 & 52 & 1 \\
\hline $\begin{array}{l}\text { Angewandte Kunst/ } \\
\text { Kunstgewerbe }\end{array}$ & 21 & 15 & 20 & 12 & 16 & 14 \\
\hline Medien- und Videokunst & 12 & 16 & 27 & 7 & 30 & 7 \\
\hline Anderes & 4 & 17 & 5 & 17 & 6 & 17 \\
\hline
\end{tabular}

Quelle: ZfKf 1998

Besucher (52 Prozent) für technisch-naturwissenschaftliche Ausstellungen, in »Eremitage « sind es vergleichsweise nur 22 Prozent, in »Sigmar Polke« nur 14 Prozent.

Dieses Ergebnis verdeutlicht noch einmal, daß es sich in den jeweiligen Ausstellungen nichtimmer um dieselben Besucher handelt, sondern ausstellungsspezifisch auch spezielle Zielgruppen angesprochen werden.

- Anders ist es bei den organisierten Besuchern: Bei ihnen steht ein persönliches ausstellungsspezifisches Interesse weniger im 
Mittelpunkt, was schon bei "Sigmar Polke« beobachtet werden konnte: Unter den organisierten Besuchern waren dort nur wenige Interessenten für zeitgenössische Kunst anzutreffen. Auch der Anteil der Interessierten an technisch-naturwissenschaftlichen Ausstellungen unter den organisierten Besuchern in "Arktis - Antarktis« liegt vergleichsweise nur bei 40 Prozent.

Die jüngeren Befragten, die in »Eremitage « und "Sigmar Polke« ein auffallendes Interesse für Design und Architektur signalisierten, bekunden in "Arktis - Antarktis" ein deutliches Interesse für Medien- und Videokunst (44 Prozent).

Die ausgewählten Beispiele belegen, in zum Teil verblüffender Weise, wie komplex das Besucherverhalten und die daraus resultierenden Besucherstrukturen je nach Ausstellung der Bundeskunsthalle sind. Dies ist zum einen der Aufgabe des Hauses angemessen und zum anderen ein Beleg dafür, daß das vielseitige Programm als integraler Bestandteil des Marketing vom Besucher angenommen wird. Die Analyse mit Hilfe bekannter Marketinginstrumente wie z. B. Besucherbefragungen ist, neben einer profunden Kenntnis des Ausstellungs- und Veranstaltungsmarktes, ebenso Grundlage für die Entwicklung des Programms wie der Standortfaktor und das ständig sich wandelnde soziodemografische Umfeld.

\section{Literatur}

Fünftes Kulturbarometer. 1994/95. Infas / ZfKf

"Stadtkultur im Bürgerurteil«. Bürgerbefragung in Bielefeld, Münster u. Dortmund. Im Auftrag der Bertelsmann-Stiftung. ZfKf. 1996/97 



\section{Kundenbindungsprogramme am Beispiel der Galeria Kaufhof Warenhaus AG}

\section{Ausgangspunkt: Wettbewerb und Profilbildung}

Die großen Kaufhäuser stehen in der Bundesrepublik Deutschland seit Jahren in einem scharfen Wettbewerb. Der private Konsum stagniert, der Wertewandel bringt ein verändertes Käuferverhalten mit sich. In jedem Moment ihrer Geschäftstätigkeit müssen sie aufs Neue ihren Kunden demonstrieren, warum es für diese Sinn macht, die vielfältigen Angebote der Kauf- und Warenhäuser zu nutzen - über den traditionellen Vorteil der City-Standorte hinaus. Dabei bestehen die Angebote der Kaufhäuser nicht nur aus Waren des täglichen Bedarfs und langlebigen Konsumgütern, sondern zunehmend aus einem ganzen Strauß unterschiedlicher Dienstleistungen, von der Beratung über Reparaturservice bis zur Finanzierung, von der Bereitstellung von Parkplätzen über Bringservice bis $\mathrm{zu}$ gastronomischen Diensten. Ein derartiges Angebot muß für Präferenzen bei breit gestreuten Zielgruppen sorgen. Dieses läßt sich nur bewerkstelligen, wenn ein Handelsunternehmen wie die Galeria Kaufhof Warenhaus AG sich in seinem Auftreten deutlich von anderen Betriebsformen des Einzelhandels unterscheidet und ein klares Unternehmens- und Angebotsprofil aufweist.

Eine erste Voraussetzung für ein derartiges Profil, mit dessen Hilfe Kundenbindung gelingen soll, ist die Schaffung und Umsetzung eines entsprechenden Unternehmensleitbildes, das als Leitlinie für gegenwärtiges und zukünftiges Handeln aller Mitarbeiter 
dient. Das Unternehmensleitbild der Kaufhof Warenhaus AG, das im Zusammenhang mit dem Galeria-Konzept entwickelt wurde und realisiert wird, ist im folgenden wiedergegeben. Es zeigt die Bedeutung der Kundenorientierung und Kundennähe - im Museum vergleichbar mit Besucherorientierung und Besuchernähe für die Erreichung der angestrebten Ziele.

Unser eigenes Selbstverständnis ist die Grundlage für unser Handeln!

- Wir richten alle unsere Geschäftsprozesse auf die Zufriedenheit der Kunden aus.

- Wir betrachten die Identifikation, Motivation und Qualität unserer Mitarbeiterinnen und Mitarbeiter als wesentlichen Erfolgsfaktor für die Zukunft.

- Wir sind für unsere Kunden und Lieferanten ein zuverlässiger Partner, der neue Wege beschreitet und Bewährtes weiterentwickelt.

- Wir handeln ertragsbewußt und kundenorientiert, um die Weiterentwicklung und den Fortbestand unseres Unternehmens nachhaltig zu sichern.

- Wir sind uns unserer gesellschaftlichen und sozialen Verantwortung bewußt und gestalten aktiv die Erhaltung und Verbesserung der Umwelt mit.

Fragen, die sich aus solchen grundsätzlichen Überlegungen und Zielsetzungen ergeben, sind: Wie können wir als Galeria Kaufhof Warenhaus AG die ca. 4-5 Mio. Besucher, die täglich in unsere Häuser kommen, zu Kunden bzw. zu Stammkunden machen? Welche Maßnahmen führen zur Kundenbindung und werden mit Erfolg praktiziert?

\section{Kundenstruktur und Kundenerwartungen}

Eine für die Möglichkeiten der Kundenbindung zentrale Frage ist die nach der Struktur und den Erwartungen der Kunden. Die Frage »Wer sind unsere Kunden? « wird durch unsere Marktforschung in regelmäßigen Zielgruppenanalysen beantwortet. Ein immer wiederkehrendes Phänomen ist die bekannte Tatsache, daß wir es mit sehr breiten und unterschiedlichen Kundengruppen zu tun haben. Und daß die meisten unserer Kunden für uns zunächst 
anonym sind - und es bleiben, solange wir nicht bestimmte Aktivitäten unternehmen, um unsere Kunden näher kennenzulernen. Dies aber erscheint uns als wichtige Chance, Kundenbindung zu erzeugen. Einer der Wege, die Kunden, ihre Erwartungen, ihr Verhalten und ihre kritischen Meinungen kennenzulernen, sind Kundenforen (auch als Kundenkonferenzen bekannt). Wir veranstalten solche Kundenforen regelmäßig und erfahren - Führungskräfte wie auch andere Mitarbeiterinnen und Mitarbeiter - auf diesem Weg vieles über Möglichkeiten zur Kundenbindung, aber auch über bestehende Hindernisse. Am Rande: Teilnehmer solcher Diskussionsrunden sind nach dieser Erfahrung, ganz besonders ernst genommen zu werden, Kunden, die nach eigenen Aussagen stärker als andere an das Haus gebunden sind.

\section{Die Grundkonzeption}

Der Kern des Galeria-Konzeptes ist ein neuer, ein »wertiger" Marktauftritt. Dieser setzt sich ab von anderen Formen des Auftrittes und der Präsentation, indem er die folgenden Aspekte fokussiert:

- zielgruppenorientierte Warenpräsentation

- Qualitätsorientierung

- Erlebniswerte

- Visuelles Merchandising

- Verbesserte Ästhetik und Übersicht

- Werbung auf hohem Niveau

- Serviceorientierung geschulter und motivierter Mitarbeiter.

Diese Kerngedanken lassen sich in dem Stichwort »Erlebnis-Warenhaus« zusammenfassen.

\section{Kundenbindungsprogramme - Beispiele und Erfahrungen}

Wie nun erreichen wir auf Dauer angelegte Kundenbindung und damit eine möglichst große Stammkundschaft? Im folgenden sollen Beispiele für das im Rahmen des Kaufhof Galeria-Konzeptes initiierte Kundenbindungsprogramm gegeben werden. Alle diese Beispiele können daraufhin überprüft werden, ob ihr Kerngedan- 
ke oder sogar ihre Ausformung in einer bestimmten Variante auch für Kulturbetriebe wie Museen Anregungen zur Besucherbindung geben können.

Die verschiedenen Mosaiksteine des Kundenbindungsprogramms beziehen sich auf unterschiedliche Ebenen unseres Verhältnisses zum Kunden: auf das Warenangebot, auf dessen Unterstützung durch Dienstleistungen, auf die Kundenbeziehung als solche, z.B. die Informationsschiene oder die Atmosphäre des Kundenkontaktes und nicht zuletzt auf die Mitarbeiter und deren Auftritt bzw. Verhalten. Die nachfolgenden Instrumente zeigen Aktivitäten, mit denen Präferenzen bei den Kunden erzeugt und im Sinne einer Bindung hin zur Stammkundenbeziehung verstärkt werden sollen und können.

\section{Beispiele aus dem Kundenbindungs-Programm:}

- Guter Standort

- Schönes Haus

- Öffnungszeiten

- Eigenes Parkhaus, ermäßigte Parkgebühren bei Einkauf, FreiParkscheine für Stammkunden

- Elektronische Leit- und Infosysteme

- Übersichtliche Wegeführung im Haus

- Informationsstand, VIP-Service, Sprachservice, Kundentelefon

- Leistungsfähiges Eigenmarken-Programm

- Große Auswahl, großes Sortiment; alle Artikel unter einem Dach

- 8o Markenshops innerhalb eines Hauses

- Vorwahlgerechte Aufmachung des Sortiments

- Selbstbedienung/Fachberatung und -bedienung, wo diese nötig ist

- Gutes Preis-Leistungsverhältnis

- Umtausch ohne »Wenn-und-aber oder »Geld-zurück«

- Kostenlose Mode- und Stilberatung

- Individuelle Kundenbedienung

- Annahme verschiedener Kreditkarten

- Galeria-Kundenkarte 
- Zusätzliche Serviceleistungen:

Kartenreservierungssystem für Konzerte, Theater, Sportveranstaltungen

Reisebüro

Geldautomaten

Kartentelefon

Reparatur-Service

Kostenloser Zustell-Service; dabei erhält das Unternehmen Adressen und die Chance der persönlichen Ansprache

Hochzeits- und Geschenkservice

Internet-Cafe mit Schulungsangebot

Ruhezonen für Kunden

Änderungsschneiderei

- Direct Mailings und Events für Stammkunden zu Themen wie besondere Warenangebote mit exzeptionellem Preis / Leistungsverhältnis

Einladungen zu Länderschauen, Modenschauen, Ausstellungen, Abendempfängen

- Kinder-Spielwochen, Kinder-Karneval (mit hohem Sympathiewert)

- Örtliche Vereine, Brauchtum und Sport haben die Möglichkeit, sich darzustellen

- Beschwerde-Management; Reklamationsbearbeitung auf der Basis eines Schulungsprogramms, mit dem Standard der Beantwortung innerhalb 24 Stunden und mit der zusätzlichen Chance der Pflege von Kundenkarteien

- Durchführung von Kundenforen (siehe oben), verbunden mit Testkäufen

- Einsatz von sogenannten »Vertrauenskunden«, die 1 x monatlich eine Art Testkunden-Funktion erfüllen, aber auch als Leitkunden bevorzugt um ihre Meinung gefragt werden

- Gutes Betriebsklima

- Mitarbeiter sind über ein Anreizsystem am Umsatz beteiligt (»Jeder Mitarbeiter ein kleiner Unternehmer«)

- Mitarbeiter-Schulung zum Thema Kundenorientierung

- Ständiges Team »Kundenorientierung«

- Gepflegtes und sicheres Auftreten des Personals 
- Mitarbeiter tragen Namensschilder

- Visitenkarten der Mitarbeiter für die Kunden, um diesen bestimmte Mitarbeiter als persönliche Ansprechpartner zu vermitteln

- Maßnahmen zur Mitarbeiter-Motivation - denn MitarbeiterZufriedenheit korreliert erwiesenermaßen mit Kunden-Zufriedenheit hoch; sie führt oft zu erhöhter Kunden-Zufriedenheit und damit zur Kundenbindung

Erste Erfahrungen mit dem umfassenden Einsatz dieses Aktionsprogramms haben folgende Ergebnisse gezeigt:

- Eine deutlich bessere Umsatzentwicklung als vergleichbare Niederlassungen

- Rückgang der Kundenreklamationen

- Erhöhung der Mitarbeiterzufriedenheit

- Ausweitung der Stammkunden (Kundenkarte + 25 Prozent)

- Erhöhung des Durchschnitteinkaufs pro Kunde

- Verbesserung des Warensortiments durch Anregung des Kunden

- Deutliche Zunahme der Kundenbindung

- Gewinnung von neuen Erkenntnissen aus Kundensicht für die Weiterentwicklung des Galeria-Konzeptes

- Einführung eines interaktiven Kunden-TV

- Verbesserung der Ertragskraft der Filiale durch den Verkauf hochwertiger Ware

\section{Fazit}

Die hinter diesen Instrumenten und Aktivitäten stehende Philosophie kann auf folgenden Nenner gebracht werden: Langfristige Beziehungen zum Kunden haben höchste Priorität. Das Wiederverkauf-Verhalten der Kunden ist der Schlüssel zur Kundenbindung und zur Verbreiterung der Stammkundenbasis. Das Motto der Galeria Kaufhof Warenhaus AG lautet: "Zufriedene Kunden kaufen mehr«. Dieser Zusammenhang zwischen einem klar profilierten Sortiment und einem kundenorientierten Service auf der einen Seite sowie Zufriedenheit der Kunden und wiederholtem Aufsuchen unserer Häuser andererseits - dieses ist ein Zusammenhang, der mit gewissen Variationen in ähnlicher Weise auch 
für Kulturbetriebe Gültigkeit hat. Im Sinne der "Selbstbedienung in der Erfahrung anderer « können Museen überprüfen, ob einzelne dieser Instrumente sie auf dem Weg zu mehr Besucherbindung weiterbringen können. 

JAN SAS

\section{Der Besucher als Berater}

Auf welche Weise schalten Museen ihre Besucher als Berater ein? Die Aufforderung der Besucher zur Stellungnahme betrachte ich als eine Form der Evaluationsstudie, wobei ich darunter die Bewertung eines Objektes, einer Sammlung von Objekten oder einer Aktivität anhand bestimmter Kriterien verstehe.

Evaluationsstudien in Museen und somit die Einbeziehung von Besuchern sind kein Phänomen jüngeren Datums. Ich möchte zunächst auf einige Hintergründe eingehen. Weshalb wird dem $\mathrm{Pu}-$ blikum Aufmerksamkeit geschenkt? Das Interesse am Publikum äußerte sich anfänglich vor allem in der Beobachtung des Publikums. Ich werde mit Hilfe einiger Beispiele aus früheren Zeiten darlegen, daß Besucher bereits durch ihr Verhalten ein Museum beraten.

Die Bedeutung der Beobachtung von Besuchern und der daraus zu ziehenden Schlußfolgerungen ist nicht zuletzt davon abhängig, welche Rolle ein Museum einer Evaluationsstudie beimißt. Aus diesem Grund werde ich auch auf den Akzeptanzgrad von Evaluationsstudien in Museen eingehen.

Danach ist näher auf die zwölf Kategorien einzugehen, in denen der Besucher als Berater auftritt. Dabei sind die Kategorien in ansteigender Reihenfolge geordnet, das heißt mit jeder Kategorie nimmt das Ausmaß des Einflusses des Beraters auf die Museumspolitik zu.

Ich möchte mit einigen Ergebnissen einer Untersuchung ab- 
schließen, die ich unter Besuchern von Amsterdamer Museen durchgeführt habe. Was halten sie von der Idee, daß sie das $\mathrm{Mu}$ seum beraten können? Sehen sie es als eine große Herausforderung an, Einfluß auf die Museumspolitik ausüben zu können und als eine Möglichkeit, über das zu klagen, was nicht in Ordnung ist: die zu kleine Beschriftung auf den Texttafeln, das Angebot des $\mathrm{Mu}$ seumsrestaurants usw.

\section{Woher kommt die große Aufmerksamkeit für das Publikum?}

Museen auf der ganzen Welt sehen sich durch politische und wirtschaftliche Entwicklungen verstärkt gezwungen, selbständig zu werden. Da Besucher für viele Einnahmen sorgen können, beispielsweise über Eintrittsgelder, den Museumsladen und das $\mathrm{Mu}$ seumsrestaurant, schenken Museen der Zufriedenheit der Besucher immer größere Aufmerksamkeit. Um die Besucher zufriedenzustellen, unternehmen Museen im Rahmen ihrer Marketing- und Öffentlichkeitsarbeit zahlreiche Anstrengungen, um Besucher sowie potentielle Besucher in die Museumsaktivitäten einzubeziehen.

Die Aufmerksamkeit, die die meisten Museen ihrem Publikum heute schenken, ist jedoch nicht neu. Bereits 1714 ließ Zar Peter der Große als Zeichen der Gastlichkeit Wodka im ersten russischen Museum, der Kunstkamara in Sankt Petersburg ausschenken. ${ }^{1}$

Interesse am Publikum heißt auch, das Publikum näher unter die Lupe zu nehmen: wie setzt sich das Publikum zusammen und was tut es im Museum? Das Studium des Publikums beschränkte sich anfänglich vor allem auf seine Beobachtung. Ich werde einige Beispiele dafür nennen.

\section{Geschichte}

Die erste Evaluationsstudie, über die öffentlich berichtet wurde, wurde meines Wissens von Henry Hugh Higgins durchgeführt, der als Honorary Curator dem Liverpool Museum verbunden war. 1884 berichtete er über einige besondere Beobachtungen, die er gemacht hatte. Bei 78 Prozent der Besucher seines Liverpool Museum war der Besuch allgemeiner Art und man zeigte großes Inte- 
resse, 20 Prozent schlenderten ohne besonderes Interesse durch das Museum und bei 2 Prozent der Besucher handelte es sich um Studenten mit wissenschaftlichem Interesse an den Exponaten (McManus 1996). Was konnte Higgins aus dem Verhalten des Publikums ablesen? Sollte man alles so lassen wie es war, oder sollten doch Änderungen vorgenommen werden?

Der erste Artikel, in dem das Museum vom Standpunkt des Besuchers aus betrachtet wurde, datiert - soweit ich weiß - aus dem Jahre 1901. Er stammt von S.P. Langley, dem Sekretär des Smithsonian Institute und Entwerfer des Children's Room, der sich von 1901 bis 1939 im Smithsonian-Schloß befand. Beim Entwurf des Children's Room identifiziert sich Langley mit Kindern. Er sagt, daß Kinder bisher nie eine ehrliche Chance in Museen hatten. Kinder können Objekte, die ganz oben im Regal stehen, nicht sehen, und die Dinge, die sie wohl sehen können und über die sie mehr erfahren möchten, tragen lateinische Namen, die sie nicht verstehen (Langley 1901).

Aufmerksamkeit für den Besucher heißt auch, den Besucher zu beobachten. Ein frühes Beispiel dafür stammt aus dem ersten Kindermuseum der Welt, dem Brooklyn Children's Museum, das 1899 eröffnet wurde. Die erste Pädagogin und spätere Direktorin dieses Museums, Anna Billings Gallup, ging bei der Konzeption von erfolgreichen Ausstellungen und Aktivitäten von einem einfachen Ausgangspunkt aus. "Follow the child around", lautete ihre Empfehlung (Alexander 1997: 141).

Ihre Bemerkung, daß Besucher beobachtet werden müßten, hat fast hundert Jahre später noch nichts an Gültigkeit eingebüßt. Billings Gallup bestand darauf, daß "no new program was accepted until the children had pronounced it full of promise (Alexander 1997: 141). Mit anderen Worten, es wurde kein einziges neues Programm ausgeführt, bevor die Kinder es nicht als vielversprechend bezeichnet hatten. Als Anna Billings Gallup das Brooklyn Children's Museum 1937 verließ, zählte das Museum 6oo.ooo Besucher jährlich. Diese Zahl läßt sich nicht zuletzt durch die besucherorientierte Vorgehensweise erklären.

Berühmt ist die Untersuchung von Benjamin Gilman, der 1916 einen Artikel über Museumsmüdigkeit veröffentlichte. Ein Besucher wurde gebeten, Texte zu lesen. Vom Verhalten dieses Besuchers wurden Fotoaufnahmen gemacht, die zeigten, daß Texte gelegentlich an den unmöglichsten Stellen angebracht waren (Gilman 1916: 62-74, 1918: 251-269). Die Empfehlungen für das Muse- 
um waren deutlich: hängt den Text an eine Stelle, an dem er gut zu lesen ist. Auch heute bin ich noch regelmäßig geneigt, Museen diese Empfehlung zu geben.

Anfänglich beschränkten sich Evaluationsstudien auf das $\mathrm{Mu}$ seum als Ganzes. So untersuchte der Psychologe Melton um 1935, wodurch Besucher bei ihrem Gang durch eine Ausstellung veranlaßt werden, sich nach rechts oder nach links zu wenden (Melton 1935). 1939 ist es Cummings, der zum ersten Mal eine Studie des Verhaltens von Besuchern in einer Ausstellung durchführt (Cummings 1940). Die wirkliche Einbeziehung des Publikums bei der Planung einer Ausstellung ist jedoch sehr jungen Datums. Erst 1968 führt der Amerikaner Harris Shettel die sogenannte formative Evaluationsstudie im Museum ein (Shettel u.a. 1968). Dabei werden Produkte während des Entwicklungsprozesses getestet, so wie Suppenhersteller wie Maggi oder Knorr zuerst eine Suppe testen, bevor sie sie auf den Markt bringen. Erst dann wird der $\mathrm{Mu}-$ seumsbesucher nach seiner Meinung gefragt, während das Endprodukt noch nicht fertig ist. Der Museumsmitarbeiter hat also ein offenes Ohr für den Rat des Besuchers.

1983 führte Steve Griggs, der damals im Londoner Museum für Naturgeschichte tätig war, den Begriff "Front-End-Evaluation" ein. Dabei geht die Beratung noch einen Schritt weiter, beginnt also, wenn sich das Produkt noch in der Konzeptphase befindet (Griggs / Hays-Jackson 1983).

Dieser kurze und sehr unvollständige historische Überblick zeigt, daß sich der Blickwinkel der Museen, die sich mit Evaluationsstudien beschäftigen, meistens auf einen Aspekt des $\mathrm{Mu}$ seumsbetriebs beschränkt, nämlich auf die Präsentation: untersucht wird die Wirkung einer Ausstellung, ihr pädagogischer Einfluß und die damit verbundenen PR- und Marketinganstrengungen. Um eine gute Ausstellung zu konzipieren, die an die Erlebniswelt der Besucher anschließt, möchten Museen unter anderem gerne wissen, wer ihre Besucher sind, wie sie sich verhalten, was sie wissen, was sie lernen möchten und wie sie lernen. 
Nicht jeder Besucher, der an einer Evaluationsstudie teilnimmt, ist ein Berater. Das Thema »Der Besucher als Berater" kann von zwei Seiten betrachtet werden: das Museum tritt an den Besucher als Berater heran, aber der Besucher kann auch ungefragt als Berater des Museums auftreten.

Ich möchte mit dem Museum beginnen, das an den Besucher als Berater herantritt. Ist dies üblich? Das Fragen um Rat beim Publikum sehe ich - wie bereits erwähnt - als eine Form der Evaluationsstudie. Längst nicht alle Museen sind so weit, daß sie Evaluationsstudien durchführen. Steve Bitgood, Hochschullehrer für Psychologie an der Universität von Jacksonville, Alabama (USA) und Autor zahlreicher Artikel über Evaluationsstudien, unterscheidet neun Stadien im Prozeß der Akzeptanz der Evaluation in Museen (Bitgood 1996: 4f.):

Das zuständige Management eines Museums:

\section{1. glaubt, daß sich Evaluation lohnt}

\section{2. läßt ab und zu eine Evaluationsstudie durchführen}

\section{3. ist sich der Vorteile einer Evaluationsstudie bewußt}

\section{4. nutzt Evaluation als Hilfsmittel zur Entscheidungsfindung}

Ein Beispiel: in einer Mitarbeiterversammlung wird festgestellt, daß ein bestimmter Bereich des Museums schlecht besucht wird. Jeder Mitarbeiter hat dafür eine andere Erklärung, und alle Erklärungen scheinen plausibel. Wer hat recht? In diesem Fall kann eine Evaluationsstudie bei der Entscheidungsfindung hilfreich sein.

\section{5. sorgt für adäquate finanzielle Unterstützung von Evaluationsstudien}

Im Leidener Museum für Naturgeschichte Naturalis, das 1998 seine Türen öffnete, sind 5 Prozent des Ausstellungsbudgets für Evaluationsstudien reserviert (Sas 1996). Dies ist jedoch nichts im Vergleich zu den Zahlen, die Alan Friedman, Direktor der New York Hall of Science, nennt. Er reserviert 30 Prozent für Evaluationsstudien (Bitgood 1996: 4). 


\section{6. gibt Evaluationsstudien auch in Zeiten finanzieller Engpässe Priorität}

\section{7. stellt einen hausinternen Evaluator ein}

Meines Wissens gibt es in keinem einzigen deutschen Museum einen hausinternen Evaluator, nicht einmal im Haus der Geschichte, in dem die einjährige inspirierende Anwesenheit des bekannten amerikanischen Besucher- und Evaluationsforschers Professor Ross Loomis nicht dazu geführt hat, daß eine feste Planstelle für Besucher- und Evaluationsstudien geschaffen wurde. Auch in den Niederlanden verfügt kein einziges Museum über einen internen Evaluator.

Museen, die dagegen einen festangestellten Evaluator haben, sind vor allem in den Vereinigten Staaten zu finden: das Art Institute of Chicago (Minda Borun), das Natural History Museum in New York (Ellen Giusti), die Smithsonian Institution, wo eine ganze Abteilung für Besucherforschung unter der Leitung von Zahava Doering steht, in Kanada im Museum of Civilisation (Karen Graham), in England im Science Museum (Ben Gammon) und in Australien, wo beispielsweise das Powerhouse (Carol Scott) und das Australian Museum (Lynda Kelly), beide in Sydney, sowie das Museum Victoria in Melbourne (Carolyn Meehan) einen eigenen Evaluator beschäftigen.

\section{8. fordert Evaluation bei (praktisch) allen Projekten und}

\section{9. implementiert die Ergebnisse der Evaluation maximal}

Hierbei hat sich der "Evaluationsvirus « in der gesamten Organisation breit gemacht. Ergebnisse führen wirklich $\mathrm{zu}$ substantiellen Verbesserungen von Ausstellungen oder Programmen. Die bereits erwähnte New York Hall of Science ist ein gutes Beispiel dafür. In den Niederlanden gibt es diese Situation noch nicht.

\section{Inwieweit schenken Museen ihren Besuchern Gehör?}

Viele Museumsdirektionen sind noch immer der Meinung, daß die Evaluation von Ausstellungen und Programmen wenig sinnvoll sei. Diese Museen haben also noch nicht einmal Stadium Eins erreicht. Und wo Evaluation durchaus als sinnvoll erachtet wird, 
stellt sich die Frage, in welchem Stadium das Museum den beratenden Besucher einbeziehen soll?

Als Dozent an der Reinwardt Academie habe ich im vergangenen Jahr gemeinsam mit Studierenden viele Museen besucht. Diese Besuche standen unter dem Motto: "Die Stimme des Besuchers. Inwieweit schenken Museen ihren Besuchern Gehör?« Bei jedem Besuch gab es mehrere Vorträge, oft vom Direktor oder von den Mitarbeitern. Ausgehend von ihren Berichten über den Umgang mit dem Publikum unterscheide ich beim Besucher als Berater die folgenden Kategorien:

\section{Ein Museum ist nicht interessiert}

Für das Museum kann der Besucher keine Rolle als Berater spielen. "Das Publikum kann nur das wollen, was es schon kennt. Menschen können sich nur nach Bekanntem erkundigen. Unsere Aufgabe ist es, dasjenige zu zeigen, was man nicht kennt. Wir gehen also nicht auf den ausgesprochenen Wunsch des Publikums ein, bestimmte Werke zu zeigen. Allerdings erzeugen wir Wünsche beim Publikum, d.h. wir gehen auf den Wunsch des Publikums ein, das zu zeigen, was es noch nicht gesehen hat«, sagte eine Mitarbeiterin vom Stedelijk Museum für Moderne Kunst in Amsterdam.

Mit anderen Worten: Dieses Museum sieht das Publikum nicht in der Rolle des Beraters bei der Ausstellungspolitik.

\section{Ein Museum reagiert nicht}

Das Museum hat kein offenes Ohr für eventuelle Empfehlungen des Publikums. Man kann oder will solche Empfehlungen nicht berücksichtigen. Oft sind es fehlende Mittel, eine zu knappe Personaldecke oder mangelnde Professionalität, die zu einer solchen Haltung des Museums führen. Ein Beispiel ist das kleine Museum mit einer Privatsammlung, dessen Verwalter/Eigentümer mitteilt: "Ich bin der Eigentümer, also bestimme ich, was hier geschieht."

\section{Ein Museum reagiert indirekt}

Der Besucher tritt hier nicht selbst beratend auf. Es ist ein $\mathrm{Mu}-$ seumsmitarbeiter, der als sogenannter Vertreter des Publikums beispielsweise zu einem Ausstellungsteam gehört. Diese Situation kommt am meisten vor. Es gibt sogar Museumsmitarbeiter, auf deren Visitenkarte als Berufsbezeichnung "Audience Advocate» steht. 


\section{Ein Museum ist konsumptiv}

Ein Museum hat zwar ein offenes Ohr für Anmerkungen der Besucher, und $\mathrm{ab}$ und $\mathrm{zu}$ (wenn auch sehr selten) wird darauf reagiert. Das Museum ergreift selbst keine Initiative, um Stellungnahmen durch die Besucher zu fördern. Ein Beispiel sind die Bemerkungen, die Besucher arglos, aber gelegentlich auch sehr bewußt dem Kassenpersonal oder den Museumswärtern im Saal gegenüber machen. Das sind die Personen in einem Museum, denen oft als erste die Stellungnahmen der Besucher zu Ohren kommen. Leider gibt es nicht immer eine adäquate Stelle, die diese Hinweise registriert und an die Verantwortlichen weiterleitet. Ein einfache Lösung, für die sich manche Museen entschieden haben, ist ein Tagebuch, in dem das Personal Anmerkungen und Empfehlungen des Publikums festhalten kann. Die Notizen in einem solchen Tagebuch sind daher fester Bestandteil der Arbeitsbesprechung. Manchmal gibt es zwar kein Tagebuch, aber die Reaktionen der Besucher sind dennoch fester Programmpunkt einer Abteilungsbesprechung. Eine Schwachstelle in dieser Situation ist die erforderliche Bereitschaft des Personals, die Hinweise des Publikums weiterzuleiten.

Eine konsumptive Haltung des Museums liegt auch bei den Hinweisen vor, die in Form von Rezensionen oder Leserbriefen in der Presse erscheinen. Auch Briefe mit Empfehlungen, die direkt an die Leitung eines Museums gerichtet sind, gehören dazu.

Das Freilichtmuseum in Arnheim hat kürzlich ein System zur Registrierung von Beschwerden eingeführt. Alle eingehenden Reaktionen, sowohl in Form von Briefen als auch in Form von Bemerkungen gegenüber dem Personal, werden registriert und zentral vom Direktionssekretär gesammelt. Dieser Koordinator - der in der Hierarchie in der Nähe der Museumsleitung steht - sorgt dafür, daß Reaktionen von Besuchern ernst genommen werden. Er sorgt für die Behandlung der Beschwerden, eventuell durch Delegation. Beschwerdeführer erhalten somit schnell Anwort, und Beschwerden werden unverzüglich behandelt. Dieses Beschwerdenregistrierungssystem ist derzeit eines der "hot items im Arnheimer Freilichtmuseum.

\section{Ein Museum bietet Hilfestellung}

Der Besucher hat die Möglichkeit, auf das Museum oder dessen Angebot zu reagieren und auf diese Weise dem Museum beratend zur Seite zu stehen. Dies geschieht über Medien, die vom Museum 
zur Verfügung gestellt werden, wie einem Gästebuch, einer Flipchart, einer Schultafel oder einem Whiteboard, Reaktionsformularen oder Haftzetteln.

Ein Beispiel für eine Ausstellung, bei der Haftzettel verwendet werden, ist das Projekt »Face to Face«. Dabei handelt es sich um eine Ausstellung über AIDS, die bereits seit mehreren Jahren durch die USA reist. In dieser Ausstellung liegen kleine Blöcke mit gelben Haftzetteln. Besucher werden aufgefordert, ihre Gedanken $\mathrm{zu}$ notieren und auf eine Wand zu kleben, wo andere sie lesen können. ${ }^{2}$

\section{Ein Museum fragt selbst um Rat, tut dies jedoch unstrukturiert}

Der Besucher wird aktiv vom Museumspersonal um eine Reaktion, um Ratschläge gebeten. Dies geschieht jedoch unstrukturiert. Ein bekanntes Beispiel ist der Museumsdirektor, der eventuell inkognito ein Gespräch mit einem Besucher anknüpft und ihn nach dessen Meinung zu diesem Museum fragt. Das Herumlaufen des Direktors oder eines Museumsmitarbeiters geschieht meistens unstrukturiert. Dieser Vorgehensweise liegt kein zuvor erstellter Plan zugrunde, wie beispielsweise: "Am Mittwoch zwei Frauen und einen Mann in der Besucherkategorie Senioren über 50 Jahre ansprechen«.

\section{Ein Museum fragt nachträglich selbst strukturiert um Rat}

In dieser Situation wird erst dann an den Besucher herangetreten, wenn das Produkt schon fertig ist. Dies geschieht strukturiert und aktiv. Ein Beispiel ist die summative Evaluation mittels eines Interviews oder eines Fragebogens, wobei dem Besucher die Möglichkeit geboten wird, seine Meinung und Ratschläge zu äußern. Der Nachteil dieser Methode besteht darin, das sie erst nach der Projektumsetzung angewandt wird: Die Ergebnisse der Evaluation können erst bei der folgenden Ausstellung berücksichtigt werden; an diese sind jedoch häufig ganz andere Anforderungen zu stellen. Damit ist der praktische Nutzen vergleichsweise gering.

\section{Ein Museum fragt zuvor selbst strukturiert um Rat}

In der Entwicklungsphase des Produkts tritt das Museum aktiv an den Besucher heran. $\mathrm{Zu}$ dieser Kategorie gehört die sogenannte Front-End-Studie (Vorab-Evaluation), bei der Besucher beispielsweise um ihre Meinung zur Konzeption eines Gebäudes, einer Aus- 
stellung oder eines pädagogischen Programms gefragt werden; sie können sich beispielsweise aber auch zu der Frage äußern, ob der "rote Faden« einer Ausstellung erkennbar ist. In diese Kategorie gehört auch die formative Evaluation, bei der Produkte in der Entwicklungsphase getestet werden.

\section{Ein Museum konsultiert aktiv}

Das Museum tritt aktiv an einzelne Besucher heran, um diese um Rat zu fragen. Beispiele sind Museen, die auf spezifische Zielgruppen zugeschnittene Ausstellungen organisieren und Mitglieder dieser Zielgruppen befragen. Die Entwicklung und Realisierung eines Produkts wird vom Museum selbst vorgenommen.

Es gibt verschiedene Formen der Konsultation:
a. Befragung
b. Nutzung von Expertisen
c. Abstimmung

\section{a. Befragung}

In den Niederlanden ist die Befragung von Lehrkräften eine der am häufigsten vorkommenden Formen der Konsultation, die von einem Museum vorgenommen wird. Diese Konsultation variiert in Abhängigkeit vom pädagogischen Programm, das von einer Lehrkraft durchgenommen wird, bis zum Einsatz von Fokusgruppen, bei denen Lehrkräfte miteinander über das Angebot und das zukünftige Angebot eines Museums sprechen. Bei Fokusgruppen ist das Museum kein Gesprächspartner, sondern lediglich Zuhörer. Ein Museum, das den Beitrag von Lehrkräften in Form von Fokusgruppen nutzt, ist das Nordbrabanter Natuurmuseum in Tilburg, ein kleines naturhistorisches Museum in einer Provinzstadt.

Die Empfehlungen brauchen nicht unbedingt eine größere Veranstaltung wie beispielsweise eine Ausstellung zu betreffen. Ein Beispiel aus dem Freilichtmuseum in Arnheim: Hier war die Beschilderung regelmäßig Gegenstand von Beanstandungen. Daraufhin trat das Museum an einige der Beschwerdeführer mit der Bitte heran, in Form einer Fokusgruppe mit dem Museum über mögliche Verbesserungen zu sprechen. Ausgehend von den Empfehlungen aus der Fokusgruppe wurden schließlich Verbesserungen vorgenommen. Anschließend trat man erneut an die Gruppe heran, um die Verbesserungen zu beurteilen. 


\section{b. Nutzung von Experten-Kenntnissen}

Es sind vor allem Community-Museen, die externen Sachverstand nutzen. Neben dem Vorteil, daß bei der Einbeziehung von Außenstehenden die Gemeinschaft mit in das Museum einbezogen wird, sind noch weitere Vorteile zu nennen. Beispielsweise die Tatsache, daß jede neue Community-Gruppe ein neues Segment der Bevölkerung in das Museum holt. Die Gemeinschaft wird außer bei der Konzeption der Ausstellung auch bei der Eröffnung, bei Lesungen, Vorführungen und zahlreichen anderen Aktivitäten mit einbezogen, was zu guten Programmen mit hohen Besucherzahlen führt. Die Hilfe aus der Gemeinschaft ist außerdem eine Arbeitserleichterung für den Museumsprofi, der nicht mehr in allen Bereichen Experte zu sein braucht. Durch die Einbeziehung von Außenstehenden können diese auch sehen, daß das Museum keineswegs statisch ist, was noch immer ein weitverbreitetes Fremdbild ist. $^{3}$

\section{c. Abstimmung}

Die Konsultation erfolgt gelegentlich auch in Form von Abstimmungen. Ein gutes Beispiel für ein Museum, bei dem eine Ausstellung dadurch entstand, daß man ein offenes Ohr für die Stimme des Publikums hatte und Konservator oder Direktor einmal nicht bestimmten, was ausgestellt wurde, ist das Walker Art Center in Minneapolis (USA). ${ }^{4}$ In diesem Museum konnten die Besucher ihr Lieblingswerk wählen und die Werke mit den meisten Stimmen sollten dann noch einmal gezeigt werden. Von etwa $500 \mathrm{Ge}-$ mälden, Zeichnungen, Plastiken, Fotos, Installationen und Videos, die im Zeitraum 1994/95 angeschafft worden waren, waren etwa 100 in der Ausstellung »Composing a Collection: Recent Gifts and Acquisitions« (6. Januar - 7. April 1996) zu sehen. Die Besucher dieser Ausstellung wurden gebeten, ihr Lieblingswerk anzugeben. Insgesamt wurden 530 Stimmen abgegeben. Die zwanzig beliebtesten Werke wurden unter dem Titel „Visitors' Voices: Recomposing the Collection« vom 7. Juli - 8. September 1996 gezeigt. Die Ausstellung, die 8o Tage dauerte, wurde sehr gut besucht. In dem Zeitraum, in dem die Ausstellung zu sehen war, konnte das Museum 102.557 Besuche verzeichnen.

Die Reaktionen der Besucher auf beide Ausstellungen waren sehr positiv. Daß die Besucher ihre Meinung zu ihrem Lieblingswerk aufschreiben durften, wird sicherlich dazu beigetragen haben. Einige der Reaktionen wurden in »Visitors' Voices« aufgenommen. 
Das Museum wollte das Publikum mit beiden Ausstellungen unmittelbarer ansprechen und es anregen, seine Meinung und seine Reaktionen auf die angeschafften Werke aktiv mitzuteilen.

\section{Ein Museum sucht die Zusammenarbeit mit Zielgruppen}

In dieser Situation dürfen Außenstehende in einem Museum selbst ihre Ideen präsentieren. Mein Beispiel stammt aus der VicHealth Access Gallery in der National Gallery of Victoria in Melbourne. Die VicHealth Access Gallery ist ein kleiner Museumssaal (etwa 100 Quadratmeter), in dem Community-Gruppen selbst ihre Kunst und Kultur präsentieren können. Als Beispiel für Aussteller nennt das Museum experimentelle Künstlergruppen, Special-interest-Gruppen und ethnische Gruppierungen. Ich werde Ihnen einige Beispiele aus dem Ausstellungskalender des Jahres 1998/99 geben.

So war vor kurzem die Ausstellung "Awakening « zu sehen. In dieser Ausstellung ist das Werk libanesischer Künstler zu sehen, die in Victoria wohnen, dem Staat, in dem Melbourne liegt. Die Ausstellung wurde von der Victorian Lebanese Artists Group präsentiert.

Am 14. November 1998 wird die Ausstellung "Autistic Eye« eröffnet, die dem Autismus gewidmet ist. Verantwortlich für die Ausstellung sind zwei Organisationen, die sich für mehr Verständnis und Akzeptanz des Autismus einsetzen. Auf die Ausstellung über Autismus folgt die Ausstellung »Ukrainian Echoes - 1948 to 1998«. In den vergangenen 50 Jahren sind 30.000 Menschen urkrainischer Herkunft nach Australien ausgewandert. Die Ausstellung präsentiert die Arbeit zeitgenössischer ukrainischer Künstler und wird von einer ukrainischen Organisation durchgeführt.

Die Organisationen bekommen in der National Gallery of Victoria nicht freie Hand. Die Gruppen arbeiten mit Konservatoren der Access Gallery zusammen, damit die Ausstellungen nicht nur den Zielen der Gruppen, sondern auch dem Standard des Museums entsprechen. ${ }^{5}$

In der Praxis besteht der Beitrag der Besucher hier darin, daß sie selbst einen Beitrag zur Erstellung einer Ausstellung leisten.

\section{Ein Museum läßt Externe selbständig eine Ausstellung oder ein Programm erstellen}

Externen wird beispielsweise die Möglichkeit geboten, eine Ausstellung zusammenzustellen und diese selbst im Museum aufzu- 
bauen. Das Museum stellt Räumlichkeiten zur Verfügung und bietet eventuell technische Unterstützung. Für Konzept, Ausarbeitung und Durchführung ist die externe Organisation voll und ganz selbst verantwortlich.

In den Niederlanden geschieht dies regelmäßig. Ein Beispiel: ein örtlicher Aquarellverein darf im örtlichen Museum ausstellen. Der Verein trifft selbst eine Auswahl der auszustellenden Werke, rahmt sie ein und hängt sie auch selbst im Museum auf. Der Unterschied zur Vic Health Access Gallery in Melbourne besteht darin, daß das Museum in diesen Fällen kaum eine Beziehung zu den Ausstellern hat.

\section{Der Besucher bestimmt voll und ganz, was im Museum geschieht}

Besuchszahlen gewinnen für immer mehr Museen an Bedeutung. Eine der Konsequenzen dieser Entwicklung kann sein, daß Museen sich voll und ganz am Willen des Besuchers orientieren. Ich kenne kein Museum, in dem die Besucher die Museumspolitik bestimmen, wo das Angebot voll und ganz auf die Wünsche des Konsumenten abgestimmt sind. Ein Beispiel für eine Situation, bei der der Besucher auf dem Stuhl des Direktors sitzt, kann ich also nicht geben. Sollten Sie solche Beispiele kennen, teilen Sie mir das bitte mit.

Obwohl ich Ihnen nun eine Einteilung in Kategorien präsentiert habe, heißt dies natürlich nicht, daß diese künstlichen Kategorien in den verschiedenen Situationen nicht ineinander übergehen können. Für das Stedelijk Museum in Amsterdam ist Mitsprache bei der Ausstellungspolitik beispielsweise undenkbar (Kategorie 1), andererseits werden hier durchaus langfristige summative Evaluationsstudien betrieben (Kategorie 7). Das Freilichtmuseum in Arnheim gibt dem Publikum mittels eines Gästebuchs Hilfestellungen (Kategorie 5), ist im nachhinein über summative Evaluation strukturiert aktiv und konsultiert Besucher direkt - mittels einer Zielgruppe - wie bereits im Zusammenhang mit den Problemen bei der Beschilderung geschildert (Kategorie 9). 


\section{Besucher in Amsterdamer Museen}

Nach der Analyse der verschiedenen Möglichkeiten von Museen, den Rat ihres Publikums einzuholen, möchte ich nun das Publikum selbst zu Wort kommen lassen.

Unterstützt von unseren Studierenden habe ich im vergangenen Frühjahr eine Studie bei über 400 niederländischen Besuchern in 16 Amsterdamer Museen durchgeführt. Eine der Kernfragen lautete: »Haben Sie dem Museum während oder nach einem Museumsbesuch schon einmal Ihre Meinung über das Museum mitgeteilt?«

Meine Hypothese lautete: Besucher möchten so viel Einfluß wie möglich ausüben. Mit anderen Worten: Eine Empfehlung in Form einer Mitteilung im Gästebuch wird niedriger eingestuft als eine Teilnahme an einer Fokusgruppe, bei der man unter Leitung eines Vorsitzenden über das Museum spricht. Und eine Teilnahme an einem Ausstellungsprojekt wie das beschriebene Projekt der Access Gallery in Melbourne wird sehr geschätzt.

Die vorläufigen Ergebnisse dieser Befragung widersprachen meinen Erwartungen. Die Besucher reagierten wie folgt:

- »Ich bin mit meinem Besuch zufrieden. Ich habe keinerlei Bedürfnis, meine Meinung zu äußern.«

oder:

- „Das Museum weiß selbst am besten, was es zu tun hat."

- Manche Besucher gaben an, gelegentlich ihre Meinung zum Ausdruck bringen zu wollen. Oft ging es dabei um die Texte. Ein größerer Schrifttyp steht noch immer ganz oben auf der Liste spontan geäußerter Empfehlungen.

Doch am bemerkenswertesten war das Ergebnis, daß der Großteil der befragten Besucher erstaunt war über die Möglichkeit, daß sie selbst Einfluß auf das Angebot des Museums haben könnten.

Die vorläufige Schlußfolgerung dieser Untersuchung scheint zu sein, daß eine große Zufriedenheit mit den untersuchten Amsterdamer Museen herrscht. Vielleicht machen die untersuchten Amsterdamer Museen ihre Arbeit nicht schlecht, die Besucher sagten jedoch nicht, daß die Museen hervorragend seien. Ein Beispiel: ein Befragter sagte, daß Dinge manchmal schwer zu verstehen seien und daß die Ausschilderung gelegentlich zu Verwirrung führen würde. Auf die Frage, warum er dies dem Museum nicht mitteile, 
antwortet er: "Ich habe Zeit. Ich laufe einfach ein bißchen herum. So finde ich schon meinen Weg durch das Museum. Und für mich ist es nicht so problematisch, wenn ich etwas länger brauche, um den Weg zu finden."

Es hat den Anschein, daß bei den Besuchern aus meiner Stichprobe kein großes Bedürfnis herrschte, dem Museum ihre Meinung mitzuteilen. Ich weiß nicht, ob diese Ergebnisse durch kulturelle Auswirkungen beeinflusst wurden. Schließlich habe ich nur niederländische Besucher befragt. Ich werde diese Befragung also auf jeden Fall mit ausländischen Touristen in Amsterdam wiederholen müssen, beispielsweise mit Amerikanern, Deutschen und Franzosen. Doch auch dann stellt sich die Frage der Repräsentativität, denn diese Touristen sind natürlich kein Querschnitt einer Museumsbevölkerung ihrer Herkunftsländer. Ich habe inzwischen das Angebot erhalten, diese Studie in Sydney zu replizieren. Ich bin jedoch auch sehr an entsprechenden Erfahrungen der Leser interessiert.

Interesse am Publikum heißt auch wissen, was das Publikum tut und was es will. Inwieweit hören Sie auf Ihr Publikum? Inwieweit berücksichtigen Sie die Besucher? Kommunikation liegt erst dann vor, wenn der Kontakt zwischen Ihnen und dem Besucher in beiden Richtungen verläuft. Oder wie Dietrich \& Laurenson es ausdrücken: "It takes two to tango«. Wie passiv oder aktiv hören Sie Ihren Besuchern zu? Werden Besucher aktiv in das Museum bzw. die Museumspolitik einbezogen? Wie bringen Sie in Erfahrung, ob Ihre Ausstellungen und pädagogischen Programme auch tatsächlich Wirkung zeigen? Ist - und wenn ja, wo, wann und wie die Stimme der Besucher in Ihrem Museum zu hören? Oder anders ausgedrückt: wann liegt ein wechselseitiger Austausch vor? Wird dies strukturell untersucht oder werden Besucher nur gelegentlich gehört? Und welche Besucher beziehen Sie mit ein?

Anfang letzten Jahres stellte ich in der Internet Museumsdiskussiongruppe MUSEUM-L die Frage, inwieweit Museen um die Meinung Ihrer Besucher bitten. Eine Reaktion kam von Dr. Christian Müller-Straten, der mir nicht so sehr mit Beispielen helfen konnte, mir jedoch das Angebot machte, meine Frage in seiner Zeitschrift Museum Aktuell (Sas 1997) zu wiederholen. Leider ging hierauf nur eine Reaktion von meiner guten Bekannten Dorothée Dennert ein. Ich fuhr nach Bonn, zum Haus der Geschichte, und habe dort gemeinsam mit ihr und zwei ihrer Kollegen über die Bereitschaft von Museen in Deutschland gesprochen, Besuchern 
wirklich Einfluß auf das Museum, die Sammlung und die Präsentation dieser Sammlung einzuräumen. Dieses Gespräch zeigte, daß die Bereitschaft in Deutschland sehr gering war und vorläufig beschränkt bleiben würde. Ich bin daher daran interessiert, von den Lesern zu erfahren, inwiefern sie bereit sind, den Besucher nicht nur als Kunden zu sehen, sondern ihn auch als Berater des Museums zu akzeptieren.

\section{Anmerkungen}

1 G. Bazin, 1967, S. 124 (mit Dank an Dr. P. van Mensch).

2 Mit Dank an Vanessa L. Ward.

3 Die Beispiele stammen aus B. Dietrich \& T. Laurenson, 1996, S. 6.

4 Mit Dank an Jill Vetter und Renee Van Der Stelt (Walker Art Center).

5 Weitere Informationen siehe: http://www.ngv.vic.gov.au/access/ access.html.

\section{Literatur}

Alexander, E.P. (1997): The Museum in America. Innovators and Pioneers, Walnut Creek u.a.: Altamira Press.

Bazin, G. (1967): The Museum Age, New York/NY.

Bitgood, S. (1996): »Institutional Acceptance of Evaluation: Review and Overview«. Visitor Behavior 11, 2, S. 4-5.

Cummings, C.E. (1940): East is East and West is West: Some Observations on the World's Fairs of 1939, by One Whose main Interest is in Museums, Buffalo: Buffalo Museum of Science.

Dietrich, B./Laurenson, T. (1996): »It takes two to tango«. GEM News 62, S. 6.

Gilman, B.I. (1916): »Museum fatigue«. The Scientific Monthly 11, S. 62-74.

Gilman, B.I. (1918): Museum Ideals of Purpose and Method, Boston: Museum of Fine Arts.

Griggs, S.A./ Hays-Jackson, K. (1983): „Visitors' Perceptions of Cultural Institutions «. Museums Journal 83, 2-3, S. 121-125.

Langley, S.P. (1901): "The Children's Room at the Smithsonian«. St Nicolas 28,11 , S. 963.

McManus, P.M. (1996): "Museum and Visitor Studies Today«. In: Jens S. Lankford/S. Bitgood (Hg.), Visitor Studies: Theory, Research, and Practice (Vol. 8). 1. Selected Papers from the 1995 Visitor Stu- 
dies Conference, Jacksonville/AL: Visitor Studies Association, S. 1-2.

Melton, A.W. (1935): Problems of installation in museums of art, Washington, D.C.: American Association of Museums (Studies in $\mathrm{Mu}$ seum Education; New Series, Number 14).

Sas, J. (1996): "Storyline testing in het NNM. Testen voor de toekomst«. Museumvisie 20, 3, S. 8.

Sas, J. (1997): "Beispiele aus Deutschland gesucht«. Museum Aktuell, S. 592 .

Shettel, H. u.a. (1968): Strategies for determining Exhibit Effectiveness, Pittsburg: American Institutes for Research, Report $n^{\circ}$ AIR E95-4/68-FR. 



\title{
BERND GÜNTER
}

\section{Was behindert und was eröffnet Wege zu Besucherbindung und Besucherintegration?}

\author{
Stammgäste - Wiederholungstäter - Serientäter \\ Warum mehr Besucherbindung?
}

Über die Bedeutung von Besucherzahlen in Museen läßt sich trefflich streiten - ob sie nachhaltig steigen, ob ihnen eine wirkliche Relevanz für die Aufgabenerfüllung von Museen zuzubilligen ist, ob sie um jeden Preis gesteigert werden sollen, wie man sie steigern kann usw. Die Museumswissenschaft beschäftigt sich mit derartigen Fragen fast gar nicht, die Museumspädagogik mit Einschränkungen und unter ganz bestimmten Zielsetzungen. Die sozialwissenschaftlich und betriebswirtschaftlich orientierte Richtung der Kulturmanagement-Forschung beginnt sich mit derartigen Fragen zu befassen. Sie kommt dabei von der Beschäftigung mit der Markt- und Meinungsforschung her (siehe z.B. Klein 1990), von der Gestaltung der Museumsleistungen, verstanden als Dienstleistungsmanagement, und von der Analyse des Besucherverhaltens, einer speziellen Ausformung des Käufer- bzw. Konsumentenverhaltens (vgl. z. B. Helm/Klar 1997, McLean 1997, Kotler/Kotler 1998 und andere Autoren, vor allem im englischsprachigen Bereich).

Unter diesen letztgenannten Aspekten wäre - über bisher untersuchte Aspekte des Besucherverhaltens hinaus - zu klären, aus welcher Motivation heraus Besucher auch ein zweites Mal ein $\mathrm{Mu}$ seum, ggf. eine Ausstellung besuchen, mit welchen Verhaltensmu- 
stern und was sie evtl. auch psychologisch an eine Kulturinstitution wie ein Museum bindet. Das museumspraktische Interesse hinter diesen Fragen kann lauten: Wie lassen sich Besucher dazu gewinnen, mehrfach ein Museum zu besuchen, Wiederholungsbesucher (»Wiederholungstäter" bzw. "Serientäter«) und damit Stammgast zu werden? Die zentrale Frage dabei heißt: Was ist es, das Besucher potentiell und tatsächlich an ein Museum bindet was ist der Kitt, der Klebstoff in der Beziehung, der Geschäftsbeziehung zwischen einem Museumsbetrieb und seiner Kundschaft?

Besucherintegration, die Einbeziehung und Mitwirkung von Besuchern über die passive Rolle im Museumsgeschehen hinaus, kann eines der Hilfsmittel sein, mit denen Besucherbindung erreicht werden kann (siehe Abbildung 1). Daneben kann Besucherintegration aber auch bei Einmalbesuchern Bedeutung besitzen für die Intensivierung des Museumserlebnisses, für die Erreichung der Ziele der Beteiligten und für das aktive Engagement eines Besuchers für ein Museum, z. B. für Weiterempfehlungen.

\section{Besucherbindung und Besucherintegration - Bausteine der Besucherorientierung und des Museum-Marketings}

Die systematische Einordnung der Themen Besucherbindung und Besucherintegration in das Museumsmanagement läßt sich über das Museums-Marketing und seine zentralen Konstrukte herbeiführen. Diese Kerngedanken sind die des Wettbewerbsvorteils und der Besucherorientierung.

Ein Museum muß, um für Besucher und andere Adressaten attraktiv zu sein, etwas Unverwechselbares aufweisen, das es in der Wahrnehmung dieser Adressaten von anderen unterscheidet und Präferenzen, etwa bei der Entscheidung über einen Besuch, erzeugt - die Marketing-Wissenschaft nennt dies den »Wettbewerbsvorteil«. Von Wettbewerb kann deswegen gesprochen werden, weil Museen, wie andere Kulturinstitutionen, mit vielerlei Kultur-, Bildungs- und Freizeitangeboten wetteifern - um Zeitbudgets, finanzielle Budgets und um »Budgets" an Weiterempfehlung und an Engagement der Besucher für eines dieser Angebote (Günter 1998).

Besucherorientierung meint nicht etwa, ein Museum und sein Angebot ausschließlich nach den wünschen der Besucher zu gestalten, aber doch, alle Maßnahmen, mit denen die Museumsziele 
erreicht werden sollen, daraufhin zu prüfen, welche Wirkung sie beim Besucher erzeugen und ob sie geeignet sind, die Akzeptanz zu erhöhen oder Barrieren aufzubauen (vgl. dazu Günter 1997 und 1998).

In diesem Sinne setzt sich Besucherorientierung aus sechs Elementen (Bausteinen) zusammen: aus der grundsätzlichen und konzeptionellen Denk- und Verhaltensweise der Besucherorientierung ("vom Besucher her«), aus der Besucheranalyse und deren Methoden, aus der Besuchersegmentierung in unterschiedlich agierende und reagierende Zielgruppen, aus der vielfältige Instrumente nutzenden besucherfreundlichen Behandlung der $\mathrm{Mu}$ seumskundschaft, aus der regelmäßig zu überprüfenden Besucherzufriedenheit und letztlich aus der Besucherbindung - die eines unter mehreren Museumszielen sein kann. Besucherintegration, aktive Mitwirkung, Partizipation der Zielgruppen spielt für alle sechs Bausteine eine Rolle, die im Einzelfall präziser abzustecken ist. Beide Konstrukte bilden ein Grundgerüst, das für erfolgreiches Museums-Marketing unerläßlich ist.

\section{Abbildung 1: Besucherbindung und Besucherintegration}

\section{Besucherbindung}

A Wiederholte Besuche bzw. Nutzung (Stammbesucher)

B »Innere«, psychologische Bindung

Besucherintegration (»Mitwirkung« der Adressaten)

A Interaktivität (museumsdidaktische Aspekte, auch bei einmaligem Besuch)

B Instrument zur Besucherbindung

Besucherbindung kann unterschiedlich verstanden werden. Aus der Sicht des Museumsbesuchers könnte (Variante A) von Besu- 
cherbindung gesprochen werden, wenn es zu mehrfachen Besuchen desselben Hauses oder - in bestimmten Fällen - derselben Ausstellung kommt. $\mathrm{Ob}$ dieses Verständnis für erfolgreiche Marketing- Anstrengungen der Museen ausreicht, darf in Analogie zum kommerziellen Marketing bezweifelt werden. Gründe dafür sind darin zu sehen, daß reine Wiederholungsbesuche durchaus unterschiedliche Anlässe und Motivationen haben können, auch mit einer eher zufälligen Komponente, und daß eine Aktivierung solcher Wiederholungsbesucher mit dem Ziel verstärkter Besucherintegration eher schwieriger ist als im Falle der zweiten Interpretationsvariante. Diese Variante B versteht unter Besucherbindung eine psychologische Affinität des Besuchers $\mathrm{zu}$ den $\mathrm{Mu}-$ seumsleistungen, eine im Zeitablauf möglicherweise zunehmende psychische Festlegung (»commitment«) auf die Angebote eines Hauses. Unter verhaltenswissenschaftlichen Aspekten ist zu erwarten, daß Besucher, die in diesem Sinne gebunden sind bzw. sich gebunden fühlen, eine stabilere und aktivere Beziehung zu einem Museum haben.

Aus der Perspektive der Anbieterseite, also des Museums als Dienstleistungsanbieter, ist Besucherbindung jede Aktivität, die geeignet ist, Besucher in einer der beiden genannten Interpretationen an das Haus und seine Leistungen $\mathrm{zu}$ binden, also eine (Management-)Aktivität gegenüber den Zielgruppen.

Es stellen sich nun die Fragen: Was erschwert oder behindert eigentlich Besucherbindung, welches sind die Mechanismen und "Klebstoffe" der Besucherbindung, und welche Instrumente und Maßnahmen stehen einem Museum zur Verfügung, um Besucherbindung zu erreichen bzw. zu steigern?

\section{Hindernisse für Besucherbindung}

Barrieren, die mehr Besucherbindung erschweren oder verhindern, liegen auf unterschiedlichen Ebenen. Es gibt Hindernisse:

a) von seiten der Besucher und

b) von seiten der Museen.

Interessant aus der Sicht einer Museumsleitung und des Kulturmanagements sind die Barrieren, die im Museum vorliegen (können), weil sie möglicherweise beeinflußbar sind. Solche Barrieren 
sind - wenn man sie personalisiert und auf das Handeln der Führungskräfte und Mitarbeiter bezieht - zu sehen in:

- nicht können und / oder

- nicht wollen und/oder

- nicht dürfen.

Nicht können bedeutet, daß den Museumsmitarbeitern die Mechanismen und Instrumente der Besucherbindung nicht geläufig sind. Dagegen hilft - abgesehen von Maßnahmen der Personalauswahl und -steuerung - vor allem Qualifizierung, Training und / oder Beratung von außen. Nicht wollen stellt auf die mentale Restriktion ab, die immer wieder Besucherorientierung und Besucherfreundlichkeit erschwert, Desinteresse fördert und den Besucher fragen läßt: Warum sollte ich wiederkommen? Nimmt man mich als Besucher in diesem Museum eigentlich ernst? Nicht dürfen meint, daß "Spielregeln« und Anweisungen der Besucherorientierung den Maßnahmen zur Besucherbindung gegenüberstehen. Daß das Personal sich in verschiedenen Situationen auf Positionen zurückzieht, in denen es durch Dritte daran gehindert wird, Aktivitäten zu mehr Besucherbindung zu entfalten. Abbildung 2 gibt Hinweise darauf, was von seiten des Museumsmanagements getan werden kann, um die genannten drei Hindernisse zu überwinden.

\section{Die »Klebstoffe« der Besucherbindung}

Was führt dazu, daß Besucher ein Museum mehrmals besuchen, daß sie, evtl. in Begleitung anderer, ein zweites Mal Exponate besichtigen, daß sie gar regelmäßige "Stammkunden« werden? Die Betriebswirtschaftslehre hat in den letzten Jahren Mechanismen aufgedeckt, die in langfristigen Geschäftsbeziehungen Bindungseffekte erzeugen. Analog dazu lassen sich für die Besucherbindung in und durch Museen Thesen zu den »Klebstoffen«, zum »Kitt« aufstellen, der die Präferenz für ein Museum verstärkt und Commitment erzeugt.

Die genannten Aspekte bieten Ansatzpunkte für die Erklärung des Besucherverhaltens, insbesondere die Einstellung zu einem Museum als einer konstant positiven Verhaltensweise. Sie geben auch Anstöße zu Überlegungen, die sich auf Maßnahmen richten, 
Abbildung 2: Was behindert und was fördert Besucherbindung im Museum?

1. Nicht können (Fähigkeitsbarriere)

Instrumente des Museumsmanagements:

Wissen vermitteln um die acht Faktoren (»Klebstoffe«) der Besucherbindung; Attraktivität steigern; "Museum plus .... etc.

2. Nicht wollen (Willensbarriere)

Instrumente des Museumsmanagements:

Mitarbeiterzufriedenheit steigern; Training/Schulung, auch des Fremdpersonals; Anreizsysteme etablieren etc.

\section{Nicht dürfen (Kompetenzbarriere)}

Instrumente des Museumsmanagements:

Kompetenzveränderungen, Entbürokratisierung;

»Empowerment« etc.

wie diese Faktoren im Sinne der Museumsziele für ein Mehr an Besucherbindung genutzt werden können.

Ein erster Faktor ist die Unverwechselbarkeit und Attraktivität, die geeignet sind, den Wunsch nach Vertiefung der Besuchserfahrung hervorzurufen. Affinität und Identifikation erhöhen die Wiederbesuchswahrscheinlichkeit, z.B. in beruflichen oder lokalen Zusammenhängen oder im Zusammenhang mit einem bestimmten Lifestyle des Besuchers. Zusatzleistungen und Kombi-Angebote sind Bindungsfaktoren, weil sie zusätzliche Anlässe zum Museumsbesuch schaffen. Erleichterungen des Besuchs - finanzieller Art oder andere Zugangserleichterungen - sind ein vierter Faktor. Persönliche Verbindungen können sowohl äußere Anlässe wie auch psychologische Bindung erzeugen. Externe Anlässe sind Events, Veranstaltungen Dritter usw., attraktive Angebote des Museumsumfeldes. Die reine Präsenz im Alltag kann für Passanten immer wieder den Anreiz zum Besuch verstärken und erneuern. Und schließlich sind - selbstverständlich - positive Erfahrungen und Zufriedenheit, eigene wie auch die durch Empfehlung 
Abbildung 3: Die acht »Klebstoffe» der Besucherbindung

- Attraktivität $\longrightarrow$ Vertiefung / Commitment

- Affinität und Identifikation

- Verbundangebote, »trojanische Pferde«

(»Museum plus ...«)

- Vergünstigungen, monetäre Anreize, Vereinfachungen

- Personale Elemente

- Externe Anlässe

- Präsenz im Alltag und in Routinen

- Zufriedenheit, positive Erfahrungen, ersatzweise Weiterempfehlung

übertragene anderer Besucher, ein Bindungsfaktor, der Besucher zu Stammgästen machen kann.

Die Wirkungsweise dieser "Klebstoffe» ist letztlich allerdings noch nicht hinreichend untersucht, es fehlt bedauerlicherweise in erheblichem Maße an »Grundlagenforschung " zum Thema Museen und Besucher, die nicht zuletzt hilfreiche Hinweise für Museumsmanagement und Kulturpolitik geben könnte.

\section{Strategien und Maßnahmen auf dem Weg zu mehr Besucherbindung}

Trotz des soeben beklagten Defizits an Wirkungsanalysen sei der Versuch gemacht, mögliche und plausible Strategien und Instrumente für Museumsleitung und Kulturpolitik anzureißen, wenn es um das Ziel geht, Besucher zu Stammgästen zu machen.

Wenn sich Museen konzeptionell mit dem Thema Besucherbindung befassen, ist aus der Sicht des Kulturmanagements zu ra- 
Abbildung 4: Merkmale »schlanker Instrumente« für mehr Besucherorientierung

- hohe Effektivität bei der Erreichung von Besucherzufriedenheit und Besucherbindung

- Möglichkeit der schnellen Konzeption und des schnellen Einsatzes

- flexible Anpassung an spezifische Museums- und Standortbedingungen

- vergleichsweise wenig (externes) Know-how erforderlich (oftmals mit »Bordmitteln« einsetzbar)

- geringe Widerstände der Mitarbeiter bei der Implementierung

- niedrige Kostenbelastung

ten, zunächst das Marketing-Bewußtsein zu stärken und die Besucherorientierung zu verstärken. Dazu helfen, insbesondere wenn keine umfassenden Neukonzeptionen geplant und implementiert werden können, »schlanke« Instrumente (vgl. Günter 1998).

Darüber hinaus können aus der Liste der Abbildung 6 Maßnahmen entnommen werden, die Besucherbindung fördern und unterstützen.

Als Leitlinie sollte auch stets die Frage verfolgt werden: Was machen andere, die in einer ähnlichen Situation sind? Erforderlich ist der Blick über den Tellerrand hinaus, das Benchmarking, der Vergleich mit der »best practice«. Dies hat das Beispiel der Kaufund Warenhäuser gezeigt (vgl. den Beitrag von Werner in diesem Band). Hier wird demonstriert, daß das Bemühen kommerzieller Betriebe um Kundenbindung, mit Maßnahmen, die zwar nicht im Maßstab 1:1, aber doch in Varianten übertragbar sein könnten, auch Museen zu Anregungen für mehr Besucherbindung verhelfen könnten. Daneben ist allerdings noch weit mehr Analyse und 
Forschung als bisher darüber erforderlich, was eigentlich Besucher zu mehr Bindung an ein Museum veranlaßt.

Abbildung 5: Zwölf »schlanke Instrumente« für mehr Besucherorientierung

1. »Jour fixe« zur Besucherorientierung

2. Besucheranalyse mit Bordmitteln:

Besucherforen, Besucherkonferenzen

3. Kontaktpunktanalyse/Blueprinting

(»Wo entsteht welcher Kontakt mit Besuchern?«)

4. Fehler-Möglichkeiten-Einfluß-Analyse (FMEA) (»Was könnte passieren?«)

5. Besucher- bzw. nutzerorientierte Information einschl. Leitsystem, Zwischeninformation etc.

6. »Schnupperkurse«

7. Erreichbarkeit/Ansprechpartner/Namentliche Vorstellung

8. Angepaßte Öffnungszeiten

9. Rückkopplung vom Besucher, z. B. Besucherbuch

10. Testbesucher (»mystery visitor«)

11. Besucherintegration, z.B. Förderverein

12. Empowerment: mehr Spielraum für Mitarbeiter 
Abbildung 6: Wie erreicht ein Museum Besucherbindung (Beispiele für Maßnahmen)

- Ermäßigung auf Wiederholbesuche

- Ermäßigung oder andere Vergünstigungen für Besuche mit Gästen u. ä.

- Einbindung in Aktivitäten (Planungen, laufende Aufgaben, Sonderaufgaben, Veranstaltungen)

- Sonder-, Wechselausstellungen

- Veränderung, Erneuerung von Dauerausstellungen

- Ausstellungsreihen (Fortsetzung ...)

- Veranstaltungsreihen

- Ausgabe oder Verkauf von Sammelobjekten

- Regelmäßige Versorgung mit Informationen

- Abonnement auf Publikationen, Veranstaltungen

- Bereitstellung und Nutzung der Räumlichkeiten eines Museums für andere Zwecke

- »Museum plus ...«: Attraktivitätssteigerung durch »trojanische Pferde«

- Attraktiver Museums-Shop

- Attraktive Cafeteria 


\section{Literatur}

Bruhn, Manfred/Homburg, Christian (Hg.) (1998): Handbuch Kundenbindungsmanagement, Wiesbaden.

Bicknell,Sandra / Farmelo, Graham (Hg.) (1993): Museum Visitor Studies in the 9os, London.

Günter, Bernd (1997): "Museum und Publikum: Wieviel und welche Form der Besucherorientierung benötigen Museen heute? « In: Landschaftsverband Rheinland (Hg.), Das besucherorientierte $\mathrm{Mu}$ seum, Köln, S. 11-18.

Günter, Bernd (1998): »Besucherorientierung: eine Herausforderung für Museen und Ausstellungen«. In: Scher, Marita Anna (Hg.), (Umwelt-)Ausstellungen und ihre Wirkung, Tagungsband zur Tagung am 29.-31.1.1998, Schriftenreihe des Staatlichen Museums für Naturkunde und Vorgeschichte, Heft 7, Oldenburg, S. 51-55.

Haus der Geschichte (Hg.) (1996): Museen und ihre Besucher, Bericht des Internationalen Symposiums vom 22. bis 24. November $1995 \mathrm{im}$ Haus der Geschichte der Bundesrepublik Deutschland, Bonn/ Berlin.

Helm, Sabrina/Klar, Susanne (1997): Besucherforschung und Museumspraxis, München.

Klein, Hans-Joachim (1990): Der gläserne Besucher: Publikumsstrukturen einer Museumslandschaft, Berliner Schriften zur Museumskunde, Band 8, Berlin.

Kotler, Neil/Kotler, Philip (1998): Museum Strategy And Marketing, San Francisco.

McLean, Fiona (1997): Marketing the Museum, London/New York. 



\section{Patricia Munro}

\section{Brückenschlag zwischen Museen und ihren Besuchern mittels Vorab-Evaluation}

Wenn im Frühjahr das Schmelzwasser die Zugspitze herabfließt, bahnt es sich als Wildbach seinen Weg durch den schmalen Höllentalklamm. Dabei strömt es mal über riesige Felsen, mal zwängt es sich durch enge Gesteinsritzen, bevor es tosend ins Tal rauscht.

Stellen Sie sich nun vor, Sie sind mit einer Gruppe von Bergwanderern um diese Zeit im Höllentalklamm unterwegs. Schließen Sie die Augen und vergegenwärtigen Sie sich die großartige Alpenlandschaft rings um Sie herum. Hören Sie den reißenden Wildbach durch die enge Schlucht herabtosen? Der Lärm des Wassers ist so laut, daß Sie sich mit Ihren Kameraden kaum verständigen können.

In gewissem Sinne kann man dieses beeindruckende Naturschauspiel mit der Kommunikation zwischen den wissenschaftlichen Mitarbeitern eines Museums und seinem Publikum vergleichen: Die Menschen suchen unsere Institutionen in ihrer Freizeit auf, und unsere einzigartigen Sammlungen von Objekten und wie sie präsentiert und interpretiert werden - ob in Form einer Ausstellung oder eines öffentlichen Veranstaltungsprogramms - bietet eine einzigartige Begegnung. Zudem erlebt und erfährt jeder Besucher das Gebotene und das Museum selbst aus seiner ganz persönlichen Perspektive. Aber hierbei können auch Hindernisse auftreten, welche den »Dialog", den wir mit den Besuchern in Gang setzen wollen, erschweren. Trotz jahrelanger hervorragender wissenschaftlicher Arbeit kann ein Museum sein Wissen, seine Bot- 
schaft oft nicht wirksam bzw. nachhaltig vermitteln. Woran liegt das? Analog zu dem tosenden Lärm des Gebirgsbaches wird es dem Besucher oft erschwert, unsere Botschaft zu »hören«, d. h. sie zu empfangen, geschweige denn sie aufzunehmen und zu begreifen. Die Vorab-Evaluation (auch: Front-End-Evaluation) ist eine Methode, mit der Museums-Fachleute wertvolle Informationen sammeln und die Kommunikation mit ihren Besuchern verbessern können. Die Evaluation bietet eine Art Forum, die einen echten Dialog zwischen dem Museum und seinem Publikum ermöglichen kann.

Eine grundlegende Voraussetzung hierfür ist, daß sich eine Institution zunächst einen Überblick über ihr potentielles Zielpublikum verschafft. Diese Informationen bilden den Ausgangspunkt jeglicher besucherorientierter Bemühungen und Aktivitäten. Je mehr ein Museum über seine Besucher (und auch über seine Nichtbesucher) in Erfahrung bringen kann, desto besser wird es deren Erwartungen verstehen und sich auf ihre Bedürfnisse und Vorlieben einstellen können. Auf diese Weise läßt sich eine Ausstellung zielgerechter und damit für die Besucher wirkungsvoller und lohnender gestalten. Die Basis solcher Besuchererhebungen bilden soziodemographische Daten (z. B. Alter, Geschlecht, Beruf, Bildungsstand, Einkommensgruppe, Wohnort). Im Idealfall werden diese Angaben über eine repräsentative Zeitperiode hinweg gesammelt, um alle Jahreszeiten und Wochentage zu erfassen. ${ }^{1}$

Zur Ergänzung dieser soziodemographischen Angaben plädieren viele Forscher für die Erhebung psychographischer Daten. Dabei geht es um die Anwort auf Fragen folgender Art: Wie häufig werden Museen/Ausstellungen besucht, welche Interessen sind vorhanden, welche Freizeit-Aktivitäten werden bevorzugt; welche Wichtigkeit wird Museumsbesuchen innerhalb der Familie beigemessen, wie hoch ist der Wissensstand in bezug auf das geplante Thema bzw. das Verfahren; gab es in der Gemeinde, in der der/ die Betreffende aufwuchs, Museen (»kulturelle Vergangenheit«) etc. (Dierking/Pollock 1998) $?^{2}$ Auf der Grundlage dieser demographischen und psychographischen Daten gewinnen Museen ein besseres Verständnis für die Erwartungen ihres Publikums an eine Ausstellung.

Vor der Darlegung der Vorab-Evaluation als "Brückenschlag» zwischen einem geplanten Ausstellungsprojekt und seinen potentiellen Besuchern soll hier zunächst ein allgemeiner Überblick über die Methode der Evaluation gegeben werden. 
Über den Einsatz der Evaluation bestehen im Museumsbereich viele falsche Vorstellungen. Schon der Begriff selbst birgt ein grundlegendes Mißverständnis: Er impliziert, daß hier etwas als "gut" oder "schlecht" bewertet wird. Museumsfachleute sollten "Evaluation" aus einer anderen Perspektive betrachten. Sie sollten sie als eine Methode begreifen, die ihnen konstruktive Informationen liefert, Ausstellungen besucherorientierter und damit erfolgreicher zu gestalten - und deren Effizienz in bezug auf die gesteckten Ziele zu erhöhen. Ein weiteres, weit verbreitetes Mißverständnis besteht in der Annahme, daß eine Evaluation erst nach der Fertigstellung einer Ausstellung stattfindet. Sowohl eine Vorabals auch eine Formative Evaluation werden jedoch bereits in den frühen Planungsphasen durchgeführt. Durch Evaluationen lassen sich bereits im Vorfeld der Realisierung einer Ausstellung wertvolle Einblicke und Anregungen gewinnen, die das Ausstellungskonzept/-design rechtzeitig positiv beeinflussen können (siehe Abbildung 1). Hinzu kommt, daß viele Museumsfachleute nach eigenem Bekunden keine Evaluationen durchführen, weil diese angeblich viel zu teuer seien. Dieser Einwand wurde von einem Museumsdirektor stichhaltig entkräftet. Er bestätigte zwar aus langjähriger Erfahrung, daß Evaluationen Zeit und Geld kosten - aber er vertrat die feste Überzeugung, daß Evaluationen seinem Museum letztlich sogar Geld sparen, da ineffektive Ausstellungskonzepte und teure Fehlentscheidungen auf diese Weise als solche erkannt und entsprechend modifiziert werden können, bevor es zu spät (und das Geld ausgegeben) sei (Friedman 1993). Es existiert noch eine weiteres gängiges Vorurteil: daß eine Evaluation von jedermann durchgeführt werden könne. Auch dies trifft nicht zu. Eine Evaluation muß, wie jede andere wissenschaftliche Tätigkeit im Museum, einem erfahrenen Fachmann (oder einer Fachfrau) anvertraut werden, der/die nicht nur mit der einschlägigen Literatur, sondern auch mit dem Einsatz qualitativer und quantitativer Forschungsmethoden vertraut ist.

Welche Vorteile kann eine Evaluation Ausstellungsplanern und -designern bieten? Chandler Screven, einer der Pioniere in der praktischen Anwendung von Evaluation im Museumsbereich, bezeichnet sie als einen "Prozeß zur Erlangung von Informationen über die Besucher - Informationen, welche letztlich die Wirkung der Ausstellung und ihrer interpretativen Komponenten auf das Verhalten bzw. die Interessen der Besucher positiv beeinflussen und damit die Fähigkeit der Ausstellung, mit ihren Besuchern zu 


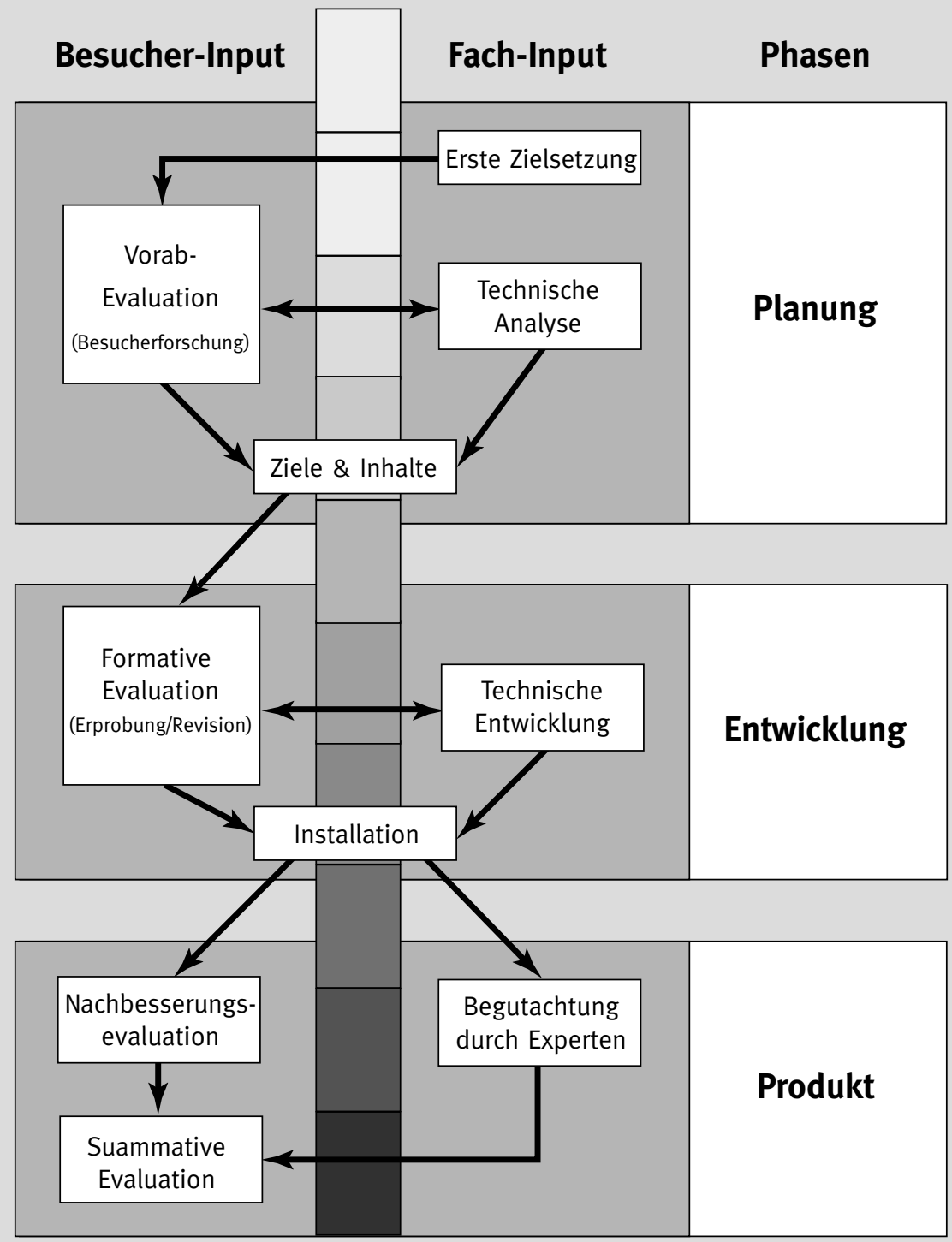

kommunizieren, verbessern können“ (Screven 1990). Zu den Aufgaben einer Evaluation gehört das Formulieren von Forschungs- 
fragen, die Erfassung von Informationen mittels systematischer Verfahren und die Analyse der erhobenen Daten auf signifikante Muster und Zusammenhänge. Anhand dieser Informationen können sich potentielle Probleme bzw. Schwachpunkte abzeichnen, die dann bereits in der Frühphase der Ausstellungsentwicklung gelöst bzw. behoben werden können. Insofern dient eine Evaluation Ausstellungsmachern als ein Instrument, um ihre potentiellen Besucher besser kennenzulernen und Wege und Möglichkeiten zu sondieren, diese gezielter und effektiver zu erreichen.

Welche konkreten Vorteile hat eine Vorab-Evaluation nun in der täglichen Praxis? Von allen Evaluationsformen hat sie am eindeutigsten einen präventiven Charakter. Sie ermöglicht es dem Museum, die Dinge »mit den Augen der Besucher zu sehen« und dient somit als Quelle von Informationen aus dem Blickwinkel des Publikums. Wer für diese »andere« Perspektive ein geschärftes Bewußtsein entwickelt, kann »das, was wir dem Publikum präsentieren und diejenigen, die dieses Publikum repräsentieren, signifikant besser aufeinander abstimmen« (Shettel 1992). Diese Art der Evaluation verschafft Museumsfachleuten ein klareres Bild darüber, aus welchen Perspektiven andere Menschen das jeweilige Thema betrachten. Zudem liefert eine Vorab-Evaluation hilfreiche Anregungen im Hinblick auf die Entwicklung von Ausstellungen, die mit den Besuchern wirkungsvoll kommunizieren. Die Ergebnisse dieser Untersuchungen können die Bemühungen des Museums um die Verwirklichung seiner Vision und seines Bestimmungszwecks/seiner öffentlichen Verpflichtung ergänzen und unterstützen. Insofern kann eine Vorab-Evaluation nicht nur die Planung einer bestimmten Ausstellung positiv beeinflussen, sondern gleichzeitig als wertvolles Management-Instrument für fundierte Entscheidungen im gesamten Museumsbereich dienen.

Inwiefern unterscheidet sich eine Vorab-Evaluation von einer Formativen Evaluation und einer Summativen Evaluation? Nun, sie betrifft noch nicht die praktischen Aspekte einer Ausstellung z. B. die Lesbarkeit von Texten oder die Wirksamkeit eines Exponats im Hinblick auf die erklärten Zielsetzungen - sondern wird bereits im Stadium der ersten Ideen und der frühen Konzepterarbeitung eingesetzt, also noch vor dem Entwurf von Lösungsversuchen. Sie bietet eine Möglichkeit, die Grundsätze einer Ausstellung während des gesamten Entwicklungsprozesses konstruktiv zu hinterfragen. Die während einer Vorab-Evaluation gesammelten Informationen betreffen den Wissensstand, die Interessen und 
Einstellungen potentieller Besucher sowie eventuell vorhandene Vorurteile oder Klischees bzw. Mißverständnisse oder Fehlinformationen in bezug auf ein bestimmtes Thema. Zudem bietet sie Experten ein Forum, um ihre persönlichen Vorstellungen und Annahmen in bezug auf ein Thema zu überprüfen!

Harris Shettel, ein früher Verfechter der Vorab-Evaluation, betont, daß diese Art der Evaluation Ausstellungsplanern "spezifische Informationen liefert, welche es ihnen ermöglichen, die zu vermittelnden Lerninhalte auf kognitiver wie auf affektiver Ebene von vornherein gezielter auf das potentielle Publikum abzustimmen«. Auf kognitiver Ebene muß bei einer Vorab-Evaluation die Frage gestellt werden: "Wie bereit ist der Besucher, sich mit dem Thema, das wir ihm nahebringen wollen, geistig auseinanderzusetzen? « Auf affektiver Ebene muß die Frage lauten: "Wie interessiert ist der Besucher daran, etwas über das Thema, das wir ihm vermitteln wollen, zu erfahren?»

Mittels einer Vorab-Evaluation können potentielle Probleme eines vorläufigen Ausstellungskonzeptes aufgedeckt werden, bevor Entscheidungen getroffen werden, die sich nicht mehr rückgängig machen lassen. So stellte sich während der Planung einer Ausstellung über das Thema »Globale Erwärmung« im Zuge der Vorab-Evaluation heraus, daß die Besucher irrigerweise davon ausgingen, "die globale Erwärmung« würde durch »das Ozonloch» verursacht. Von dieser Fehlvorstellung hatten die Ausstellungsplaner vor der Evaluation keine Ahnung gehabt, aber dank dieser rechtzeitig gewonnenen Erkenntnis wurde klar, daß die Ausstellung den Besuchern zusätzliche Informationen liefern mußte, damit diese beiden Themen sinnvoll vermittelt werden konnten. Daraufhin wurde das ursprüngliche Ausstellungskonzept (bei dem man unbesehen davon ausgegangen war, daß den Besuchern der Unterschied zwischen der globalen Erwärmung und dem Ozonloch bekannt war) entsprechend abgeändert und somit vermieden, daß die Besucher diese beiden Umwelterscheinungen in einen falschen Zusammenhang brachten. So ließen sich dank der VorabEvaluation wertvolle Design-Entwicklungszeit und/oder teure Investitionen in Ausstellungs-Prototypen vermeiden.

Eine Vorab-Evaluation liefert besucherspezifisches Feedback zu unterschiedlichen Aspekten, etwa Erwartungen, Eindrücke und/oder Vorstellungen seitens der Besucher in bezug auf ein bestimmtes Ausstellungsthema. Während der Planung einer Ausstellung über »Festmüll« stellte sich z. B. im Rahmen der Vor- 
ab-Evaluation heraus, daß »die Leute im allgemeinen die Verantwortung für Müll woanders sahen, nur nicht bei sich selbst ... die meisten erwarteten von der Ausstellung praktische Informationen und Vorschläge, und in allererster Linie eine "Anti-Umweltverschmutzungs-Botschaft«; am häufigsten tauchte der Begriff $>$ Recycling` auf« (Dierking / Pollock 1998: 109ff.).

Eine Vorab-Evaluation kann auch dazu beitragen, den Wissensstand der potentiellen Besucher, ebenso wie ihre "populären Vorstellungen« bzw. Vorurteile und Klischees in bezug auf ein ausgewähltes Ausstellungsthema zu sondieren. Im Rahmen der Vorbereitung eines neuen Ausstellungsraumes ermittelte ein großes Museum, was Schulkinder über Dinosaurier wußten und welche Vorstellungen sie mit dem Thema verbanden. Die Ergebnisse dieser Vorab-Evaluation ergaben, daß »8-12jährige Schüler Dinosaurier für Kaltblüter hielten und der Meinung waren, alle großen Tiere im Mesozoikum seien Dinosaurier gewesen und daß diese schwerfällig und stupide waren« (Dierking/Pollock 1998: 94ff.).

Mit einer Vorab-Evaluation läßt sich auch ausloten, ob seitens des Publikums generell Interesse an einem bestimmten Thema besteht, wie stark das Interesse ist, etwas über bestimmte Aspekte eines Themas zu erfahren, und welche Präsentationsformen die Besucher am ehesten ansprechen würden. Während der Besucher-Interviews, die während der Vorab-Evaluation zu der Ausstellung »Verflixte Schönheit» durchgeführt wurden, erhielten die Ausstellungsplaner nicht nur die Bestätigung, daß das Thema »Gesundheit und Schönheit « auf reges Publikumsinteresse stoßen würde, sondern sammelten zudem wertvolle Impulse und Vorschläge für weitere Konzepte und Themenbereiche, die in das Ausstellungskonzept eingebunden werden konnten (Noschka-Roos 1993).

Im Rahmen einer Vorab-Evaluation kann auch das NichtVorhandensein von Kenntnissen ermittelt werden, die für das Verständnis der Ausstellungs-Botschaft jedoch unverzichtbar sind. Die Vorab-Evaluation zu einer Ausstellung über Kernfusion ergab, daß »nur knapp die Hälfte der Besucher wußte, daß Atome bzw. deren Komponenten die Grundbausteine der Materie darstellen; sie verwechselten Atome mit Zellen. Die Leute hatten zwar schon einmal etwas von "Fusion« und "Spaltung" gehört, konnten diese Begriffe aber weder definieren, noch erläutern« (Dierking / Pollock 1998: 98).

Und last, but not least kann eine Vorab-Evaluation hilfreiche Aufschlüsse über die Beweggründe liefern, die Besucher dazu 
motivieren, eine Ausstellung zu besuchen - und welche Wirkung sie möglicherweise auf die Besucher hat. Bei der Planung einer Ausstellung über »Quallen« im Monterey Bay Aquarium (Kalifornien) ergab sich aus der Vorab-Evaluation, daß unter den Befragten die "weitverbreitete Ansicht herrschte, Quallen seien wertlose glibbrige Dinger, oder aber gefährliche Lebewesen, denen man am besten aus dem Weg geht«. Die Ausstellungsplaner mußten sich also etwas einfallen lassen, um die Besucher für das Thema zu erwärmen. Während der Evaluationsstudie ergab sich dann das Leitthema "Schönheit" als der vielversprechendste Ansatz für die Entwicklung dieser Ausstellung« (Dierking/Pollock 1998: 89).

Die Ausstellung "Verflixte Schönheit« bot eine ausgezeichnete Fallstudie im Hinblick auf den praktischen Einsatz der VorabEvaluation als Instrument der Ausstellungsplanung. ${ }^{3}$ Im Zuge der Planung für diese Ausstellung wurde eine intensive VorabEvaluation durchgeführt mit dem Ziel, eine Bewußtsein für Gesundheit schaffende Ausstellung $\mathrm{zu}$ konzipieren, welche die Wechselbeziehungen zwischen den Themen "Schönheit« und "Gesundheit" herausstellen sollte. Das Thema "Gesundheit« sollte auf ganzheitliche Weise dargestellt werden, d.h. unter Einbeziehung der damit verknüpften physischen, als auch psychologischen und sozialen Aspekte. Auf der Basis einer interdisziplinären Studie wurde zunächst ein vorläufiges Ausstellungskonzept erarbeitet. Im Rahmen mehrerer strukturierter Interviews und FokusGruppen-Gesprächsrunden wurde dieses Konzept dann mit Vertretern der potentiellen Zielgruppe sowie mit Fachexperten diskutiert. Weitere Informationen und Erkenntnisse ergaben sich aus Einzel- und Gruppenbefragungen von Laien (Männer und Frauen aus unterschiedlichen Altersgruppen). Und schließlich wurden in Fokus-Gruppen Sachverständige aus den Bereichen "Schönheit» und "Gesundheit« zusammengeführt, die ihr jeweiliges Fachwissen zum Thema einbrachten. Die Ergebnisse dieser Vorab-Evaluation ermöglichten es dem Ausstellungsteam, ein endgültiges Ausstellungskonzept $\mathrm{zu}$ formulieren. Ohne diese Studien hätte die Ausstellung "Verflixte Schönheit« sicherlich ein anderes Profil erhalten - dies ergab sich eindeutig sowohl aus der Schwerpunktverlagerung auf bestimmte Themen, die letztlich für die Ausstellung ausgewählt wurden, als auch aus der Art und Weise, wie diese Themen in der Ausstellung gestalterisch umgesetzt wurden. Wer sich mit dieser Fallstudie eingehender befassen möchte, kann die zur Ausstellung erschienene Dokumentation anfordern. ${ }^{4}$ 
Wie das oben beschriebene Ausstellungsprojekt veranschaulicht, liefert eine Vorab-Evaluation Einblicke in die Sichtweise des potentiellen Zielpublikums, welche von den Ausstellungsplanern bereits im ersten Planungsstadium einbezogen werden kann. Die Vorab-Evaluation ist aber auch in anderen Bereichen eines Museums einsetzbar, die ebenfalls von Rückkopplungen mit dem Zielpublikum profitieren können. Im Fall der Ausstellung "Verflixte Schönheit« wurde die Vorab-Evaluation genutzt, um schon im Vorfeld zu erfahren, wie potentielle Besucher auf eine Auswahl geplanter Ausstellungstitel und deren Logos reagieren würden. Diese Informationen lieferten wertvolle Hinweise und erleichterten die endgültige Auswahl von Titel und Logo der Ausstellung. In der folgenden Kurzbeschreibung der Vorgehensweisen sollen Wert und Bedeutung einer solchen begleitenden Vorab-Evaluation veranschaulicht werden.

Die Ergebnisse der Vorab-Evaluation bestätigten, daß zwischen den Erwartungen, der Zielgruppe in bezug auf eine Ausstellung zum Thema "Schönheit" und den Intentionen der Ausstellungsplaner eine Diskrepanz bestand. Das Projektteam wollte durch Titel und Logo der Ausstellung eine eindeutige Aussage vermitteln: »Wer schön sein will, muß nicht leiden ... Lust an einer pluralistischen Schönheit«. Mit anderen Worten, es galt unter allen Umständen jegliche Assoziationen mit den gängigen Stereotypen und Klischees zu vermeiden, die bei dem Thema "Schönheit" allzu häufig geweckt werden. Titel und Logo sollten den Besucher vielmehr dazu animieren, sich auf eine Ausstellung einzustellen, die das Thema "Schönheit" nicht in der üblichen Weise darstellen würde, wie er es tagtäglich erlebt.

Während einer 3ominütigen Brainstorming-Sitzung wurden vom Projektteam 45 Vorschläge für mögliche Ausstellungstitel entwickelt. Mit Blick auf die Zielsetzung der Ausstellung wurden die vier besten ausgewählt:

- "Schönheit: Lust und Last«

- "Sein und Schein«

- "Verflixte Schönheit"

- »Echt schön - schön echt«

Diese Titel dienten als Grundlage für eine Vorab-Evaluation »im Schnellverfahren«, die in der Fußgängerzone in der Münchner In- 
nenstadt durchgeführt wurde. Dabei wurden rund 50 Passanten die folgenden Fragen gestellt:

1) „Stellen Sie sich bitte Ausstellungsplakate vor mit folgenden Titeln. Welcher Titel spricht Sie so an, daß Sie auf die Ausstellung neugierig würden?«

2) „In der Ausstellung soll gezeigt werden, daß jeder schön sein will, daß jeder von uns seine liebe Not mit der allseits erwünschten Schönheit hat, für die man immer wieder mal shungert oder sich anderen Torturen unterzieht. Gleichzeitig ist es doch so: Wenn wir jemanden mögen, dann gefällt er oder sie uns in jedem Fall - und wenn wir uns wohlfühlen, auch das kennt jeder, dann finden wir uns schön. Das soll in der Ausstellung angesprochen werden. Würden Sie das bei dem genannten Titel erwarten? Ja oder nein?«

3) »Welcher der anderen Titel würde Ihrer Meinung nach diesen Themen entsprechen?«

Abbildung 2: Entwurf des Ausstellungs-Logos

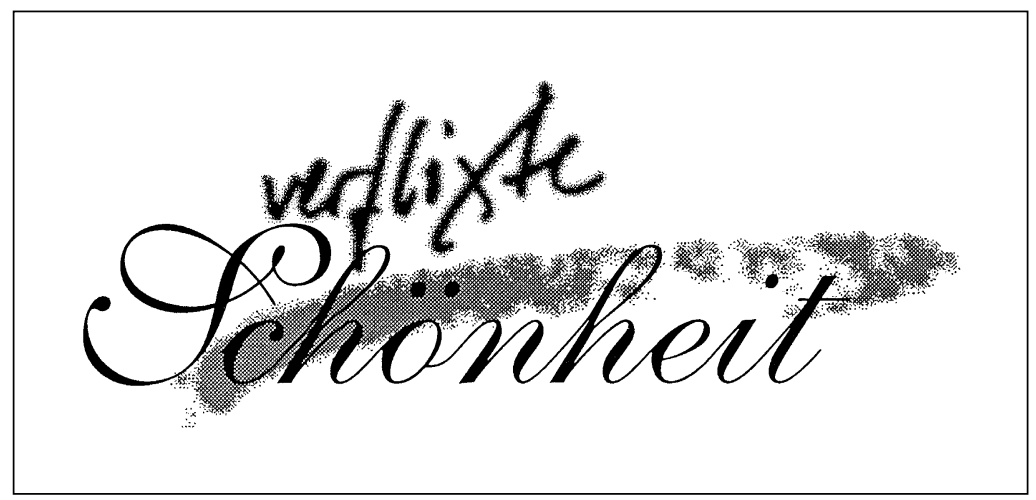

Die Befragten entschieden sich mit überwältigender Mehrheit für den Ausstellungstitel »Verflixte Schönheit«. Dieser Titel spiegelte exakt die Kernidee des Ausstellungskonzeptes wieder. Innerhalb von weniger als drei Stunden konnte also mit nur zwei Interview$\mathrm{ern}^{5}$ genügend Feedback eingeholt werden, um eine fundierte Entscheidung im Hinblick auf den Ausstellungstitel zu treffen. Der Titel »Verflixte Schönheit« ist ein Ergebnis dieser Vorab-Evalua- 
tion; er vermochte potentiellen Besuchern den besonderen Charakter der geplanten Ausstellung unmißverständlich zu vermitteln.

Abbildung 3: Entwurf des Ausstellungs-Logos

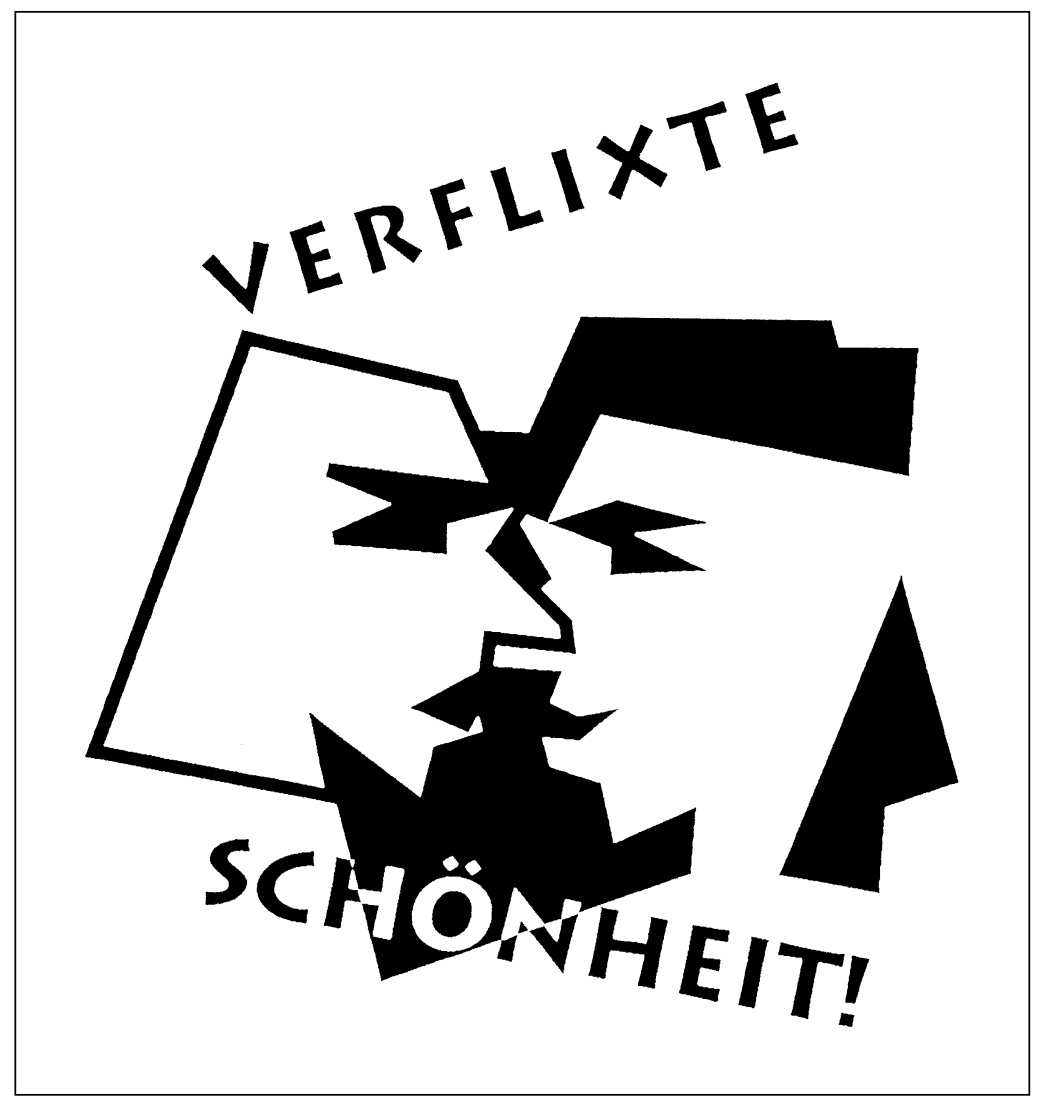




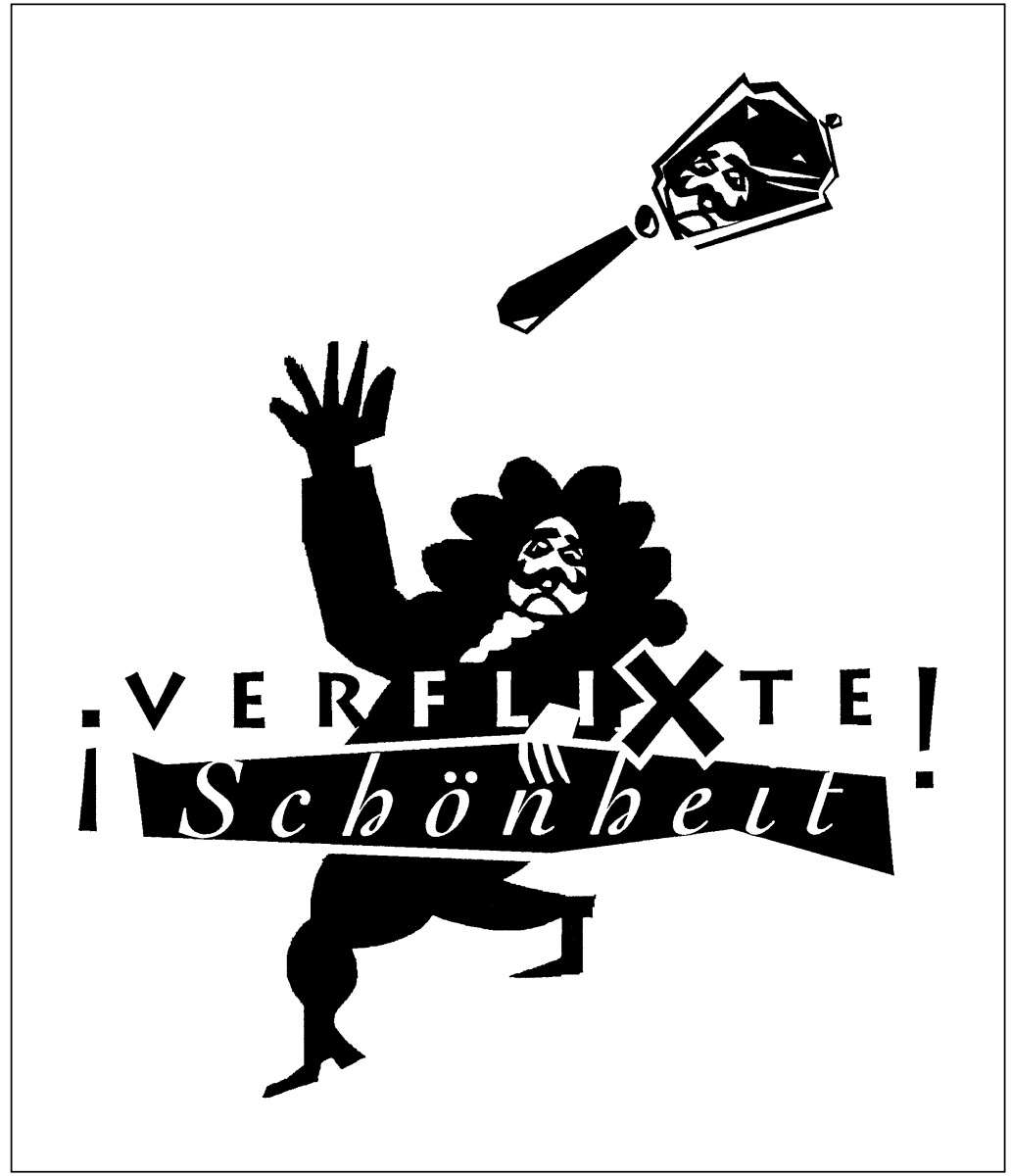

Als nächster Schritt sollte sichergestellt werden, daß das Ausstellungs-Logo visuell dieselbe Funktion erfüllte. Für den Titel "Verflixte Schönheit" wurden drei Entwürfe erarbeitet (siehe Abbildungen 2 bis 5). ${ }^{6}$ Diese wurden insgesamt 120 Personen gezeigt und hierzu folgende Fragen gestellt:

- Welche Veranstaltung würden Sie hinter diesem Plakat vermuten?

- Theater

- Ausstellung 
- Informationsveranstaltung

- Kabarett

- Sonstiges

Die weiteren Fragen beziehen sich nur auf jenes Plakat, bei dem eine Ausstellung vermutet wurde:

- Spricht dieses Plakat Sie so an, daß Sie auf die Ausstellung neugierig wären?

- Welche Themen vermuten Sie in der Ausstellung?

- Es werden Schönheitsideale von gestern und heute gezeigt.

- Es wird gezeigt, daß jeder schön sein will, daß jeder von uns seine liebe Not mit der allseits erwünschten Schönheit hat, für die man auch mal »hungert« oder sich anderen Torturen unterzieht.

- Es wird das Thema »Masken und Kostüme« gezeigt.

- Es wird gezeigt, daß man die sogenannte Schönheit, wie man sie üblicherweise in Illustrierten sieht, nicht so ernst nehmen soll.

Aus den Evaluationsergebnissen ging hervor, daß das "Gesicht«Logo und die "Barockfigur" am häufigsten mit einer Ausstellung verbunden wurden. Bei über der Hälfte der Befragten lösten diese Logos Neugierde aus. Der entscheidende Faktor jedoch war die Art der Assoziationen, die die Logos bei den Befragten erweckten. Sie verbanden das "Gesicht« mit "Schönheitsidealen« (48,3 Prozent), mit »Schönheitszwängen« (55 Prozent), mit »Masken und Kostümen« (55 Prozent) und mit "Schönheit nicht so ernst nehmen« (71,7 Prozent). Die »Barockfigur« errang in allen Kategorien höhere Bewertungen (»Schönheitsideale«: 68,3 Prozent, "Schönheitszwänge«: 58,3 Prozent, »Masken und Kostüme«: 81,7 Prozent und "Schönheit nicht so ernst nehmen«: 82 Prozent). Aufgrund dieser Ergebnisse fiel die Entscheidung zugunsten der »Barockfigur" als Ausstellungs-Logo. Der hohe Prozentsatz an Assoziationen mit "Masken und Kostüme" gab dem Ausstellungsteam allerdings zu denken, so daß bestimmte Aspekte des Logos eigens modifiziert wurden, um der Figur eine modernere Anmutung zu verleihen und somit, so hoffte man, die »Kostüm«-Assoziation auszulöschen (siehe Abbildung 5). 


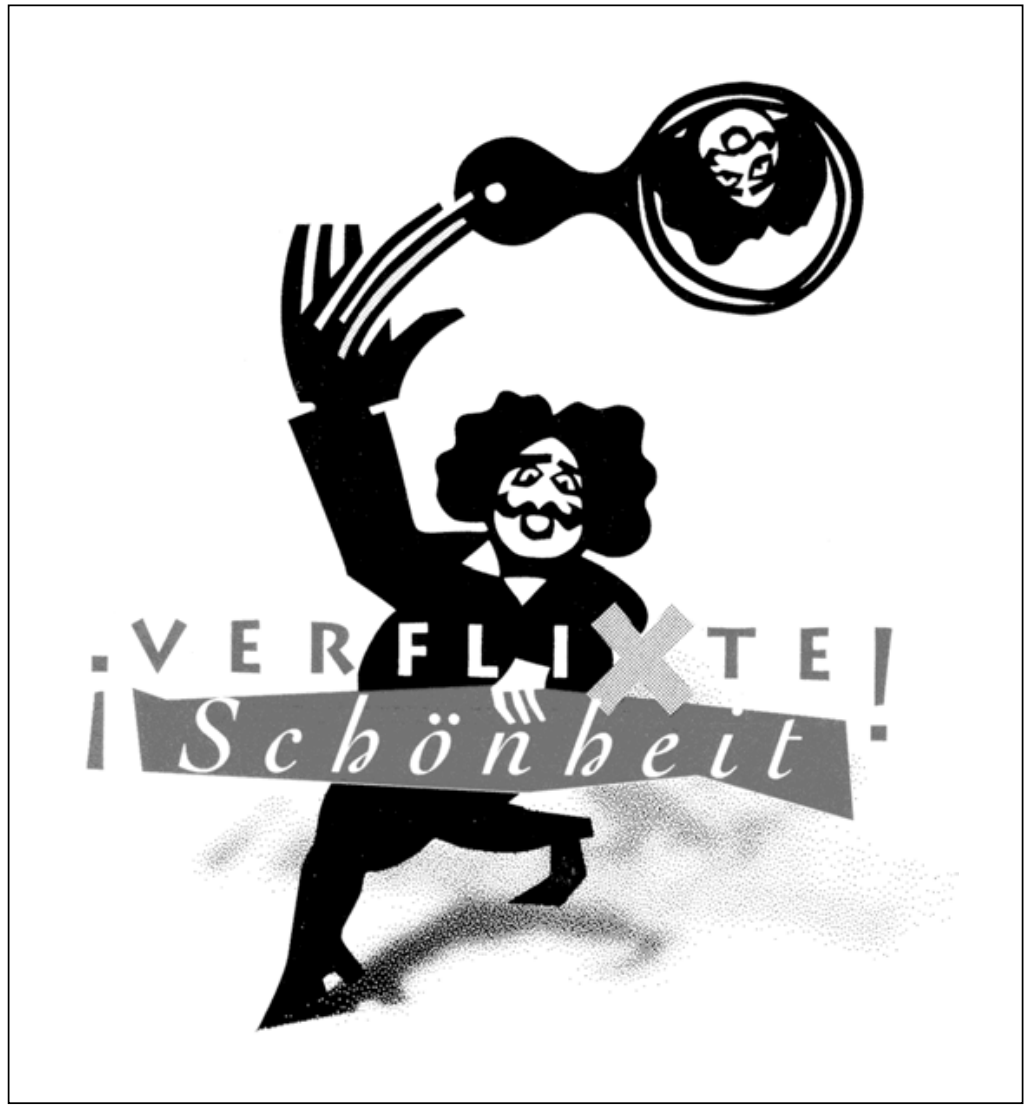

Wie die oben dargelegten Beispiele verdeutlichen, ist die VorabEvaluation eine ausgezeichnete Methode, um zu dem potentiellen Zielpublikum eine Brücke zu schlagen. Die Evaluation kann dem Ausstellungsteam Informationen darüber liefern, wie die Besucher auf ein bestimmtes Thema reagieren - welches Vorwissen, aber auch welche Mißverständnisse und Vorurteile sie mitbringen, was sie sich von der Ausstellung erwarten, wie man sie erreichen, fesseln, beeinflussen kann. Unmittelbares Feedback seitens der Besucher kann auch zu einer erkenntnisreichen Hinterfragung der Effektivität eines geplanten Ausstellungskonzeptes führen. Eine Vorab-Evaluation schärft somit beim Ausstellungsteam das Bewußtsein für die Erwartungen der Besucher und fördert das Sich-Hineinfühlen-Können in deren Sichtweise. Sie liefert die Grundlage 
für den Brückenschlag über die »tosenden Gewässer, die durch die enge Schlucht talwärts strömen«, eröffnet gleichsam den Dialog zwischen Ausstellungsmachern und Ausstellungsbesuchern. Das Ergebnis: Erfolgreichere und gelungenere Ausstellungen.

Praktische Erfahrungen mit der Vorab-Evaluation liefern die überzeugendsten Argumente für den Einsatz dieses Planungsinstrumentes. Wenn ein Ausstellungsteam erst einmal aus erster Hand erfahren hat, welche wertvollen Erkenntnisse und Hinweise sich mit Hilfe dieser Methode gewinnen lassen, wird es auf diese Untersuchungen im Vorfeld der Planung einer Ausstellung nie mehr verzichten wollen.

\section{Anmerkungen}

1 Eine Einführung in die Erhebungsmethoden bieten U. Paatsch/ C. Schulze 1992.

2 Für eine detaillierte Beschreibung der Bedeutung psychographischer Daten im Museumsbereich siehe Falk 1998 sowie Hood 1983.

3 Dieses Ausstellungsprojekt und die begleitende Vorab-, Formative und Summative Evaluation wurden von der ANstiftung (Gemeinnützige Forschungsgesellschaft zur Förderung zunkunftssichernder sozialer, kultureller und ökonomisch / ökologischer Maßnahmen m.b.H., München) unterstützt. Die vollständige Dokumentation zur Ausstellung »Verflixte Schönheit« (Veröffentlichungen und Videos) kann direkt bei der ANstiftung (Fax: 089-74 74 60 30) bestellt werden.

4 Front-End Evaluation - Ein nichtssagender Name für eine vielsagende Methode, Karlsruher Schriften zur Besucherforschung, Heft 4, Institut für Soziologie, Universität Karlsruhe, 1993, (124 Seiten) und Front-End Evaluation - Video zur Besucherforschung, ANstiftung, München, 1993, VHS, 25 Minuten.

5 Leiterin des Evaluations-Projektteams: Dr. Annette NoschkaRoos (München).

6 Die Logos wurden vom Designteam Polygon (Offenbach) entworfen, das auch die Ausstellung »Verflixte Schönheit« gestaltete.

\section{Literatur}

ANstiftung (1993): Front-End Evaluation - Video zur Besucherforschung, VHS, 25 Minuten, München. 
Dierking, L. / Pollock, W. (1998): „Questioning Assumptions. An Introduction to Front-End Studies in Museums «. Association of ScienceTechnology Centers, Washington, DC, S. 53 ff.

Falk, J. (1998): „Visitors: Towards a Better Understanding of Why People Go to Museums«. Museums News (March/April 1998), S. 37-43ff.

Friedman, A. (1993): "Convincing the Director«, Museum Visitor Studies in the 90s, London: Science Museum, S. 43-46.

Hood, M. (1983): "Staying Away: Why People Choose Not to Visit Museums «. Museums News (April 1983), S. 50-57.

Institut für Soziologie, Universität Karlsruhe (1993): Front-End Evaluation - Ein nichtssagender Name für eine vielsagende Methode, Karlsruher Schriften zur Besucherforschung, Heft 4.

Noschka-Roos, A. (1993): »Wegweiser der Front-End Evaluation für die Ausstellungsplanung«. In: Institut für Soziologie, Universität Karlsruhe, Front-end Evaluation - Ein nichtssagender Name für eine vielsagende Methode, Karlsruher Schriften zur Besucherforschung, Heft 4, S. 57-103.

Paatsch, U./Schulze, C. (1992): Besuchererhebungen selbst durchführen. Ein Werkstattbericht aus der Praxis bildungsorientierter Erhebungen an Museen, Methoden, Reichweite, Probleme, Heidelberg.

Screven, C. (1990): "The Use of Evaluation Before, During and After Exhibit Design«. ILVS Review: A Journal of Visitor Behavior 1, 2, S. 36.

Shettel, H. (1992): »Front-End Evaluation: Another Useful Tool«. ILVS Review: A Journal of Visitor Behavior 2, 2, S. 275-280. 


\section{Rick Vercauteren}

\section{Sorry is not enough}

\section{Besucherbindung durch Beschwerde-Management}

Nach einleitenden Ausführungen zu einigen aktuellen Entwicklungen auf dem Gebiet der Managementkultur in Museen sowie zur Bedeutung, die man heutzutage den Interessen und Wünschen der Besucher und Kunden beimißt, wird das Thema der Besucherbeschwerden im Museumsbetrieb erörtert. Dabei gehe ich auf Beispiele aus der Praxis ein.

Als konkreten Fall erwähne ich auch Besucherbeschwerden zu der Ausstellung "Pop im Bild - die visuelle Kultur in der Popmusik seit 1967«, die im Frühjahr 1998 im Noordbrabants Museum in Herzogenbusch zu besichtigen war.

Der Beitrag wird mit einer Reihe von Empfehlungen zum Umgang mit Beschwerden beendet.

\section{Mystery Shopping}

Stellen Sie sich einmal folgendes vor: Sie sind ein leitender $\mathrm{Mu}-$ seumsmitarbeiter. Eines Morgens stehen Sie, obwohl es Ihr freier Tag ist, früh auf, rasieren oder waschen sich, frühstücken, gehen zurück ins Schlafzimmer zu Ihrem Kleiderschrank, ziehen sich Sachen an, die Sie sonst nie tragen, setzen eine Perücke auf und kleben sich, je nach Geschlecht, einen falschen Bart oder Schnurrbart oder aber falsche Wimpern und Fingernägel an.

Der Ordnung halber sei gesagt, daß Sie nicht an kriminellen 
Taten beteiligt sind, keinen Kontaktklub für Artgenossen mit bizarren Vorlieben besuchen wollen und auch nicht in einem noch zu probenden Stück des örtlichen Theatervereins für engagierte Amateure auftreten werden.

An diesem Morgen begeben Sie sich inkognito zu Ihrer Arbeitsstätte: dem Museum, in dem Sie schon seit Jahren mit Freude arbeiten. Sie sind nicht Arbeitnehmer, sondern Schauspieler im »Universellen Theater", wie es der südamerikanische Schriftsteller und Nobelpreisträger Jorge Luis Borges einmal nannte. Heute spielen Sie einen gewöhnlichen Besucher.

Sie machen sich nicht durch "große Töne« bemerkbar und sind kein »klassischer Nörgler«. Sie verhalten sich unauffällig und treten nicht hervor. Es ist, als würden Sie in einem Restaurant heimlich prüfen, ob es einen Michelin-Stern verdient.

Stellen Sie sich vor, wie Sie sich hinten anstellen, ein wenig mit anderen Besuchern reden, wie Sie sich mit bestimmten Fragen am Infoschalter melden, wie Sie zur Rezeption gehen und eine Karte kaufen.

Sie stellen eine Frage nach der anderen und lassen sich ausführlich über die ständigen Sammlungen, die Sonderausstellungen und Vermittlungsprogramme informieren. Sie verbringen viele Stunden im Museum. Zwischendurch unterhalten Sie sich regelmäßig mit anderen Besuchern, aber auch mit Leuten vom Sicherheitsdienst und dem Dienstpersonal im Museumsladen und im Restaurant. Sie hören aufmerksam zu, loten auf subtile Weise die Meinungen aus und studieren eingehend alles, was sich so in den Museumsräumen abspielt. Nach einem Tag besitzen Sie einen Schatz an aktuellen Informationen über den Handel und Wandel in Ihrer Firma und über das Verhalten und die Ansichten Ihrer Besucher.

Als Museumsleiter verfügen Sie über wichtige, "ungefilterte« Informationen, an die man sonst, zum Beispiel über andere Mitarbeiter oder durch eine standardisierte Befragung des Besucherpublikums, kaum herankäme.

Was Sie wahrscheinlich nicht wissen, ist, daß es jemanden gab, der diesem durchaus ernsthaften modernen Managertrend voraus war: der Amerikaner Walt Disney, bekannt als Zeichentrickfilmer, Filmregisseur und Manager der Walt Disney Company.

Disney, ein Mitbegründer der modernen Unterhaltungsindustrie und Erfinder des ultimativen Themenparks Disneyland, verkleidete sich in den 5 oer und 6oer Jahren mehrmals im Jahr als 
Tourist und besuchte als Ausflügler sein eigenes Disneyland in Los Angeles.

Das tat er, um das von ihm erdachte Produkt zu prüfen und um persönlich herauszufinden, was das breite Publikum überhaupt interessiert und was es in seinem Themenpark positiv oder negativ bewertete.

Es liegt auf der Hand, daß er besser als jeder andere über die Gedanken in seiner Belegschaft Bescheid wußte, und daß er anhand seiner »Transformationsmethode« präzise feststellen konnte, ob sich die Besucher wirklich amüsierten. Außerdem wußte er genau, wo die potentiellen Probleme lagen, und von welcher Abteilung oder Parkeinheit Beschwerden drohten.

Walt Disney kann als einer der Pioniere dessen gelten, was man heutzutage Mystery Shopping oder auf deutsch verdeckten Einkauf nennt. Ein neuer Trend, wobei sich Wirtschaftsmanager, verkleidet und womöglich travestiert, ähnlich wie die HollywoodSchauspieler Dustin Hoffman und Robin Williams als sogenannter »mystery guest«, als getarnter Gast also, in Freizeitparks, Banken, kulturellen Einrichtungen, Imbißketten, Warenhäusern usw. umschauen.

Mit diesen unangekündigten Besuchen sollen - wie es der verstorbene Walt Disney oder der Guide Michelin tat - Publikumsorientierung und Kundenfreundlichkeit getestet werden. Genau genommen wird damit der tägliche Gang der Dinge im "front office» des Unternehmens, der Einrichtung oder Organisation untersucht.

\section{Kundendienst und Kundenzufriedenheit}

Sie alle kennen das Klischee vom »König Kunde«. In jüngst entwickelten Managementtheorien widmet man sich eingehend der Beziehung zwischen dem Image von Einrichtungen und der $\mathrm{Zu}$ friedenheit von Besuchern.

Heute gilt mehr denn je, daß die persönliche Aufmerksamkeit der festen Mitarbeiter gegenüber zeitweiligen Gästen und Besuchern eine entscheidende Voraussetzung für das langfristige Überleben von Museen ist.

Kundenorientierung und Publikumsfreundlichkeit werden in der neueren, überwiegend amerikanischen Managementliteratur mit den vornehmen, aus der Wirtschaft stammenden Begriffen Customer Service oder Customer Satisfaction bezeichnet. 
Die ständige Befriedigung von Kundenwünschen steht im modernen Management an allererster Stelle. Diese postmoderne und auf das Zwischenmenschliche gerichtete Revitalisierung eines wohlbekannten Klischees zielt darauf ab, den Kunden mehr zum König zu machen, als er es je war.

Das bereits zitierte Mystery Shopping spielt bei der Sicherstellung von Servicequalität und Satisfaction als Instrument und Maßstab für das Management eine wichtige Rolle.

Von herausragender Bedeutung ist der Umstand, daß ein Direktor, ein zuständiger Manager oder der Leiter einer Abteilung ungefiltert und unmittelbar persönliche Informationen über das Wohlergehen des eigenen Unternehmens sammelt und selbst eventuelle Schwachstellen ermitteln kann. Vielleicht regt das Phänomen Mystery Shopping auch Ihre Phantasie an. Schlüpfen Sie eine Weile in eine andere Rolle. Ich wünsche Ihnen im voraus viel Vergnügen beim Ärgern.

\section{Vorbeugen ist immer besser als heilen}

In vielen Veröffentlichungen zum Thema Management liest man folgendes: "Jede Organisation sollte täglich den Bedürfnissen und Wünschen ihrer Gäste, Besucher oder Kunden Rechnung tragen."

Im nun folgenden Abschnitt möchte ich diese hübsche Formulierung mit der täglichen Praxis des Museumsbetriebs vergleichen, insbesondere der der ohnehin verwundbaren Kunstmuseen. In das breite Spektrum habe ich - unter dem Motto, daß vorbeugen besser als heilen ist - verschiedenste Praxiserfahrungen auf spielerische Weise verarbeitet.

Viele Museen, auch jenes, in dem ich arbeite, liegen in den Zentren mittelalterlicher Städte und sind daher meist schwierig zu erreichen, sowohl für die Besucher als auch für Lieferanten und Spediteure - ein Umstand, den man oft vergißt.

Eine gute Ausschilderung im Umkreis von fünf bis zehn Kilometern ist sehr wichtig. Einer anhaltenden Auseinandersetzung mit der kommunalen und regionalen Politik, der Polizei und dem Touristikgewerbe um die dauerhafte Umsetzung darf man nicht aus dem Wege gehen. In manchen deutschen Städten, darunter auch Essen, wo ich mir neulich eine große Gauguin-Ausstellung angesehen habe, ist die Ausschilderung vorbildlich. 
Durch den intimen, etwas engeren Charakter alter Orte fehlen in der direkten Umgebung des Museums häufig Parkplätze in genügender Zahl. Durch gute Vorab-Information - sowohl mündlich als auch schriftlich in Form von Druckschriften wie Handzetteln und Faltblättern - läßt sich bei den Besuchern viel unnötiger Ärger vermeiden.

Viele Museen, so auch das Provinzmuseum von Nordbrabant, bestehen aus einer Kombination alter Gebäude, etwa aus dem 17. oder 19. Jahrhundert, und aus Neubauten des 20. Jahrhunderts. Wegen der großen Ausstellungsfläche und des relativ komplexen baulichen Charakters sind Textinformationen und Beschilderungen innerhalb der Gebäude in der Praxis außerordentlich wichtig für Besucher.

Grundsätzlich empfiehlt es sich, einen Grundriß der Ausstellungsbereiche, Museums- und Filmräume, Auditorien, Archive, Büchereien, Cafés, Restaurants, Toiletten, Konferenz- und Besprechungsräume in gedruckter Form auszulegen. Darüber hinaus ist es sehr zu empfehlen, das Schalter- und Rezeptionspersonal und die Mitarbeiter des Sekretariats (regelmäßig) mit Anweisungen zu versehen.

Die interne Verbreitung von Fehlinformationen schädigt das Image eines Museums sofort und wirkt sich, wie die Praxis zeigt, langfristig mehr oder weniger fatal aus.

Zögern Sie daher nicht, Ihren Museumsmitarbeitern einen Auffrischungskurs zu verordnen oder das Personal in festen Abständen selbst zu schulen.

Ferner müssen auch automatische Anrufbeantworter und Internet-Sites mit Informationen über das Museum nach gewisser Zeit angepaßt werden. Aus einer internen Studie der niederländischen Museen geht hervor, daß man sich selten daran hält. Veraltete Informationen, überholte Ausstellungskalender und Sites, die nicht aktualisiert werden, hinterlassen, gelinde gesagt, einen unprofessionellen, publikumsfeindlichen Eindruck.

Das gleiche gilt mutatis mutandis für die Anbringung von Textschildern neben Kunstwerken, die an andere Museen ausgeliehen wurden. Durch gute interne und externe Informationsvermittlung läßt sich viel Ärger vermeiden.

Wie die positive, kundenfreundliche Ausstrahlung der Walt Disney Company und der New York Metro Services zeigt, ist auch die tägliche Kontrolle von High-Tech-Geräten wie Computern, 
Diaprojektoren, interaktiven CD-ROM-Playern, Beleuchtung und Videoprojektoren in den Ausstellungsräumen von großer Bedeutung.

Komplizierte Handhabung oder defekte Geräte führen sofort zu Beschwerden. Umfragen haben ergeben, daß Besucher Wert darauf legen, daß alle empfindlichen Geräte funktionstüchtig und betriebsbereit sind. Schlechte Erreichbarkeit, mäßige Zugänglichkeit, eine undeutliche Routenführung durch das Museum sind dem $\mathrm{Mu}$ seumspublikum ebenfalls ein Dorn im Auge.

\section{Museum und Kundendienst}

In den letzten Jahren wurde in der internationalen Museumswelt im allgemeinen und im deutschen, französischen und niederländischen Museumswesen im besonderen bei der Schaffung neuer Räumlichkeiten, der Modernisierung bestehender alter Gebäude und der geänderten Präsentation von festen Sammlungen ein enormer Aufwand getrieben. Ein auffälliger Trend in diesem Erneuerungsstreben ist die Verbesserung dessen, was die Franzosen so elegant »accueil« nennen.

Ganz allgemein ist den Museumsleitungen bewußt, daß Rahmenbedingungen und Standardeinrichtungen wie gute und sichere Haupteingänge, beaufsichtigte Garderoben, Rezeptionen und Informationsschalter, kundenfreundliche Kassen und Schließfächer, die Verfügbarkeit von Geh- und Sitzhilfen sowie Rollstühlen, einfach zu benutzende Fahrstühle, ein umfassend sortierter Museumsladen und ein angemessenes Imbißangebot heute absolut unverzichtbar und darüber hinaus eine Voraussetzung dafür sind, daß Besucher wiederkommen (Wiederholungsbesuche).

Generell ist festzustellen, daß es inzwischen immer mehr architektonische und technische Möglichkeiten gibt, Türschwellen in den Boden einzulassen, schräge und getreppte Bodenbereiche zu markieren, Glasscheiben deutlich zu kennzeichnen und Fußböden rutschsicher zu gestalten. Wir haben die Möglichkeit, für klare, benutzerfreundliche Sichtlinien, erkennbare und subtile Farbdifferenzen und eine freundliche Akustik zu sorgen.

Was wir niemals vergessen dürfen, ist die Tatsache, daß sich wirklich jeder in einem Museum wohlfühlt, das harmonisch eingeteilt, farblich ausgewogen, gut ausgeleuchtet und akustisch angenehm ist. 
Diese allgemein bekannten Normen und Maßstäbe wurden nicht für speziell ausgesuchte Zielgruppen geschaffen, wie man manchmal irrtümlicherweise $\mathrm{zu}$ glauben scheint. Sie besitzen vielmehr für jeden Museumsbesucher Gültigkeit.

Wenn (wiederholte) Beschwerden etwa von Tauben, Blinden, Sehbehinderten, Kleinwüchsigen und Rollstuhlfahrern zeigen, daß Sichthöhe und Griffhöhe für sie erhebliche Hemmnisse bilden, dann sollte man sofort aktiv werden. Positive Maßnahmen haben den Vorteil, daß häufig auch andere Besucher und Benutzer von den Verbesserungen profitieren.

Das gleiche gilt für Beschwerden über Informationen, die rein oder überwiegend visueller Art sind. Auch dann muß die Institution die Schuld bei sich selbst suchen und Alternativen in Form von gesprochenen Informationen oder Blindenschrift entwickeln, um allen Bedürfnissen gerecht zu werden.

Dennoch erweist es sich in der üblichen Museumspraxis als äußerst schwierig, publikumsfreundliche Einrichtungen zu schaffen, mit denen auch tauben, blinden, sehschwachen und mit anderen Behinderungen kämpfenden Mitmenschen so gut wie möglich geholfen ist. Wenn wir diese komplexe Materie, in der Zeit und Geld immer eine undurchsichtige Rolle spielen, unter ein Motto stellen wollen, so müßte dieses lauten: "Zugang geboten«, und nicht: »Zugang verboten«.

\section{Für und wider von PR-Arbeit}

Lernen wir aus unseren Fehlern? Führen Beschwerden tatsächlich zu Verbesserungen, sind wir bereit, nach den Regeln des »learning management« zu arbeiten? Betrachten wir die Tätigkeit im Museum auch als eine Form von »éducation permanente«?

Museen betreiben für Sonderausstellungen einen großen organisatorischen, finanziellen und PR-Aufwand. Manche Museen erweckten in den vergangenen zehn Jahren mehr den Eindruck einer Expo- oder Kunsthalle als den eines Museums. Das Angebot ist überwältigend, das Tempo mörderisch, und aus Kollegen werden fast Widersacher. Bleibt in diesem gehetzten Klima überhaupt noch genügend Zeit, um sich in Ruhe Gedanken zu machen und Urteile zu bilden?

Die unersättliche Gier nach Gratiswerbung, nach der teuren Hauptsendezeit, den griffigen Slogans und edlen Broschüren, all 
das hat zur Folge, daß die Kosten für Werbekampagnen steigen und die internen und externen Kommunikationsteams stetig wachsen.

Ferner führen die große Zahl der zeitgleich organisierten Ausstellungen und die relativ kurze Ausstellungsdauer zu schwindelerregenden Verwicklungen. Wie kann sich ein Museum heutzutage mit seinen ausgeliehenen Werken noch abheben, wie lenkt es die Aufmerksamkeit des ohnehin schon reizüberfluteten Publikums auf sich? Indem es leise flüstert, oder statt dessen lauter schreit als alle anderen Kollegen beziehungsweise Konkurrenten im Marktgedränge zwischen Angebot und Nachfrage?

Customer Service bedeutet auch, daß in den Medien vorher ein angemessener Eindruck über die Sonderausstellung vermittelt wird. Ein Rat aus der Praxis: Schaffen Sie vor allem ein integres und wahrheitsgetreues Bild der Ausstellung. Widerstehen Sie der Versuchung, das Ereignis aufzubauschen, gaukeln Sie kein falsches Bild der Veranstaltung vor, und verzichten Sie vor allem auf durchsichtige Tricks.

Kurz und gut, eine leere Hülse soll nicht als Ei präsentiert werden. Immer mehr Besucher machen Bemerkungen über die manipulierte Auswahl von Bildträgern und den übertrieben formulierten Inhalt von Museumsdruckschriften wie Plakaten, Prospekten und Handzetteln. Wie die Beschwerden zeigen, ärgert man sich außerordentlich über das Mißverhältnis zwischen dem Schein, also dem Werbematerial, und dem Sein - das heißt Form und Inhalt einer Ausstellung.

\section{Ein Fall aus der Museumspraxis: Pop im Bild}

Das Museum von Nordbrabant präsentierte vom 4. April bis zum 5 . Juli 1998 für eine jugendliche Zielgruppe eine Ausstellung zum Phänomen Popkultur. Ausgestellt wurden Plattenhüllen, Entwurfszeichnungen, Trickfilmbilder, Malereien, Originalfotos und dreidimensionale Objekte von bekannten Designern, Fotografen und Künstlern innerhalb und außerhalb der Niederlande, die ihr kreatives Talent in die Dienste der Popmusik gestellt haben. »Pop im Bild « umfaßte einzigartiges Bildmaterial bekannter Gruppen wie, z.B. den Beatles, den Rolling Stones, den Doors, Pink Floyd, Prince, U2 und The Prodigy.

Mit Hilfe eigens installierter Satellitenantennen wurden per- 
manente Live-Sendungen von MTV Networks aus London übertragen, um die Rolle des Mediums Fernsehen, das seit 1975 stark an Bedeutung gewann, wörtlich und bildlich zu illustrieren. Außerdem wurden historische Werbefilme und Videoclips als Filmschleifen vorgeführt und interaktive CD-ROMs sowie interaktive Offline-Internet-Sites präsentiert, die der Besucher selbst steuern konnte.

Auffällige Merkmale der Ausstellungseinrichtung waren die Verdunkelung sämtlicher Ausstellungsräume, mit der ein »Poptempel-Effekt« erzielt werden sollte, die Aufstellung eines riesigen, sich drehenden Plattenspielers mit Lautsprechern und die ununterbrochene Wiedergabe der Satellitenbilder von MTV Networks. Das Konzept, insbesondere der rotierende Plattenspieler im großen Saal, erntete bei dem jungen Publikum großes Lob.

Auch das Medienecho zur Ausstellung »Pop im Bild « war positiv. Viele Journalisten, Rundfunk-Diskjockeys und Fernsehproduzenten begaben sich nach Herzogenbusch. Das alles führte dazu, daß dem Museum im Fernsehen insgesamt eine Stunde Sendezeit gewidmet wurde: ein absoluter Rekord.

Die von uns durchgeführten standardisierten Publikumsbefragungen ergaben, daß der junge "Durchschnittsbesucher" die Ausstellung ebenfalls hoch bewertet. Es ist natürlich sehr ermutigend, wenn man von Punkern, Skatern und Hiphoppern gute Noten bekommt. Dennoch ist dies kein Grund - und sei es auch nur kurz sich damit zu brüsten.

Denn im Verlaufe der Ausstellung erhielten wir viele mündliche und schriftliche Beschwerden von jungen Besuchern. Die wichtigste betraf die geringe Lautstärke der Satellitensendungen und der Videobildschirme. Alle waren sich einig, daß die Lautstärke zu leise eingestellt war.

Eine andere Beschwerde bezog sich auf die Beleuchtung. Wie ich bereits erwähnte, sah das ursprüngliche Konzept eine völlige Verdunkelung vor, um eine Stimmung wie in einem Poptempel oder einem Kino zu erzeugen. Die Museumsdecke wurde tatsächlich lichtdicht verschlossen; vor den Fenstern wurden Jalousien angebracht. Um dennoch eine Art Tageslicht-Situation zu schaffen, ordnete die Museumsleitung an, die Jalousien halb zu öffnen. Das starke Sommerlicht war für die Betrachtung der großen Fernsehschirme leider sehr ungünstig.

Da die Drucksachen bereits sehr frühzeitig fertig sein mußten, entstand ein weiteres Problem. Nach internen Beratungen wurde 
beschlossen, auf den Textplakaten die Namen einiger bekannter niederländischer und internationaler Popgruppen zu erwähnen.

Einige Leihgabeverträge waren jedoch noch nicht zurückgeschickt worden. Eine beliebte holländische Band stellte der Ausstellung, anders als vorgesehen, keine Leihgaben zur Verfügung.

Kaum verwunderlich, daß die Fans dieser Gruppe lange Gesichter machten. In solch einem Augenblick gibt es erheblichen Erklärungsbedarf.

Diese drei Arten von Beschwerden sind mittlerweile in einem internen Prüfbericht verarbeitet worden und liegen auch der Direktion vor. Projektleiter werden ab jetzt sorgfältig darauf achten, daß in Zukunft kein neuerlicher Beschwerdeanlaß entsteht.

\section{Auf dem Weg zu einer echten Besucherbindung}

Kann ein Museum aus Beschwerden Vorteile ziehen? Kann man jemanden, der sich beschwert, durch gutes Management als Stammbesucher gewinnen?

Als Leiter der Abteilung Kommunikation im Museum von Nordbrabant antworte ich, aufgrund der zuvor geschilderten persönlichen Erfahrungen, mit einem eindeutigen ja.

Der berühmte zeitgenössische deutsche Künstler Emil Schumacher selbst war es, der mir 1993 anläßlich einer Eröffnung anvertraute, er sei zusammen mit seiner Frau und seinem Sohn nach Herzogenbusch gekommen, um das Museum von Nordbrabant persönlich einer Prüfung zu unterziehen. Erst nachdem er sich selbst davon überzeugt hatte, daß dies ein kundenfreundliches Museum war, war er bereit, wichtige Leihgaben für eine Ausstellung zur Verfügung zu stellen. Für mich macht diese Anekdote sehr deutlich, welchen Stellenwert das Phänomen Customer Satisfaction besitzt.

Es empfiehlt sich, feste Abläufe für die Bearbeitung von begründeten Beschwerden festzulegen, einen verantwortlichen Mitarbeiter zu ernennen und, nach dem Beispiel großer Unternehmen, ein »complaints manual« zu erstellen. Wer es ernst meint mit Besucherbindung durch Beschwerdenmanagement, für den ist persönlicher Kontakt eine unverzichtbare und zugleich zeitaufwendige Voraussetzung. Eine sorgfältige Abwicklung kostet Zeit, sorgt aber, wenn sie gut ausgeführt wird, durch Wiederholungsbesuche für zusätzliche Einnahmen. 
Wer auf Beschwerden reagiert, sollte immer bedenken, daß der Ton die Musik macht. Geben Sie ruhig zu, daß ein Fehler gemacht wurde, aber stehen Sie jederzeit zur eigenen Organisation und deren Mitarbeitern.

Behandeln Sie Menschen mit Beschwerden, wie schwierig es auch sein mag, immer als gleichwertig. Versuchen Sie, wo möglich, das psychologische oder soziale Gleichgewicht wiederherzustellen und machen Sie manchmal von einer Belohnung Gebrauch, etwa in Form von Freikarten. Diese Art der »Wiedergutmachung« wird oft gerne angenommen.

Ein klassischer Lehrsatz für Manager lautet: "Kundenfreundlichkeit bedeutet, daß man den derzeitigen und zukünftigen Wünschen und Bedürfnissen von Besuchern sowohl jetzt als auch später optimal Rechnung trägt." Jeder unzufriedene Besucher reicht seine schlechten Erfahrungen weiter. Verschiedene Studien haben ergeben, daß jemand, der eine Beschwerde hat, im Schnitt drei anderen Personen davon berichtet. Geht man nicht ordnungsgemäß auf ihre Beschwerde ein, so wird es gleich zehn Leuten erzählt. Beschwerdenmanagement ist wirklich von vitaler Bedeutung: "Sorry is not enough«. 



\section{Partnerschaft mit dem Besucher als strukturelles Element der Museumsarbeit}

\section{Einleitung}

Das Verhältnis von Museen und Besuchern wird - inhaltlich betrachtet - definiert vom Ziel der Museen, den Besuchern und Besucherinnen etwas zu vermitteln. Dabei wird "vermitteln« prinzipiell verstanden als die schwierige Aufgabe, dem Besucher Informationen mitzuteilen und nach Möglichkeit mit auf den Weg zu geben.

Eine besondere Herausforderung stellt bei der musealen Informationsdarbietung eine gewisse Sprachlosigkeit und Ohnmacht auf Seiten der Ausstellungsmacher dar. Ihre "Vermittler«, die Exponate, sprechen anscheinend nicht zu jedem Besucher, nicht immer werden sie überhaupt, nur gelegentlich "richtig" und selten "völlig" verstanden. Diese (teilweise) Sprachlosigkeit der Objekte kann nur unzureichend wettgemacht werden durch die zahlreichen zusätzlichen Informationsangebote der Ausstellungen in Form von Texten, Bildern, Videos, Dias etc., denn ohnmächtig registrieren die Aussteller, daß das Publikum diese Darbietungen zu einem individuellen mehr oder minder großen Teil nicht wahrnimmt. Rätselhaft bleibt, welche Informationen Besucher »aufnehmen«, völlig im Dunkeln ist, ob das geneigte Publikum aus dem Dargebotenen etwas "mitnimmt«, und falls ja, was (Noschka-Roos 1994: 194). 
Bei den meisten Bemühungen, die Wirksamkeit der Informationsvermittlung präziser und zuverlässiger $\mathrm{zu}$ steuern, ist der Ausgangspunkt aller Überlegungen der Inhalt des zu vermittelnden, die (fachliche) Botschaft selbst, in der Hoffnung, diese Botschaft beim Besucher »ankommen« zu lassen.

Besucherorientierung in diesem Sinne meint »Inhaltsorientierung«. Das Vorwissen und die Einstellung der Besucher vor dem Ausstellungsbesuch bleiben im Wesentlichen unberücksichtigt (John 1997: 8), ihre Auffassung und ihre Situation nach dem Ausstellungsbesuch bleiben verborgen.

Im folgenden werden zunächst die inhaltlichen Strukturen des Verhältnisses Besucher, Ausstellungen und Ausstellungsmacher analysiert, um die bisher häufig unterschätzte Funktion der Besucher im Hinblick auf die Ausstellungsaussagen darzustellen. Ausgehend von der These, daß die Besucher so wesentliche Einflüsse nehmen auf die in Ausstellungen zustande kommenden Inhalte, daß die Besucher selbst als (mit-)sinnkonstituierende Kommunikationspartner der Aussteller angesehen werden müssen, soll anschließend ein Modell der Besucherorientierung im Sinne inhaltlicher Integration in die Ausstellungs- und Projektplanung vorgestellt werden.

Die Ausführungen beziehen sich dabei im besonderen auf historische Ausstellungen und Museen, die anzuführenden Beispiele stammen aus den Erfahrungen der Arbeit des Stadtmuseums Hagen.

\section{Historische Ausstellungen und Kommunikation}

Aus der klassischen Aufgabenstellung der Museen, zu sammeln, zu bewahren und zu erforschen, ergibt sich zwangsläufig, daß die Tradierung der Gegenstände sich schnell löst vom Bewahren des Objektes zu Erkenntnis und Dokumentation eines fachwissenschaftlichen historischen Zusammenhangs, der sich erschließt auf Grund wissenschaftlicher Analysen und weiterer Quellen und vor dem Hintergrund des aktuellen Forschungsstandes. Die Aussagekraft der Objekte für die Fachwissenschaft entfernt sich dabei schnell vom äußeren Eindruck der Objekte und definiert sich nicht nur über die Bedeutung der Objekte in ihrem "ursprünglichen" Funktions- und Bedeutungszusammenhang, der in den meisten Fällen nicht fachwissenschaftlich war. Bei der Betrachtung des 
Objektes, bei der Dokumentation wird seitens der Museen das Objekt als Quelle für die weitere wissenschaftliche Erkenntnis genutzt, so daß durch die fachwissenschaftliche Erforschung mit den ihr eigenen Methoden und Kenntnissen das Bedeutungsfeld der Objekte qualitativ erweitert wird, wobei diese Bedeutungsqualität mit dem Objekt von den Fachwissenschaftlern assoziiert wird, ohne streng genommen tatsächlich sichtbar zu sein. Die Konzeption musealer Präsentationen ist unmittelbar verknüpft mit den den Objekten zugeordneten Inhalten und mit akademischen Prinzipien, so daß die Ausstellungsbotschaft konstruiert wird auf der Grundlage der mit den Objekten verknüpften fachwissenschaftlichen Inhalte (Hobein 1994a: 43). „Unter den Bildungszielen, die die Museumsleitungen nennen, dominieren jene bei weitem, die unter der Kategorie skognitive Wissensvermittlung، zusammengefaßt werden können« (Rath 1998: 8of.).

Keineswegs verwunderlich ist es deshalb, daß die »klassische» und zahlenmäßig wichtigste Gruppe der Museumsbesucher als gebildet bzw. bildungsbeflissen gilt und über eine höhere Schulbildung verfügt, die der beschriebenen Arbeitsweise der Museen entgegenkommt (Treinen 1991: 40).

Diese Gruppe verfügt über den richtigen "Schlüssel zur Dekodierung « der Präsentation, da sie zugleich mit der weiterführenden Schulbildung über akademische Denkweisen verfügt; obwohl auch ihr Vorwissen - gemessen an den Ausstellungsinhalten - für das fachliche »Verstehen« nicht spezifisch genug ist (Treinen 1991: 41).

Trotzdem ermöglicht selbst die ähnliche Denkweise von Ausstellungsmachern und Besuchern keine deckungsgleiche Dekodierung musealer Präsentationen. Differenzen zwischen musealer Aussage und Besucherwahrnehmung entstehen durch Vorwissen und Vorerfahrung des Publikums, sie entscheiden z. B. über das Verweilverhalten der Besucher und die Auswahl der von ihnen wahrgenommenen Gegenstände sowie die Wahrnehmungsintensität der einzelnen Objekte. Obwohl bekannt ist, daß das Interesse der Aussteller, möglichst viele Exponate zu präsentieren, sich deckt mit dem Interesse der Ausstellungsbesucher, möglichst viele Exponate zu sehen, steht einer intensiven Wahrnehmung und einem tiefen Verständnis seitens der Museumsbesucher die kurze Zeit des Ausstellungsbesuches und der Verweildauer vor den Exponaten im Wege, so daß seitens der Ausstellungsmacher immer wieder Zweifel angebracht werden, ob der Besucher überhaupt ei- 
nen inhaltlichen Nutzen aus der Ausstellungsbetrachtung zieht oder tatsächlich dem "window-shopping « verhaftet ist.

Aufschluß über die Zusammenhänge von Besucherverhalten einerseits sowie Ausstellungsinhalten und Ausstellungsgestaltungen andererseits geben Verhaltensanalysen und Besucherbewertungen, die grundsätzlich über einen hohen Anwendungsbezug verfügen (Treinen 1997: 45). Inhaltliche Besucherorientierung im Hinblick auf die Präsentationsweise bedeutet, die Dekodierung des Gesehenen grundsätzlich nicht nur zu ermöglichen, sondern auch zu erleichtern, indem die Möglichkeiten zur »Entschlüsselung der Bedeutungsgehalte« bereits bei der Ausstellungsplanung angemessen berücksichtigt werden (Treinen 1997: 44). Doch diese Form der Besucherorientierung beinhaltet noch keine uneingeschränkte, sondern eher eine asymmetrische Kommunikation mit dem Publikum, das grundsätzlich keine Möglichkeit hat, Ausstellungsthemen, -inhalte und -präsentationsweisen $\mathrm{zu}$ beeinflussen (Noschka-Roos 1994: 215).

Ungelöst bleiben "wichtige Kernfragen« der Rezeption, wie "z. B. Fragen nach der Bildung und Veränderung von Einstellungen, nach dem Wahlverhalten angesichts vielfältiger kultureller und Freizeitalternativen etc." (Günter 1997a: 9).

Faßt man die Adressaten von Museen und Ausstellungen grundsätzlich als Besucher und (bisherige) Nichtbesucher auf, verbindet beide Gruppen ihre Funktion als »Träger von Einstellungen und Beurteilungen mit Erwartungen und Ansprüchen« (Günter 1997b: 12).

In dieser Funktion beeinflussen beide Gruppen direkt und indirekt Ausstellungen und Ausstellungsmacher: Die große Gruppe der Adressaten entscheidet zunächst, ob eine Ausstellung überhaupt besucht wird, die kleinere Gruppe der tatsächlichen Besucher bestimmt auf Grund ihres Vorwissens, ihrer Erwartung, ihrer Kenntnisse etc. darüber, welche Aufmerksamkeit welchen Teilen des Ausstellungsarrangements gewidmet und ob und vor allen Dingen wie das präsentierte Thema tatsächlich verstanden wird.

Das Fatale bei allen Bemühungen, auch die bisherigen Nichtbesucher in die Gruppe der Besucher zu integrieren, liegt darin, daß Museen an einer Eigenschaft der Nichtbesucher meistens scheitern, die sie zumindest mit inhaltlicher Ausstellungsgestaltung kaum beeinflussen können: Nichtbesucher »entscheiden sich ausschließlich und überwiegend für andere Betätigungsfelder, weil das Zusammensein mit anderen Menschen, eine vertraute Umge- 
bung und die aktive Teilnahmemöglichkeit ihnen in Museen kaum gegeben zu sein scheinen« (Klein 1997: 41). Erstbesucher, die nicht vorrangig dem Bildungsbürgertum angehören, vermuten häufig zunächst, daß Museen im allgemeinen mit »verstaubt« und "langweilig « zutreffend zu charakterisieren seien (Foerster 1998: 12).

Die asymmetrische Kommunikation mit dem Besucher ist also als Wesenszug der Museen so offensichtlich, daß die Nichtbesucher genau genommen deshalb auch nicht erscheinen.

Gehen wir davon aus, daß trotz eines zeitweise zu verzeichnenden Besucherbooms der größte Teil der Bevölkerung von den Museen nicht erreicht werden kann, so liegt ein Grund wohl darin, daß ein großer Teil der Adressaten nichts mit der musealen Denkweise anfangen kann, vom Angebot der Museen nicht wirklich berührt wird, da es an den beschriebenen Bedürfnissen vorbei zu gehen scheint, während die erreichten Besucher sich mit der Dekodierung der Ausstellungsinhalte »herumschlagen«.

Beiden Gruppen ist gemeinsam, daß sie das, was sie erwarten, nur teilweise erhalten werden, nämlich eine Orientierung an ihren Bedürfnissen, ihren Vorkenntnissen, ihren Einstellungen.

\section{Die Anknüpfung an Bekanntes}

Der Bezug zu den möglichen Adressaten musealer Leistungen ist der entscheidende Faktor, der sowohl Besucher als auch Nichtbesucher bei der Entscheidung über Wahrnehmung oder Nichtwahrnehmung von Ausstellungen lenkt.

In ihrem Verhältnis zu den Besuchern ist den Gegenständen ein wichtiger Faktor gemeinsam, nämlich die Frage, ob an Bekanntes beim Publikum angeknüpft wird. Der mögliche Bezug zum Publikum, das Berühren von Bekanntem spricht nicht nur das Interesse an, sondern verdient Berücksichtigung im Hinblick auf die Vorkenntnisse der Besucher, da Lernen sich durch Verknüpfung mit bereits vorhandenen Wissensstrukturen vollzieht (NoschkaRoos 1994: 215).

Die »etwaige Bildungsfunktion einmaliger oder wiederholter Museumsbesuche [ist] von den mitgebrachten Vorinformationen abhängig« (Noschke-Roos 1994: 216).

Das hohe Interesse, das dem Besucher an der Identifizierung von Gegenständen eigen ist, führt nicht grundsätzlich zur intensi- 
ven Betrachtung der Objekte, sondern paradoxerweise zur scheinbar oberflächlichen Betrachtung möglichst vieler Dinge in möglichst kurzer Zeit, da das »irgendwo Bekannte« gesucht wird, Bekanntes sozusagen beim Museumsbesuch neu gesehen wird (Faulenbach 1991: 13). Die Einordnung der Wahrnehmungsinformationen über die betrachteten Gegenstände in die individuell kognitiven Schemata ist Voraussetzung für »jedes Lernen« (Nuissl/ Schulze 1991: 32) in der Ausstellung, aber zugleich auch Problem in der Kommunikation, denn weder erlaubt die Wahrnehmung möglichst vieler einzelner Gegenstände in kurzer Zeit die Einordnung in den historischen Zusammenhang, noch können Fehlinterpretationen auf Grund überformter Alltagserfahrungen verhindert werden (Jelich 1991: 50). Zu fragen ist, ob und wie sie überhaupt verhindert werden können.

Unbestritten ist, daß ohne das "Wissen über Geschichte« die gesehenen Dinge nicht verstanden werden können (Steen 1991: 55), andererseits entstehen bei der Rezeption von Geschichte »innere « Ausstellungsbilder, die sich der Kenntnis der Ausstellungsmacher entziehen.

"Sie [die Vorstellungsbilder, Erg. d. Verf.] sind ungegenständlich, nicht technisch reproduzierbar, nicht einmal durch erinnernden Gedankenakt unverändert zu reproduzieren sie bieten kein Anschauungs->Material<, obwohl gerade sie offenkundig ein tieferes Bedürfnis nach Anschauung befriedigen. Sie scheinen vor allem nicht für alle Betrachter gleich zu sein, sondern eine Schöpfung subjektiver Vorstellungskraft« (Schörken 1994: 34).

Die Dekodierungsfrage ist für die in Ausstellungen zustandekommenden historischen Aussagen, Vorstellungen und Bewertungen letztlich inhaltlich von so großer Bedeutung, daß eine asymmetrische Kommunikation, das Nichtwissen der Ausstellungsmacher über Vorkenntnisse, Einstellungen, Beurteilungen der Adressaten die Ausstellung zum Scheitern bringen kann - entweder durch weitgehende Nichtbeachtung oder falsches oder nur äußerst rudimentäres Begreifen seitens des Publikums. Auch die Kombination von Exponaten, Texten, Fotos etc. kann dieses Problem nicht grundsätzlich beseitigen, da für jeden wahrgenommenen Gegenstand die beschriebene Problematik gleichermaßen gilt. Die Verdichtung möglichst vieler Objekte, Texte und Gegenstände allein ist noch nicht in der Lage, die evtl. Sprachlosigkeit der einzelnen 
Gegenstände oder die Überlagerung mit falschen Vorkenntnissen und Vorstellungen aufzuheben. Angesprochen werden von den Museen eben nicht nur Adressaten, sondern mögliche Rezipienten, deren Erfahrungen und Erwartungshorizonte über Verständnis und Wirkung des Gesehenen (mit-)entscheiden, so daß die Leistung des Publikums als konstruierend bezeichnet werden muß im Hinblick auf die Ausstellungsinhalte, die einerseits in den Köpfen, Vorstellungen und Papieren der Ausstellungsmacher, andererseits in der Meinung des Publikums existieren, das das Gesehene mit dem Erkannten und nicht mit der vom Aussteller beabsichtigten Botschaft identifiziert. Die Ausstellungsrezeption ist nicht nur das Ergebnis der Reaktion der Besucher auf das Ausgestellte, sondern ganz wesentlich abhängig von der Berücksichtigung des Besucherwissens und der Besuchereinstellung während der Ausstellungsplanung, eine »falsche« oder sonstwie unzufriedenstellende Rezeption wird (mit-)verursacht durch die Ausstellungsmacher selbst. Bei der Integration der Besucher in die Präsentationsaktivitäten der Museen geht es letztlich nicht nur darum, die Interessen der Besucher zu respektieren, sondern auch darum, die eigenen Ausstellungsziele optimal zu verfolgen.

\section{Die Bedeutung der Erinnerung für historische Ausstellungen}

Die Rezeption historischer Ausstellungen beinhaltet in ihrer Struktur Gemeinsamkeiten mit und Unterschiede von der musealen Konzeption. Die Gemeinsamkeiten bestehen in der Identifizierung und Verfolgung einer Spur (Schörken 1994: 17), im Interesse an einem Thema und den damit in Verbindung gebrachten Exponaten, im Interesse an der Kommunikation über den Ausstellungsgegenstand selbst. Differieren werden in einem individuellen Maß die mit dem Thema verknüpften Assoziationen, Vorstellungen, Erfahrungen, Erwartungen und Kenntnisse sowie die Methoden der inhaltlichen Annäherungen. Während die Aussteller der Wissenschaft verpflichtet sind und sich bei der Recherche und Darstellung um intersubjektive Überprüfbarkeit und Seriosität bemühen, scheint sich das Publikum lediglich an subjektiven Kriterien zu orientieren. Persönliche Erfahrungen und Erwartungen sowie Emotionen bestimmen anscheinend Rezeptionsverhalten und Verständnis, die Rezeption der Besucher wird seitens der Fachwissenschaftler assoziiert mit Unzuverlässigkeit, Sprunghaf- 
tigkeit, Unkontrollierbarkeit. ${ }^{1}$ Diese Rezeptionsfaktoren haben ihre Ursache jedoch nicht nur in der Vermittlung durch »Bilder" und "Gegenstände», deren Bedeutung im Gegensatz zu Texten nicht eindeutig festgelegt ist, sondern entspringen paradoxerweise demselben Ziel, das Ausstellungsmacher und Museumsbesucher verfolgen. Beide Gruppen versuchen Geschichte $\mathrm{zu}$ erinnern, wobei Ausstellungsmacher und Besucher über Gemeinsamkeiten und Unterschiede in ihren Gedächtnissen verfügen. Ausstellungsmacher bewahren eine Fülle von Dokumenten und Gegenständen als Quellen in einer Art "Speichergedächtnis « (Assmann 1999: 409) auf. Diese Quellen bilden jedoch »nur potentielle Erinnerungsanlässe, denn das Wissen um diese Gegenstände und $\mathrm{Zu}$ sammenhänge ist (teilweise) verloren gegangen, die fachwissenschaftlichen Bezüge sind nur wenigen Spezialisten bekannt. Bei diesem Vorgang »kollektiven Vergessens " handelt es sich um ein Spezifikum, das Aleida Assmann als "Verwahrenvergessen« bezeichnet:

"Dabei handelt es sich um Spuren, Reste, Relikte, Sedimente einer vergangenen Zeit, die zwar noch da sind, aber (vorübergehend) bedeutungslos, unsichtbar geworden sind ...« (Assmann 1999: 409).

Demnach besteht eine Aufgabe der historischen Museen darin, Erinnerungsanlässe zu stiften und für die Genauigkeit und Zuverlässigkeit der Erinnerung zu sorgen, wobei die Objekte, mit denen gesellschaftliche Erinnerungsarbeit initiiert werden soll, zumindest historischem Lernen nicht nur förderlich gegenüberstehen:

"Die Geschichte wird gleichsam im Bild ihrer Erinnerung stillgestellt. Der ästhetische Eindruck hat seinen historischen Preis: Der Glanz der Vergangenheit im Bilde ihrer Überreste läßt die realen Veränderungsprozesse und damit insbesondere den eigentlich historischen Zusammenhang der Gegenwart mit der Vergangenheit aus dem Blick geraten. Der Schatten des ästhetischen Glanzes ist eine enthistorisierte Vergangenheit“ (Rüsen 1998: 4).

Nicht nur die individuellen Vorkenntnisse der Besucher, ihre Emotionen, Vorstellungen und Erwartungen sind es demnach, die die Kommunikation in historischen Ausstellungen erschweren, sondern die Objekte verfügen über ästhetische Qualitäten, die ihre Bedeutungsfelder überlagern können. Die imaginative »Wiederbe- 
lebung ", die »Wiederentdeckung« der Objekte durch eine spätere Epoche gehört mit zum Kommunikationsprozeß in historischen Ausstellungen, wobei ganz offensichtlich die Rolle des Besuchers im Hinblick auf das Zustandekommen des Erinnerungsprozesses als konstruierend bezeichnet werden muß, da ansonsten das "Hinüberführen" des historischen Gedächtnisses vom Wissensspeicher der Fachwelt zur funktionierenden historischen Erinnerung nicht gelingen kann. Auf Grund der beschriebenen »Dekodierungsart« historischer Ausstellungen, die mit »der Konstruktion von Erinnerung " besser beschrieben wird als mit "Rezeption", darf die Leistung von Ausstellungen nicht verwechselt werden mit fachwissenschaftlichen Publikationen oder schulischem Lernen. Die Erinnerungsarbeit in historischen Ausstellungen gehört gleichwohl zur "Geschichtskultur«, die über verschiedene Erinnerungsmodi wie z.B. Belehrung, Unterhaltung, Legitimation, Kritik, Ablenkung, Aufklärung verfügt (Rüsen 1994: 212).

Historische Erinnerung ist demnach als Teil einer lebendigen Geschichtskultur auch in Ausstellungen auf Kommunikation aller Beteiligten angelegt, da ansonsten das Ausgestellte entweder dem Vergessen erst gar nicht entrissen oder ihm gleich wieder überlassen wird.

Nur die Artikulation der Differenzen zwischen Ausstellungskonzeption und -rezeption kann gewöhnlich gewährleisten, daß die subjektiven Bestandteile der Erinnerung, die der fachwissenschaftlichen Überprüfung nicht standhalten, als solche überhaupt erkannt und eingeordnet werden können. Eine asymmetrische Kommunikation mit dem Besucher kann nicht dazu verhelfen, das eigentliche Ziel, Geschichte zu erinnern, historisch zu orientieren, historisches Lernen zu ermöglichen, auch tatsächlich zu erreichen. Es bleibt zu klären, wie diese Kommunikation erfolgen kann.

\section{Kommunikationsmöglichkeiten mit dem Besucher}

Emotional und sensationsaufgeladen sind die musealen Angebote mit den höchsten Besucherzahlen (Sielmann 1998: 8), so daß Skepsis angebracht erscheint bei der Forderung nach der indirekten Einbeziehung der potentiellen Nutzer in die Ausstellungsplanung und einem höheren $\mathrm{Ma}$ an »aktivitätsermöglichender Gestaltung (Treinen 1997: 48).

Unterstellt wird dem geneigten Publikum ein hohes Interesse 
an Unterhaltung, ein niedriges jedoch an Wissenserweiterung und Bildung. Dem widersprechen Analysen, die eine deutliche Ausrichtung des Besucherinteresses an einer "Kombination aus Streben und Wissenserweiterung und anregender Unterhaltung“ (Klein 1990: 280) belegen. Die vielfach

"getrennt gedachten Komplexe des Belehrens und Erfreuens [sollten, Erg. d. Verf.] als zwei zusammengehörige Ebenen subjektiver Erlebensweisen betrachtet werden, die beide bei jedem Museumsbesuch mehr oder minder beteiligt sind“ (Klein 1990: 279).

Unterhaltung und Emotionen sind feste Bestandteile von Lernprozessen in und außerhalb von Museen, sie können kaum als Widersprüche einer musealen Bildungsabsicht gelten. Schwer scheint die »Teilhaberschaft" des Besuchers bei der Sinnkonstitution in Ausstellungen zu akzeptieren zu sein, da der Verzicht auf museale Fachkompetenz zugunsten eines auf Amüsement ausgerichteten Publikums befürchtet wird. Ziel der Einbeziehung von Besuchern in die Ausstellungstätigkeit ist jedoch,

"Planungsrationalität für Ausstellungen in Museen [zu erreichen, Erg. d. Verf.] und zwar durch Berücksichtigung von Grundgegebenheiten auf Seiten der Besucher, also von Interessen, Motiven, Einstellungs- und Erwartungshaltungen, Sichtweisen und kognitiven Voraussetzungen ..." (Treinen 1997: 46).

Für diese Form der Besucherorientierung muß nicht Fachlichkeit aufgegeben, sondern ergänzt werden durch Kommunikationskompetenz.

Um »Lernen«, auch mit und durch Anschauung und Unterhaltung zu ermöglichen, um Erinnerungsarbeit zu leisten, müssen einige Grundprinzipien von Erinnerungs- und Kommunikationstechnik beachtet werden, die die verantwortungsvolle Ausdehnung (nicht Einschränkung) der Museumsaktivitäten beinhalten. 


\section{Die Bedeutung der Zielgruppen}

Präzise Kenntnisse über die Zielgruppen historischer Ausstellungen ermöglichen die frühzeitige Analyse des Interesses, des Vorwissens, der Erinnerungs- und Verständnismöglichkeiten dieser potentiellen Besucher (Günter 1997a: 9).

Nur wenige »Grundgegebenheiten auf seiten der Besucher" sind einer großen Gruppe gemeinsam, Sehgewohnheiten, Betrachtungsweisen, Erfahrungs- und Erwartungshorizonte unterscheiden sich nicht nur individuell und nach Generationen, sondern auch deutlich im Hinblick auf das gewählte Thema und die mit ihm verbundenen Gegenstände. Erfolg oder Mißerfolg von historischen Ausstellungen lassen sich kaum anhand von absoluten Besucherzahlen, sondern nur in bezug auf die betroffene Zielgruppe messen. Wenn die Besucherzahl einer Ausstellung gering ausfällt, wurde entweder die Zielgruppe nicht erreicht oder diese Zielgruppe ist nicht besonders groß. Unterstellt wird dem potentiellen $\mathrm{Pu}$ blikum mangelndes Interesse im Sinne einer »niederen Sensations- und Konsumgier «, da Ausstellungen mit abstrakten Themen nur geringere Besucherzahlen erreichen als andere. Tatsächlich belegen solche Ausstellungen und Themen jedoch, daß zumindest der Nichtbesucher sich nicht genug angesprochen und "betroffen« fühlt, das Thema tatsächlich dem kollektiven Vergessen zum Opfer gefallen ist. Leicht nachvollziehbare, zur eigenen Situation Parallelen bergende Ausstellungen schaffen Einordnungsmöglichkeiten, sind für den Besucher und seine Bedürfnisse relevant; Themen, die zu weit weg sind, schaffen kein Bedürfnis zur thematischen Auseinandersetzung und zum Besuch des Museums.

Die Orientierung an Zielgruppen und deren Bedeutung (Scheele 1997: 23) darf dabei nicht verwechselt werden mit einer einseitigen Wunschbefriedigung, diese Besucherorientierung »bedeutet nicht (Hervorhebung im Original): tun, was der Besucher wünscht ('give the market what its wants`) (Günter 1997a: 8), sondern die alte Forderung zu erfüllen, den Besucher dort abzuholen, wo er tatsächlich steht. Die Vertrautheit mit einem Thema und den fachlich zugeordneten Gegenständen als Bedingung für Besuchermotivation und -verständnis kann in das Handeln des Museums ohne fachwissenschaftliche Verluste einbezogen werden, da die Vertrautheit dort, wo sie auf Grund von kollektivem Vergessen nicht gegeben ist, durch das Setzen von Erinnerung hervorgerufen werden kann. Bedingung sind Kenntnisse über die Einordnung histo- 
rischer Themen und Gegenstände in derzeitige kommunikative Gedächtnisspeicher sowie museales Handeln im Sinne eines systematischen Gestaltungsprozesses der öffentlichen Erinnerung. Da mit der Anzahl von wiederholten Museumsbesuchen die Kenntnisse und Vorbildung des Publikums und sein Interesse an weiteren Informationen und Kommunikationen grundsätzlich steigt, wird es für das Erreichen einer nachhaltigen Wirksamkeit musealen Handelns darauf ankommen, die erinnerungsträchtigen oder erinnerungssetzenden symbolisch wirksamen Gegenstände und Bedeutungsfelder in einen Kommunikationsprozeß mit dem Besucher einzubeziehen und gleichzeitig das historische Orientierungsbedürfnis der Besucher durch seine Beteiligung an Sammlungstätigkeit und Ausstellungsprojekten prozeßhaft zu wecken.

Diese "Passung von strukturierten Interessenprofilen und musealen Objekten « kann nur hergestellt werden, indem die Identifikationsleistungen des Besuchers als Bestandteil eines Bildungsprozesses verstanden werden (Noschka-Roos 1994: 33), bei dem das Museum und seine Zielgruppen sich in der Kommunikation verändern und weiterentwickeln (Faulenbach 1991: 17). Museales Handeln, das historische Orientierungsbedürfnisse weckt, Symbole und Bedeutungsfelder wiederbelebt, Erinnerung setzt und die Besucher als sinnkonstituierende Partner versteht, definiert $\mathrm{Mu}$ seen nicht (nur) als Präsentationsorte sondern als Kommunikationspartner, die für und mit dem Besucher Orte und Anlässe für die Erinnerungsarbeit stiften und gestalten. Im folgenden sind ausgewählte Beispiele und Aktivitäten des Stadtmuseums Hagen beschrieben, die einige Möglichkeiten inhaltlicher Besucherorientierung veranschaulichen sollen.

\section{Beispiele aus der Arbeit des Stadtmuseums Hagen}

Im Herbst 1994 machte sich das Stadtmuseum Hagen die Vorliebe seines Publikums an "schönen alten Dingen« zu Nutze und dokumentierte in der Ausstellung "Zur steten Erinnerung - Hagener Kostbarkeiten« (Hobein 1994) große Teile seiner bisher noch nicht gezeigten Bestände mit einer mehrfachen Zielsetzung:

Die ästhetische Faszination der Objekte sowie die kostbar anmutende Aura der »uralten« Gegenstände sollte die Aufmerksamkeit des Besuchers fesseln, um die mit den Objekten verbundenen Geschichten ihres Weges in das Museum zu erzählen, die Samm- 
lungsgeschichte des Hauses darzustellen, weitere Gegenstände und die mit ihnen verbundenen Geschichten zu sammeln und über die musealen Aufgaben des Sammelns, Bewahrens und Erforschens zu informieren (Hobein 1994b; Blank 1994). Schon vor der Ausstellung wurde über diese Absichten mit Faltblättern informiert, einige besonders »augenfällige« Gegenstände mit auch kuriosen Geschichten (z. B. das sog. "Jérome-Bett", in dem angeblich Napoleons Bruder Jérome auf der Flucht in Hagen genächtigt haben soll [Osses / Blank 1994]) in der Presse ausführlich vorgestellt, die Bevölkerung zum Mitmachen aufgerufen. Ausgestellt wurden dann die ausgewählten Objekte ohne jede Inszenierung in der Art des "musée sentimentale«, klassisch angeordnet nach Material und zeitlicher Zuordnung, jedoch erhielt jedes Objekt einen mitnehmbaren Text von mindestens einer bis vier DIN A4-Seiten mit ausführlicher Beschreibung zur Geschichte dieses Sammlungsgegenstandes. Auf diese Weise wurden sowohl die Sammlungsbestände als auch die Objekte der sich beteiligenden Bürger und Bürgerinnen präsentiert (Schmidt 1994), wobei der »Wert« dieser Gegenstände, d.h. ihre Aussagekraft, ihre Seltenheit, ihr Alter und sonstige Besonderheiten für die Aufnahme in die Ausstellung entscheidend waren.

Das Ausstellungsziel bestand darin, die Besucher über ihre Emotionen und Assoziationen für die präsentierten Gegenstände $\mathrm{zu}$ interessieren; für die von den Ausstellungsmachern mit den Objekten verbundenen, nicht sichtbaren Geschichten. Die Ausstellungsbotschaft, daß diese Geschichten den Objekten nicht anzusehen waren, sondern in dieser Ausstellung nur durch Lesen der angebotenen Texte erkannt werden konnten, war so einfach wie erfolgreich:

Im Vergleich zu anderen Ausstellungen erfuhr diese große Aufmerksamkeit seitens eines Publikums, das fast alle ausgestellten Texte las. Bei allen Führungsgesprächen wurde die Arbeit der $\mathrm{Mu}-$ seumsleute mit großem Respekt seitens der Besucher thematisiert und die Aussagefähigkeit von Sammlungsgegenständen lebhaft diskutiert. »Ganz nebenbei« wurde der Wissens- und Objektspeicher des Museums durch viele Dauerleihgaben und Schenkungen qualitativ und quantitativ erweitert.

Solche Sammlungsaktionen und Befragungen der Bevölkerung im Vorfeld der Ausstellungen gehören seitdem im Stadtmuseum Hagen (wie auch in anderen Häusern [vgl. z.B. Gößwald/Thamm 1991]) grundsätzlich zur Phase der Ausstellungsplanung, aber 
auch zur Realisierung. Sie sind normaler Bestandteil des Arbeitsalltages im Museum geworden und dienen keineswegs "nur« zur Akquirierung neuer Leihgaben und zur Erweiterung lokalhistorischer Kenntnisse der Ausstellungsmacher, sondern sichern darüber hinaus die zutreffende Einschätzung der auf das zu bearbeitende Thema bezogenen Besucherinteressen, vermitteln Kenntnisse über den Erfahrungs- und Erwartungshorizont einer bestimmten Zielgruppe, stimmen die angesprochene Zielgruppe in der Bevölkerung auf das neue Ausstellungsthema ein und schaffen dem kommunikativen Gedächtnis neue Erinnerungsanlässe, die auch außerhalb des Museums zu Gesprächen in der Bevölkerung Anlaß geben.

Bei einem Projekt des Stadtmuseums Hagen war die thematische Besucherresonanz ein Jahr vor Ausstellungsbeginn so erfreulich, daß ihr eine eigene Präsentation gewidmet wurde. Angekündigt wurde eine Ausstellung über die Hagener Denkmäler, denen fachlich betrachtet besonders in ihrer Häufung und wegen der vergleichsweise großen Anzahl von Türmen eine besondere fachlichwissenschaftliche Bedeutung zukommt (Hobein/Osses: 1996).

Ziel der Betrachtungen sollte jedoch nicht nur die Entstehungsgeschichte der Denkmäler und ihr Stiftungszusammenhang sein, sondern auch die Rezeptionsgeschichte sowie ihre gegenwärtige Bedeutung für die Bevölkerung.

Bekannt war lange vor der Ausstellungsvorbereitung die Existenz einiger Vereine und anderer Gruppen, die sich die Pflege eines Denkmals zur Aufgabe gemacht hatten, ebenso war bekannt, daß diesen Gruppen keine Fachkollegen angehörten. Etwa ein halbes Jahr vor der Eröffnung der Ausstellung zur Denkmalgeschichte in Hagen wurde eine sog. "Erinnerungswerkstatt« eingerichtet (Osses 1996), die museumsseitig eine schlichte Foto- und Textdokumentation aller Hagener Denkmäler beinhaltete und darüber hinaus die Hagener Denkmalinitiativen und das Ergebnis eines Schulklassenwettbewerbs vorstellte. Das Besondere an dieser Erinnerungswerkstatt bestand darin, daß die betroffenen Gruppen nicht durch das Museum vorgestellt wurden, sondern sich auf bereitgestellten Tafeln selbst präsentierten.

Durch dieses Projekt standen die beteiligten Gruppen nicht nur in der Situation, sich mit ihrem Anliegen mitteilen zu können, sondern sie erhielten ähnliche Probleme und Aufgaben wie das $\mathrm{Mu}$ seum. Die Rezeptionsgeschichte der Denkmäler in Hagen zu vermitteln war gemeinsames Thema, die Symbolik der Denkmäler zu 
entschlüsseln und anderen zu vermitteln wurde gemeinsame Aufgabe, und möglichst viele für das Thema zu begeistern, wurde zum gemeinsamen Anliegen.

Das Stadtmuseum Hagen erhielt im Vorfeld der eigentlichen Ausstellung ausführliche Kenntnisse über Erfahrungs- und Erwartungshorizont, Einstellungen möglichst vieler Adressaten, die schon im Vorfeld selbst als mögliche Multiplikatoren bei der Erschließung weiterer Besucher halfen und sich mit großem Interesse um die eigenständige und vom Museum unterstützte Erarbeitung des Themas bzw. einzelner Aspekte bemühten.

Einer diesem Projekt entgegengesetzten Situation sah sich das Stadtmuseum Hagen 1995 ausgesetzt, als das Museum zum 250jährigen Stadtjubiläum 1996 neben vielen anderen »klassischen« Projekten wie einer Vortragsreihe, Ausstellungen u.ä. auch ein historisch ausgerichtetes Fest unter breiter und aktiver Beteiligung der Bevölkerung $\mathrm{zu}$ initiieren versuchte. Die $\mathrm{zu}$ erwartende Schwierigkeit bestand darin, daß ein großer Teil der Bevölkerung weder über eine intensive Kenntnis der Geschichte verfügte noch sich mit der Stadt Hagen identifizierte, da die konkurrierenden Stadtteilidentitäten wesentlich stärker und mit einem gewissen Ausschließlichkeitsanspruch versehen waren.

Eine breit angelegte Bürgerbeteiligung zu einem eng gefaßten historischen Thema schied aus, da mit der Aktion eine überwältigende Teilnehmerzahl erreicht werden sollte. Das Problem bestand darin, die Bürger mit ihrer Geschichte als Teil der Stadtgeschichte darzustellen, begreifbar zu machen und eine große Beteiligung der Bevölkerung herbeizuführen, obwohl der größte Teil dieser Zielgruppe weder historisch vorgebildet noch besonders interessiert oder gar zu den Gelegenheits- oder Stammbesuchern des Museums gehören konnte. Zielgruppe der Aktivitäten war mit anderen Worten der "typische" Nichtbesucher. Um auch diese große Gruppe zu erreichen wurde analysiert, was das Stadtmuseum in diesem Fall ohne Umfrage unter anderem über seine Nichtbesucher wissen konnte: Diese Adressaten besaßen zum großen Teil Stadtteilidentität, engagierten sich in ihrer Freizeit, waren vermutlich gern mit Gleichgesinnten zusammen, besaßen eine Affinität zum Festefeiern, wären aber ohne tatsächliche Betroffenheit, ohne persönlichen Bezug nicht in großer Zahl zu diesem Fest gekommen und hätten sich schon gar nicht engagiert. Eine Motivation für die Jubilarin war aus den genannten Gründen ausgeschlossen, die Erarbeitung eines gemeinsamen historischen The- 
mas brauchte gar nicht erst erwogen zu werden. Diese Aspekte berücksichtigend, wurde mit einem Jahr Vorlauf zum "Markt der Vereine eingeladen und alle Vereine und Gruppen dazu aufgefordert, die Geschichte ihres Vereines, Stadtteiles oder eines beliebigen Themas unter dem Motto "250 Jahre Stadt Hagen« darzustellen. Jeder Verein bzw. jede Gruppe bekam an einem ausgewählten Sonntag im Jubiläumsjahr eine Standfläche oder eine Auftrittsmöglichkeit auf einer von fünf Bühnen zugeteilt. Ziel war eine Momentaufnahme der aktiven Vereine zum 250. Geburtstag der Stadt Hagen analog zu Generationen übergreifenden Familienfotos, die als Bestandsaufnahme bei besonderen Festen und Anlässen üblich sind. Trotz anfänglicher Skepsis weniger Vereinsmitglieder beteiligten sich alle aktiven ca. 220 Vereine und Gruppen in Hagen und stimmten ihre Aktivitäten mit anderen Vereinen ihres Stadtteiles $\mathrm{ab}^{2}$ Organisation und Moderation übernahmen die Mitarbeiter des Stadtmuseums Hagen. Die Vorführungen und Darstellungen reichten von der Demonstration alter Buchdrucker-Kunst über die Vorstellungen »klassischer" und "exotischer" Sportarten und Musikvorführungen bis hin zu Aufführungen kleinerer Theaterstücke mit historischen Themen. In den meisten Fällen wurde die Geschichte des Vereins in einem bestimmten Stadtteil dokumentiert. Einer der Höhepunkte der Veranstaltung war eine professionelle »Moden-Schau« durch 250 Jahre Mode-Geschichte, wobei alle vorgestellten Kleidungsstücke aus Tüten eines bekannten ortsansässigen Zwieback-Herstellers gefertigt waren, dessen Geschichte sehr eng mit einem Stadtteil verknüpft ist.

Die Resonanz dieses Festes war beeindruckend: Ca. 80.00o Besucher von etwa 200.000 Einwohnern wurden mit dieser Aktion erreicht.

Das Ziel dieses Festes bestand nicht darin, historisches Wissen seitens des Museums weiterzugeben, historische Forschungsergebnisse zugänglich zu machen. Ziel war es auch nicht, fachwissenschaftlich begründete Ausstellungen und Projekte durch populistische Aktionen zu ersetzen. Dieses Fest der Bürger diente dazu, 250 Jahre Stadt Hagen mit Aspekten der persönlichen Relevanz in der Gegenwart zu verknüpfen und den Bevölkerungsteil, der normalerweise nicht oder kaum museal erreicht werden kann, für die Beschäftigung mit der Geschichte der Stadt Hagen zu gewinnen.

Nachdem das Stadtmuseum Hagen seine Pforten am alten Standort am Ende des Jubiläumsjahres 1996 geschlossen hatte, 
wurde anläßlich der Eröffnung des Hauses mit der Wiederaufnahme des Wechselausstellungsbetriebes im neuen Domizil im August 1998 die Erinnerung an das Fest im kleineren Rahmen zum Thema gemacht: Die erste Ausstellung war eine Retrospektive des Marktes der Vereine unter dem Titel »Hagen Verein(t)«, die während des Eröffnungswochenendes bereichert wurde um eine Ausstellungsbörse, wieder bestritten von der Zielgruppe selbst. Während 1996 die gesamte Innenstadt als Aktionsfläche für den Markt der Vereine hergehalten hatte, standen nun gerade 1.000 qm für Ausstellung, Ausstellungsbörse und ein Fest, das durch Aufführungen der Bürger gestaltet wurde, zur Verfügung. Angepeilt wurde eine Besucherfrequentierung von ca. 2.00o an diesem Wochenende, erreicht wurden ca. 4.00o Menschen, die aus allen Stadtteilen kamen und - angenehmer Nebeneffekt - als Multiplikatoren ihre Eindrücke aus erster Hand in die Stadtteile an die Nichtbesucher weitergaben.

\section{Fazit}

Die klassische museale Aufgabe des Bewahrens wird oft einseitig angewandt auf die konservatorische Verwahrung von Objekten, deren Zusammenhänge fachwissenschaftlich erforscht wurden, um die gewonnenen Erkenntnisse anschließend den Besuchern im Sinne eines Informationsangebotes zu »vermitteln«.

Dieses Verständnis musealer Arbeit wird dem möglichen Bewahren historischer Erinnerung jedoch nur teilweise gerecht. Sollen historische Ausstellungen nicht nur Zusammenhänge darstellen und einem kleinen, "eingeweihten Publikum« in (gesellschaftliche) Erinnerung rufen, sondern systematisch den kollektiven Gedächtnisspeicher der Zielgruppe(n) auffüllen und auffrischen, damit diese wichtigen Zusammenhänge auch kollektiv in Erinnerung bleiben, dann ist es erforderlich, neben der mit den Objekten verbundenen Arbeit des Bewahrens, auch das Publikum als zweiten Pol des musealen Interesses angemessen zu berücksichtigen. Die Konsequenz eines solchen Ansatzes ist neben allen Bemühungen um fachwissenschaftliche Arbeit auch die Besucherforschung sowie die Erinnerungsarbeit mit den Zielgruppen. Die Rezeption eines musealen Themas ist nicht mehr nur "Nebenschauplatz« des Ausstellungsgeschehens, sondern gleichzeitig Bestandteil der Projektplanung und Ziel des Dargestellten. Darüber hinaus verlangt 
die Entwicklung des historischen Gedächtnisses möglicher Zielgruppen auch solche Projektarbeit, deren Beziehung zur musealen Sammlung nur mittelbar gegeben ist. Historische Präsentationen verflüchtigen sich, ohne Spuren zu hinterlassen, im Nebel des Vergessens, wenn sie nicht auf den fruchtbaren Resonanzboden interessierter und das heißt auch vorbereiteter, persönlich berührter Museumsbesucher treffen. Insofern führt der Weg einer inhaltlichen Besucherbindung nur über die möglichst intensive Kommunikation mit dem Besucher. Dieser Weg ans Ziel musealer Projekte und Ausstellungen ist anstrengend, sein Verlauf ist häufig schwer prognostizierbar, hohe Anforderungen an die Flexibilität der Aussteller werden gestellt. In einem solchen Modell ist der Weg der historischen Kommunikation auch das museale Ziel. Zu Beginn eines Projektes mag die fachwissenschaftliche Erarbeitung des gewählten Themas vorerst als abgeschlossen gelten; sobald die Kommunikation mit der Zielgruppe in den Fokus musealer Recherche gerät, wird häufig auch das fachwissenschaftliche Interesse an neuen Fragen und Aspekten geweckt. Inhaltliche Besucherbindung bedeutet keinesfalls den Verzicht auf fachwissenschaftliche Kompetenz, sondern die Ergänzung dieser Qualität um Kommunikationskompetenz, deren Anwendung häufig auch fachwissenschaftlich neue Herausforderungen beinhaltet.

\section{Anmerkungen}

1 Diese Attribute gelten für die über Bilder geführte Überlieferung und keineswegs nur für die Rezeption durch Museumsbesucher. Vgl. Aleida Assmann, 1999, S. 410.

2 Ausführlicher: Beate Hobein und Sabine Oetzel: "Wir in Hagen. Ein »Markt der Vereine« zum Stadtjubiläum». In: Hagener Impuls 1996, Heft 16, S. 19-24.

\section{Literatur}

Assmann, Aleida (1999): Erinnerungsräume. Formen und Wandlungen des kulturellen Gedächtnisses, München.

Blank, Ralf (1994): »Museumsarbeit: Inventarisierung und Dokumentation«. In: Beate Hobein (Hg.), Zur steten Erinnerung - Hagener Kostbarkeiten, Hagen, S. 59-64.

Faulenbach, Bernd (1991): "Zur Rolle der historischen Museen in der gesellschaftlichen Auseinandersetzung mit Vergangenheit und Gegenwart«. In: Bernd Faulenbach/Franz-Josef Jelich (Hg.), Besu- 
cherinteressen und Besucherverhalten in historischen Museen und Ausstellungen. Dokumentation einer Tagung, Recklinghausen, S. 6-19.

Foerster, Cornelia (1998): "Das Historische Museum Bielefeld. Geschichtsdarstellung zwischen Rekonstruktion und Inszenierung «. In: Fachgruppe Stadt- und Heimatgeschichtliche Museen im Deutschen Museumsbund, Redaktion Jürgen Steen (Hg.), Zur Struktur der Dauerausstellung stadt- und heimatgeschichtlicher Museen, Frankfurt/M., S. 7-13.

Gößwald, Udo/Thamm, Lutz (Hg.) (1991): Erinnerungsstücke. Das Museum als soziales Gedächtnis, Berlin.

Günter, Bernd (1997): "Besucherorientierung und Besucherbindung der Weg dorthin ist noch weit«. inform! Museen im Rheinland 2/ 1997, S. 8-9.

Günter, Bernd (1997): »Museum und Publikum: Wieviel und welche Form der Besucherorientierung benötigen Museen heute?«. In: Abtei Brauweiler, Abteilung Museumsberatung (Hg.), Das besucherorientierte Museum, Köln, S. 11-18.

Hobein, Beate (Hg.) (1994): Zur steten Erinnerung - Hagener Kostbarkeiten, Hagen (Hagener Stadtgeschichte(n) Bd. 3).

Hobein, Beate (1994a): "Gegenstände im Museum - Zeugen der Vergangenheit?«. In: Beate Hobein (Hg.), Zur steten Erinnerung, Hagen, S. 39-48.

Hobein, Beate (1994b): "Zur steten Erinnerung - Was Gedächtnis und Erinnerung bedeuten«. In: Beate Hobein (Hg.), Zur steten Erinnerung - Hagener Kostbarkeiten, Hagen, S. 49-58.

Hobein, Beate/Oetzel, Sabine (1996): "Wir in Hagen. Ein "Markt der Vereine« zum Stadtjubiläum«. Hagener Impuls 1996, Heft 16, S. 1924.

Hobein, Beate/Osses, Dietmar (Hg.) (1996): "Bis in die fernste, fernste Zeit ...« Hagen und seine Denkmäler, Hagen (Hagener Stadtgeschichte(n) Bd. 6).

Jelich, Franz-Josef (1991): "Museum als Lernort und dann? Einleitende Bemerkungen zum Werkstattgespräch«. In: Bernd Faulenbach/Franz-Josef Jelich (Hg.), Besucherinteressen und Besucherverhalten in historischen Museen und Ausstellungen. Dokumentation einer Tagung, Recklinghausen, S. 48-51.

John, Hartmut (1997): „Das besucherorientierte Museum: Einführung in das Thema des Kolloquiums«. In: Abtei Brauweiler, Abteilung Museumsberatung (Hg.), Das besucherorientierte Museum. Tagungsband zum gleichnamigen Kolloquium des Fortbildungszentrums für Museen - Abtei Brauweiler, vom 11.-12. September 1995, Köln, S. 7-10.

Klein, Hans-Joachim (1990): »Der gläserne Besucher. Publikumsstruk- 
turen einer Musumslandschaft«. Berliner Schriften zur Museumskunde, Bd. 8, S. 280.

Klein, Hans-Joachim (1997): "Nichtbesucher und museumsferne Milieus: »lohnende« Zielgruppen des Museumsmarketings?«. In: Abtei Brauweiler, Abteilung Museumsberatung (Hg.), Das besucherorientierte Museum. Tagungsband zum gleichnamigen Kolloquium des Fortbildungszentrums für Museen - Abtei Brauweiler, vom 11.-12. September 1995, Köln, S. 28-43.

Noschka-Roos, Annette (1994): Besucherforschung und Didaktik. Ein museumspädagogisches Plädoyer, Opladen.

Nuissl, Ekkehard/Schulze, Christa (1991): "Besucherinteressen und Besucherverhalten im Museum. Neue empirische Untersuchungen«. In: Bernd Faulenbach/Franz-Josef Jelich (Hg.), Besucherinteressen und Besucherverhalten in historischen Museen und Ausstell ungen. Dokumentation einer Tagung, Recklinghausen, S. 2436.

Osses, Dietmar (1996): "Lebendige Denkmalkultur in Hagen. Die Denkmalaktivitäten der Hagener Vereine in der Erinnerungswerkstatt des Stadtmuseums«. In: Beate Hobein/Dietmar Osses (Hg.), "Bis in die fernste, fernste Zeit ...« Hagen und seine Denkmäler, Hagen (Hagener Stadtgeschichte(n) Bd. 6), S. 157-166.

Osses, Dietmar/Blank, Ralf (1994): »Bettgeschichten um Jérome und Blücher«. In: Beate Hobein (Hg.), Zur steten Erinnerung - Hagener Kostbarkeiten, Hagen, S. 81-86.

Rath, Gabriele (1998): Museen für BesucherInnen. Eine Studie, Wien.

Rüsen, Jörn (1994): Historische Orientierung. Über die Arbeit des Geschichtsbewußtseins, sich in der Zeit zurechtzufinden, Köln, Weimar, Wien.

Rüsen, Jörn (1998): »Industriedenkmale und Geschichtskultur im Ruhrgebiet«. Industriedenkmalpflege und Geschichtskultur 2/ 1998, S. 4.

Scheele, Walter (1997): »Grundlage für die systematische Ansprache der Besucher«. In: Abtei Brauweiler, Abteilung Museumsberatung (Hg.), Das besucherorientierte Museum. Tagungsband zum gleichnamigen Kolloquium des Fortbildungszentrums für Museen - Abtei Brauweiler, vom 11.-12. September 1995, Köln, S. 19-27.

Schmidt, Hans Günter (1994): "Bürgerbeteiligung im stadthistorischen Museum«. In: In: Beate Hobein (Hg.), Zur steten Erinnerung - Hagener Kostbarkeiten, Hagen, S. 123-150.

Schörken, Rolf (1994): Historische Imagination und Geschichtsdidaktik, Paderborn, München, Wien, Zürich.

Sielmann (1998): "Erotik und Schauder - oder was Museumsbesucher heute fasziniert«. inform! Museen im Rheinland 2/1998, S. 2-9.

Steen, Jürgen (1991): „Konzeptioneller Prozeß und Besucheranspra- 
che am Beispiel des Historischen Museums Frankfurt a.M.«. In: Bernd Faulenbach/Franz-Josef Jelich (Hg.), Besucherinteressen und Besucherverhalten in historischen Museen und Ausstellungen. Dokumentation einer Tagung, Recklinghausen, S. 52-64.

Treinen, Heiner (1991): "Motivationen zum Museumsbesuch. Museumstypen und Besucherprofile«. In: Bernd Faulenbach/FranzJosef Jelich (Hg.), Besucherinteressen und Besucherverhalten in historischen Museen und Ausstellungen. Dokumentation einer Tagung, Recklinghausen 1991 (Beiträge, Informationen, Kommentare. Beiheft 7), S. 37-47.

Treinen, Heiner (1997): "Museumsbesuch und Museumsbesucher als Forschungsgegenstand: Ergebnisse und Konsequenzen für die Besucherorientierung «. In: Abtei Brauweiler, Abteilung Museumsberatung (Hg.), Das besucherorientierte Museum. Tagungsband zum gleichnamigen Kolloquium des Fortbildungszentrums für Museen Abtei Brauweiler, vom 11.-12. September 1995, Köln, S. 44-53. 



\section{Die Autoren}

Univ.-Prof. Dr. Bernd Günter, geboren 1946；1965，1967-1972 Studium der Betriebswirtschaftslehre, Volkswirtschaftslehre, Germantistik, Geschichte und Philosophie an den Universitäten in Münster und Bochum; 1972 Examen als Diplom-Ökonom, 1978 Promotion an der Universität Bochum; 1979-1989 Geschäftsführer des Instituts für Unternehmensführung und Unternehmensforschung der Unversität Bochum; 1989-1991 Professur an der Freien Universität Berlin; seit 1991 Professur für Betriebswirtschaftslehre an der Heinrich-Heine-Universität Düsseldorf mit Schwerpunkt Marketing; seit 1998 Direktor des Instituts für Dienstleistungsmanagement der Heinrich-Heine-Universität Düsseldorf.

Beate Hobein M.A., geboren 1960; Studium der Geschichte, Germanistik und Philosophie an der Ruhr-Universität Bochum; 19881989 wissenschaftliche Mitarbeiterin bei den Stadtmuseen Lüdenscheid; seit 1989 Leiterin des Stadtmuseums Hagen, des Museums Hohenlimburg und des Stadtarchivs Hagen.

Dr. Hartmut John, Studium der Geschichtswissenschaft, Politik und Wirtschaftsgeographie; Leiter der Abteilung Museumsberatung und des Fortbildungszentrums Abtei Brauweiler/Rheinisches Archiv- und Museumsamt des Landschaftsverbandes Rheinland. 
Maja Majer-Wallat, geboren 1948; Hutmacherlehre; 1968-1969 Kostümbildnerin am Theatre Nationale Populaire; Studium an der Kölner Werkschule; 1978-1979 Wienaufenthalt, Arbeitskreis für Tiefenpsychologie, Meisterschülerin von Eduardo Paolozzi; Deutsche Vertretung der Internationalen Messen für Museen und Ausstellungswesen im Grand Palais, Paris; Pressesprecherin der Kunst- und Ausstellungshalle der Bundesrepublik Deutschland.

Patricia Munro M.A., Fulbright-Stipendium in Museumskunde an der George Washington University; Tätigkeit in den USA im Bereich Ausstellungsdesign und -bau, in Deutschland Leitung und Organisation verschiedener Ausstellungen und Projekte, die zum Teil auch im europäischen Ausland durchgeführt wurden; Beratungstätigkeit und Durchführung von Seminarveranstaltungen mit den Schwerpunkten Ausstellungsplanung, Projektleitung/-koordination, und Evaluation/Besucherforschung.

Dr. Dieter Pesch, Studium der Volkskunde, Vor- und Frühgeschichte, Mittlere und Neuere Kirchengeschichte; 1970-1981 Leiter des Niederrheinischen Freilichtmuseums Grefrath; seit 1981 Direktor des Rheinischen Freilichtmseums Kommern - Landesmuseum für Volkskunde; 1992-1995 Chairman des ICOM Komitees für PR an Museen.

Jan Sas M.A., Studium der Literatur an der Universität Amsterdam, Studium der Soziologie an der Universität Utrecht; Dozent an der Reinwardt Academy, Fachbereich Museologie, der Amsterdam School of the Arts, Gastdozent in Indonesien, Vietnam, China und Ägypten.

Rick Vercauteren M.A., geboren 1956; 1975-1982 Studium der Kunstgeschichte und Ägyptologie an der Universität Nijmegen, 1981-1982 Studium der Amerikanischen Literatur des 19. und 20. Jahrhunderts ebendort; Lehrtätigkeit im Bereich der Sozialgeschichte am Intercollege, Eindhoven; Lehrtätigkeit im Bereich der Kunstgeschichte an der Akademie Tilburg; 1988-1990 Leiter des Educational Department of the Noordbrabants Museum; seit 1990 Leiter des Museums; Mitglied des Prüfungsausschusses an der Reinwardt Academy, Amsterdam. 
Johannes Werner, geboren 1935; Schule, kaufmännische Ausbildung; 1959 Eintritt in das Unternehmen KAUFHOF als kaufmännischer Angestellter; ab 1972 tätig als Geschäftsführer in verschiedenen Filialen; seit 1983 1. Geschäftsführer im Haus Düsseldorf, Königsallee; tätiges Mitglied in verschiedenen Berufsverbänden und Interessengemeinschaften. 


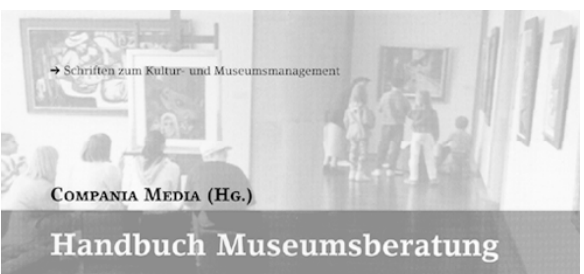

Akteure - Kompetenzen - Leistungen

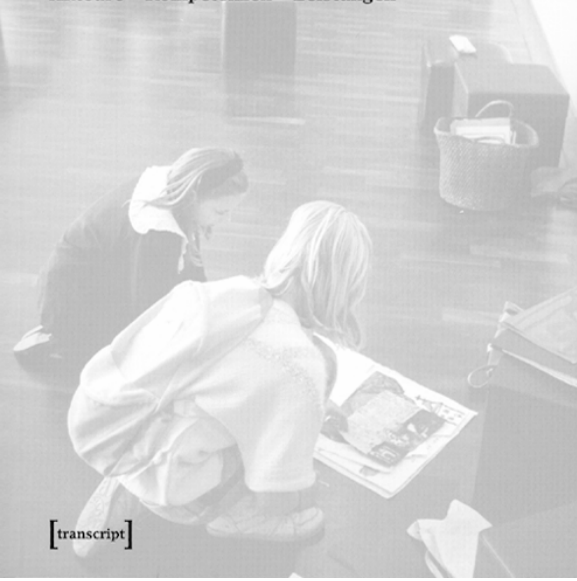

Compania Media (Hg.)

Handbuch Museumsberatung

Akteure - Kompetenzen Leistungen

Januar 2000, 468 Seiten, kart., $78 \mathrm{DM}$

ISBN 3-933127-41-6
Während sich bis vor kurzem neben den öffentlichen Beratungseinrichtungen nur eine kleine Zahl freier Beratungsunternehmen im Museumsumfeld betätigte, diversifiziert sich die Beraterlandschaft im deutschsprachigen Raum zusehends. Damit Museen aller Größen von den neuartigen Beratungsangeboten profitieren können, werden folgende Fragen behandelt:

- Welche Beratungsangebote gibt es, und wie finden Museen die Beratung, die sie brauchen?

- Welche Formen der Beratung sind wirtschaftlich machbar und langfristig sinnvoll?

- Worauf sollten Museen bei der Kooperation mit Beratern besonders achten?

Konkret finden Sie Informationen $\mathrm{zu}$ Beratungsleistungen und -angeboten in den folgenden Bereichen:

Organisationsentwicklung, Managementberatung, Strukturberatung, Besucherorientierung, Evaluation, Ausstellungsgestaltung, Museumspädagogik, Museumsmarketing, Öffentlichkeitsarbeit (PR), Museumsdokumentation, Neue Medien, Visuelle Kommunikation, Konservierung 


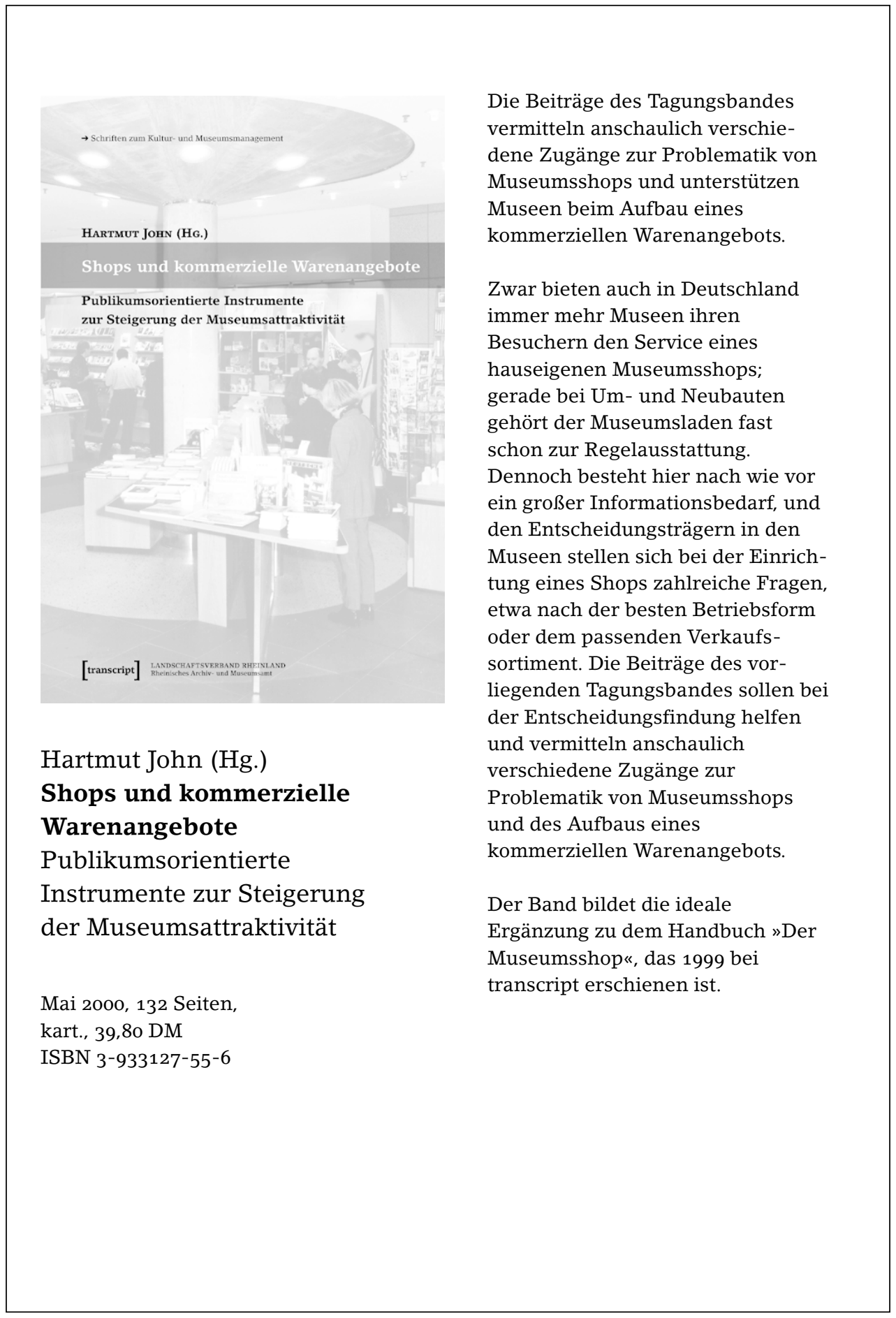




\section{Fortbildungs-}

\section{zentrum}

\section{Abteilung Museumsberatung und Fortbildungszentrum Abtei Brauweiler des Rheinischen Archiv- und Museumsamtes}

Abtei

Brauweiler

\section{Schriften des Rheinischen Museumsamtes:}

Nr. 57 Neue Strukturen für Museen?

Tagungsband zum gleichnamigen Kolloquium 1993

Rheinland-Verlag, Pulheim 1994,

160 S., Abb., kart., 14,80 DM
Nr. 61 Vom Elfenbeinturm zur Fußgängerzone Tagungsband zum gleichnamigen Kolloquium 1994 Verlag Leske + Budrich, Opladen 1996, 204 S., kart., 28,00 DM

\section{Publikationen der Abteilung Museumsberatung:}

Nr. 1 Das besucherorientierte Museum

Tagungsband zum gleichnamigen Kolloquium 1995

Rheinland-Verlag, Pulheim 1997,

139 S., Abb., kart., 18,00 DM

Nr. 2 Dem «Zahn der Zeit» entrissen!

Neue Forschungen und Verfahren zur

Schädlingsbekämpfung im Museum

Rheinland-Verlag, Pulheim 1997,

186 S., Abb., kart., 25,00 DM

Nr. 3 Der Salamander - ein gar fürchterliches Thier Zur Natur- und Kulturgeschichte des Feuersalamanders Katalog zur gleichnamigen Ausstellung

Rheinland-Verlag, Pulheim 1997,

96. S., Abb., kart., 25,00 DM

Nr. 4 Zum Bedeutungswandel der Kunstmuseen.

Positionen und Visionen zu Inszenierung,

Dokumentation, Vermittlung

Tagungsband zum gleichnamigen Kolloquium 1996

Verlag für moderne Kunst, Nürnberg 1998,

198 S., Abb., kart., 45,00 DM

Nr. 5 Süßes Rheinland

Zur Kulturgeschichte des Zuckers

Katalog zur gleichnamigen Ausstellung 1998

Bouvier Verlag, Bonn 1998,

120 S., Abb., kart., 24,80 DM

Nr. 6 „Farbfehler! « Gegen das Verschwinden der Farbfotografie

Tagungsband zum gleichnamigen Kolloquium 1997

Verlag Rundbrief Fotografie, Sonderheft Nr. 5 ,

Stuttgart 1998, 200 S., Abb., kart., 29,50 DM

\section{Nr. 7 Die Lust zu Wohnen - \\ Das Rote Haus in Monschau \\ Wienand Verlag, Köln 1998,}

190 S., Abb., kart., 49,00 DM

Nr. 8 Shops und kommerzielle Warenangebote Tagungsband zur gleichnamigen Veranstaltung des Fortbildungszentrums Abtei Brauweiler 1998 transcript Verlag, Bielefeld 2000,

130 S., Abb., kart., 39,80 DM

Nr. 9 Besucher zu Stammgästen machen! Neue und kreative Wege zur Besucherbindung Tagungsband zum gleichnamigen Kolloquium des Fortbildungszentrums Abtei Brauweiler 1998 transcript Verlag, Bielefeld, erscheint Sommer 2000, ca. 180 S., kart., ca. 40 DM

\section{Nr. 10 euphorie digital?}

Aspekte der Wissensvermittlung in Kunst, Kultur und Technologie

Tagungsband zum gleichnamigen Kolloquium 1998 des Fortbildungszentrums Abtei Brauweiler und des Heinz Nixdorf MuseumsForums Paderborn transcript Verlag, Bielefeld, erscheint Sommer 2000, ca. 180 S., kart., ca. 40 DM

Nr. 11 Museen und Sammlungen im Rheinland (Museumsführer) erscheint 2000

Bestelladresse: Landschaftsverband Rheinland, Rheinisches Archiv- und Museumsamt Abteilung Museumsberatung und Fortbildungszentrum Abtei Brauweiler Ehrenfriedstraße 19, D-50259 Pulheim Tel.: 02234/9854-302 oder -313, Fax: 02234/9854-202 e-mail: t.martini@mail.lvr.de, Internet: http://www.lvr.de

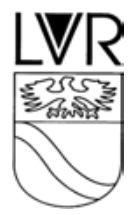

